BRUNO OLIVEIRA DA SILVA

Estimativa do torque de instalação de fundações por estacas helicoidais por meio de resultados de ensaio SPT

São Carlos - SP

2018 

BRUNO OLIVEIRA DA SILVA

\title{
Estimativa do torque de instalação de fundações por estacas helicoidais por meio de resultados de ensaio SPT
}

\author{
Versão corrigida \\ (Versão original encontra-se na Escola de Engenharia de São Carlos)
}

Dissertação apresentada à Escola de Engenharia de São Carlos, da Universidade de São Paulo, como parte dos requisitos para obtenção do título de Mestre em Ciências.

Área de concentração: Geotecnia

Orientadora: Profa. Dra. Cristina de Hollanda Cavalcanti Tsuha

Coorientador: Prof. Dr. André Teófilo Beck

São Carlos - SP 
AUTORIZO A REPRODUÇÃO TOTAL OU PARCIAL DESTE TRABALHO, POR QUALQUER MEIO CONVENCIONAL OU ELETRÔNICO, PARA FINS DE ESTUDO E PESQUISA, DESDE QUE CITADA A FONTE.

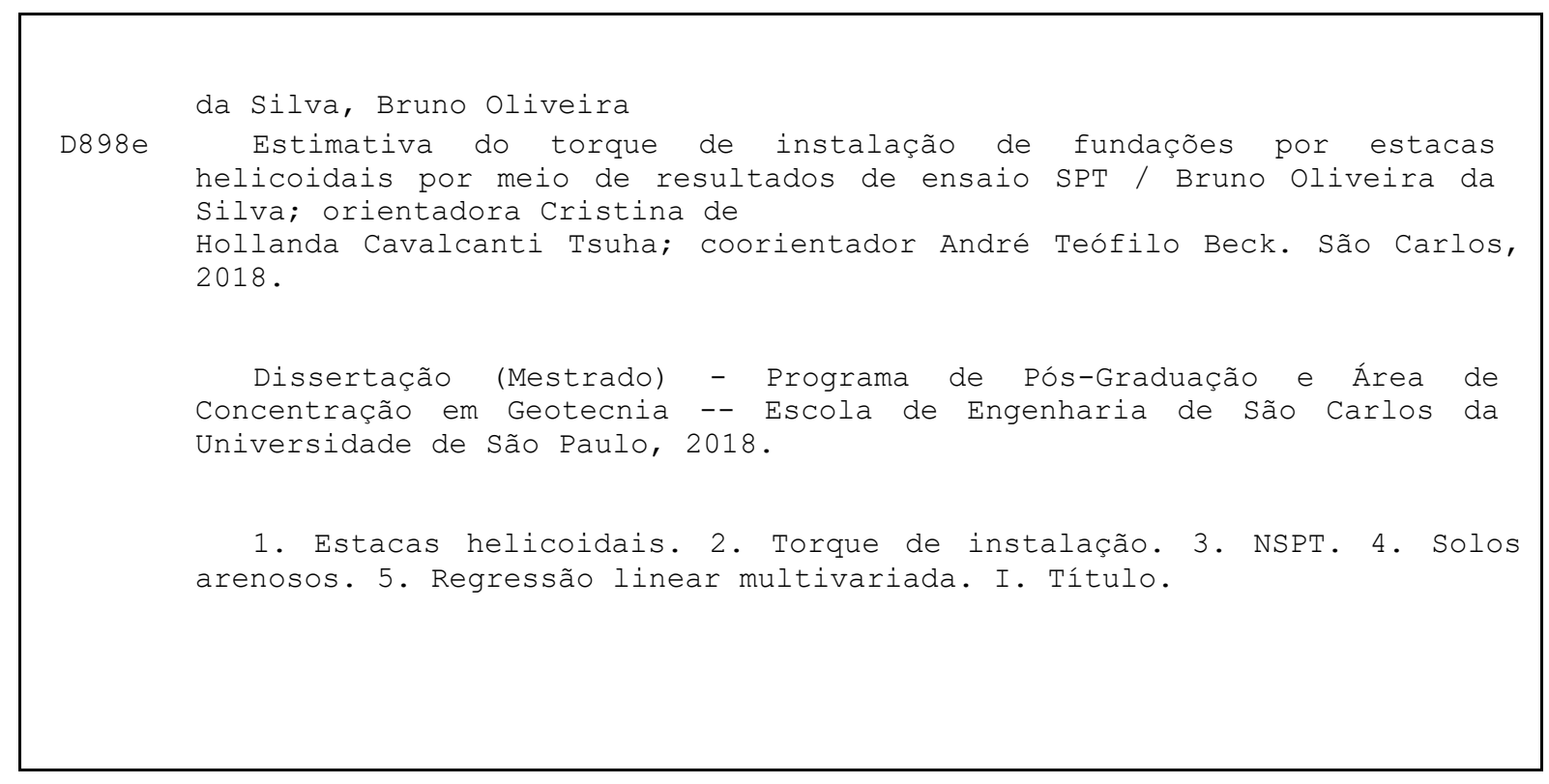




\section{FOLHA DE JULGAMENTO}

Candidato: Engenheiro BRUNO OLIVEIRA DA SILVA.

Título da dissertação: "Estimativa do torque de instalação de fundações por estacas helicoidais por meio de resultados de ensaios SPT".

Data da defesa: 10/10/2018.

\section{Comissão Julgadora:}

Profa. Associada Cristina de Hollanda Cavalcanti Tsuha (Orientadora)

(Escola de Engenharia de São Carlos/EESC)

Prof. Dr. José Antonio Schiavon

(Instituto Tecnológico de Aeronáutica/ITA)

Prof. Dr. Fernando Artur Brasil Danziger

(Universidade Federal do Rio de Janeiro/UFRJ)
Resulfado:
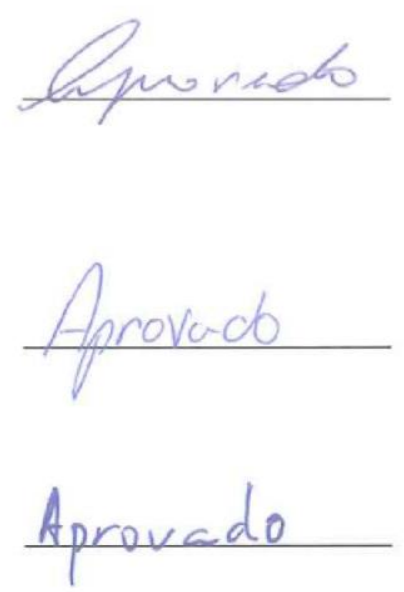

Coordenadora do Programa de Pós-Graduação em Geotecnia:

Profa. Associada Valéria Guimarāes Silvestre Rodrigues

Presidente da Comissão de Pós-Graduação:

Prof. Associado Luís Fernando Costa Alberto 



\section{AGRADECIMENTOS}

À minha família pela compreensão, pela paciência e pelo apoio. Aos meus pais por sempre terem acreditado em mim. Ao meu irmão, pelo companheirismo.

À professora Cristina de Hollanda Cavalcanti Tsuha pela sugestão da problemática que deu origem a esta pesquisa e pela sábia orientação e dedicação, que contribuíram para a construção deste trabalho.

Ao professor André Teófilo Beck pela disponibilidade e pelas recomendações que foram fundamentais para a realização desta pesquisa.

Aos professores Fernando Artur Brasil Danziger e José Antônio Schiavon pela composição da banca examinadora deste trabalho e por suas indicações e recomendações que ajudaram a refinar esta pesquisa.

À Vértice Engenharia por disponibilizar o material que compôs o banco de dados utilizado durante o trabalho.

À Coordenação de Aperfeiçoamento de Pessoal de Nível Superior (CAPES), pela disponibilização de bolsa de estudos.

Aos professores e técnicos do Departamento de Geotecnia da Escola de Engenharia de São Carlos, pelos ensinamentos compartilhados, e aos funcionários do departamento pela disposição e assistência.

Aos colegas da pós-graduação, principalmente Diego, Maiuly e Mara pela paciência, apoio e pelo trabalho em equipe.

E a todos que contribuíram direta ou indiretamente para a realização deste trabalho. 

"We demand rigidly defined areas of doubt and uncertainty"

Douglas Adams, em The Hitchhiker's Guide to the Galaxy (1979). 



\section{RESUMO}

SILVA, B. O. Estimativa do torque de instalação de fundações por estacas helicoidais por meio de resultados de ensaio SPT. 108 p. Dissertação (Mestrado) - Departamento de Geotecnia, Escola de Engenharia de São Carlos, Universidade de São Paulo, São Carlos, 2018.

As linhas de transmissão no Brasil são geralmente muito extensas, uma vez que os grandes centros de consumo de energia ficam distantes das usinas hidrelétricas. Por essa razão, a construção e manutenção de linhas de transmissão é de grande importância e, em uma grande porcentagem destas linhas, as estacas helicoidais são usadas como fundações. No entanto, a previsão da profundidade final de instalação destas estacas ainda é um grande desafio para os projetistas, fornecedores de estacas helicoidais e construtoras. A profundidade final destas fundações é controlada pelo torque de instalação; portanto, se o torque necessário para instalar uma estaca pudesse ser calculado com acurácia, com base em suas dimensões, e nos resultados de ensaios de investigação de solo in situ (SPT), a previsão de comprimentos de estaca para estimativas de custos, a definição de equipamentos adequados para instalação e a estimativa da quantidade de seções de estacas a serem transportadas para uma determinada linha de transmissão seriam mais acuradas. Além disso, a capacidade de carga de estacas helicoidais pode ser estimada usando os resultados do torque final de instalação. Sendo assim, para atender à necessidade de se determinar o torque de instalação de fundações helicoidais ainda na fase de projeto, um método simplificado foi desenvolvido e validado com os resultados de 752 estacas helicoidais multi-hélices instaladas em solos predominantemente arenosos, de uma linha de transmissão brasileira. O modelo desenvolvido baseia-se nos resultados de ensaios SPT e considera o efeito de instalação das estacas no solo penetrado. Nesta dissertação é apresentada uma descrição detalhada do método proposto e uma comparação entre os resultados medidos em campo e calculados pelo método. Os resultados da comparação mostram que o método proposto pode estimar com sucesso o torque de instalação de estacas helicoidais.

Palavras chave: estacas helicoidais, torque de instalação, SPT, solos arenosos, regressão linear multivariada 



\begin{abstract}
SILVA, B. O. Estimation of the installation torque of helical piles using SPT data. 108 p. Master Thesis - Department of Geotechnical Engineering, São Carlos School of Engineering, University of Sao Paulo, Sao Carlos, 2018

The transmission lines in Brazil are usually very extensive, since the centers of power consumption are often far from the most hydroelectric plants. For this reason, the construction and maintenance of transmission lines is frequent in this country, and in a large percentage of transmission lines, helical piles are used as guy wire anchors and foundations for transmission towers. However, the estimates of the final embedded depth of numerous helical piles to be used in several towers of the transmission lines is still a challenge for the designers, pile suppliers and contractors. The final depth of helical foundations is controlled by the installation torque; therefore, if the torque necessary to install a helical pile could be accurately calculated based on the pile dimensions and results of in-situ soil tests (SPT), the prediction of pile lengths for costs estimations, the definition of suitable equipment for pile installation, and the estimate of the quantity of helical piles sections to be transported for a particular transmission line would be more precise. Additionally, the uplift capacity of helical piles can be estimated using the results of final installation torque. In order to address the existed need of determining the installation torque of helical foundations during the design phase, a simplified method was developed and validated with the results of 753 multi-helix piles installed in predominantly sandy soils of a Brazilian transmission line. The model proposed is based on the results of SPT tests, and considers the installation effect of helical piles on the soil penetrated. This text presents a detailed description of such method and a comparison between measured and predicted results. The comparison shows that the method proposed can successfully estimate the installation torque of helical piles.
\end{abstract}

Key words: helical piles, installation torque, SPT N-value, sandy soils, multivariate linear regression 



\section{LISTA DE FIGURAS}

Figura 1 - Componentes de amarração e da ancoragem helicoidal desenvolvida por Mitchell.

Figura 2 - Esquema do Farol Maplin Sands ............................................. 26

Figura 3 - Estaca metálica helicoidal ..................................................... 27

Figura 4 - Sistema de estaca com múltiplas hélices ..................................... 28

Figura 5 - Estaca helicoidal básica ......................................................... 28

Figura 6 - Espaço ao redor da haste central após a instalação da estaca ......... 31

Figura 7 - Equipamento típico de instalação de estacas ................................ 32

Figura 8 - Torquímetro ........................................................................ 32

Figura 9 - Métodos da superfície de atrito e das capacidades individuais ........ 36

Figura 10 - Diferentes configurações dos modelos reduzidos projetados por Ghaly et. al (1991) - dimensões em milímetro ....

Figura 11 - Sistema de forças mobilizadas durante instalação das ancoragens helicoidais

Figura 12 - Forças atuando na placa helicoidal

Figura 13 - Placa helicoidal (vista superior)

Figura 14 - Esquema das hipóteses assumidas por Tsuha (2007): (a) momentos resistentes durante a instalação; (b) forças resistentes ao arrancamento

Figura 15 - Esquema das forças atuantes na superfície das placas helicoidais

Figura 16 - Variação de $\delta_{c v}$ com D 50

Figura 17 - Gráfico de atrito na interface para aço, FRP e madeira ..................

Figura 18 - Esquema básico de uma estaca típica de seis hélices ....................

Figura 19 - Relação entre o erro de modelo e o comprimento instalado $L$......

Figura 20 - Relação entre o erro de modelo após a primeira correção e o

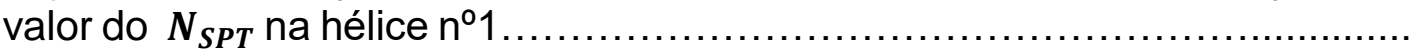

Figura 21 - Erro de modelo antes e depois das correções para $\boldsymbol{\delta}_{\boldsymbol{r}}=\mathbf{2 0}^{\circ} \ldots \ldots \ldots$.

Figura 22 - Erro de modelo antes e depois das correções para $\boldsymbol{\delta}_{r}=29^{\circ} \ldots \ldots \ldots$.

Figura 23 - EM após correções para estacas em argila siltosa e em silte argiloso

Figura 24 - Erro de modelo após correções para estacas com 4 hélices.

Figura 25 - Exemplo de protocolo de instalação de estacas em torres autoportantes

Figura 26 - Exemplo de relatório de sondagem com SPT ............................

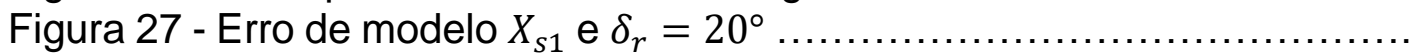

Figura 28 - Erro de modelo $X_{s 2}$ e $\delta_{r}=20^{\circ} \ldots$

Figura 29 - Erro de modelo $X_{s 3}$ e $\delta_{r}=20^{\circ}$

Figura 30 - Erro de modelo $X_{s 3,2}$ e $\delta_{r}=20^{\circ}$.

Figura 31 - Erro de modelo $X_{s 3,3}$ e $\delta_{r}=20^{\circ}$

Figura 32 - Erro de modelo $X_{s 4}$ e $\delta_{r}=20^{\circ}$

Figura 33 - Erro de modelo $X_{S 1}$ e $\delta_{r}=29^{\circ}$

Figura 34 - Erro de modelo $X_{s 2}$ e $\delta_{r}=29^{\circ}$

Figura 35 - Erro de modelo $X_{s 3}$ e $\delta_{r}=29^{\circ}$

Figura 36 - Erro de modelo $X_{s 3,2}$ e $\delta_{r}=29^{\circ}$

Figura 37 - Erro de modelo $X_{s 3,3}$ e $\delta_{r}=29^{\circ}$

Figura 38 - Erro de modelo $X_{s 4}$ e $\delta_{r}=29^{\circ}$ 



\section{LISTA DE TABELAS}

Tabela 1 - Propriedades físicas e mecânicas da areia ensaiada ................. 41

Tabela 2 - Ensaios de cisalhamento direto no solo e na interface ................... 57

Tabela 3 - Medidas de $\delta_{r}$ na interface do material da hélice e as amostras de areia de diferente $D_{50}$

Tabela 4 - Composições e quantidades das estacas por torre

Tabela 5 - Resumo dos resultados das análises de regressão e das

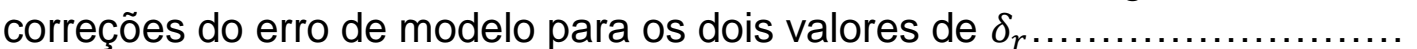

Tabela 6 - Resultados das sondagens SPT para as torres 36/1 até $114 / 2 \ldots \ldots$.

Tabela 7 - Resultados das sondagens SPT para as torres 137/2 até 200/1 ...

Tabela 8 - Resultados das sondagens SPT para as torres 201/2 até 221/1 ... 94

Tabela 9 - Resultados das sondagens SPT para as torres 221/2 até 246/1 ... 95

Tabela 10 - Síntese das principais informações disponíveis na base.

Tabela 11 - Resumo dos resultados das análises de regressão e das correções do erro de modelo para 769 estacas e $\delta_{r}=20^{\circ}$

Tabela 12 - Resumo dos resultados das análises de regressão e das correções do erro de modelo para 769 estacas e $\delta_{r}=29^{\circ}$ 



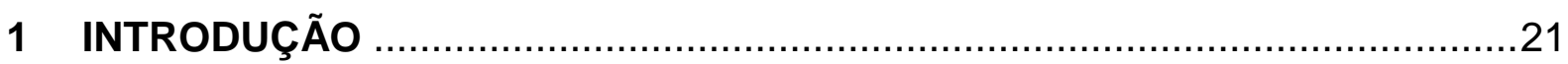

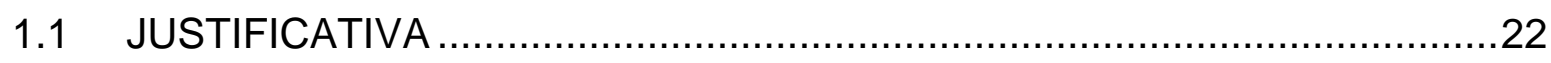

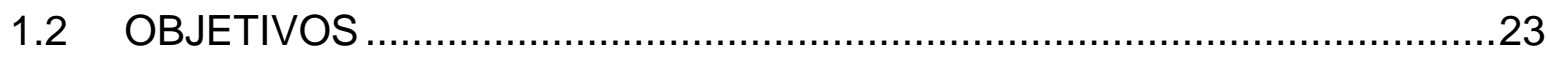

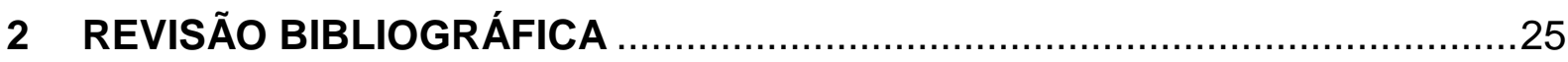

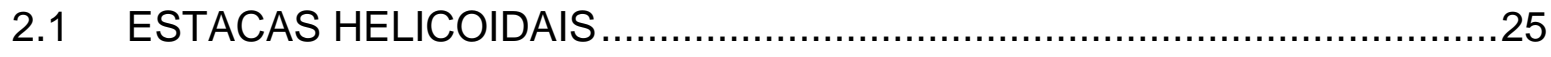

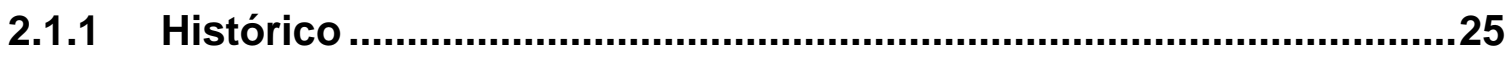

2.1.2 Definições e características principais............................................26

2.1.3 Vantagens e restrições ..................................................................29

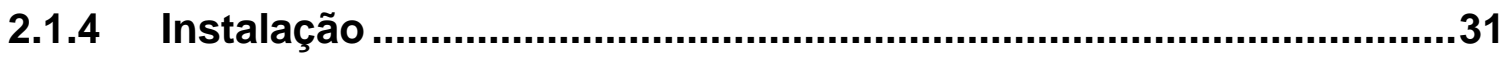

2.1.5 Previsão de capacidade de carga à tração........................................34

2.1.6 O ângulo de atrito residual na interface hélice-solo $(\delta r) \ldots \ldots \ldots \ldots . . . . . . .55$

2.2 ANÁLISE DE REGRESSÃO LINEAR .................................................

2.2.1 Estimativa dos coeficientes de regressão pelo método dos mínimos

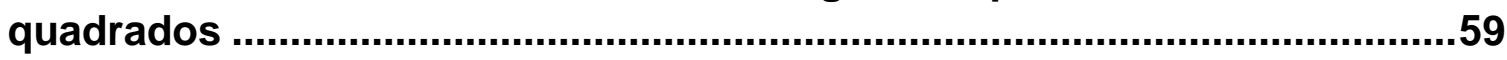

2.2.2 Análise de variância e coeficiente de determinação ........................60

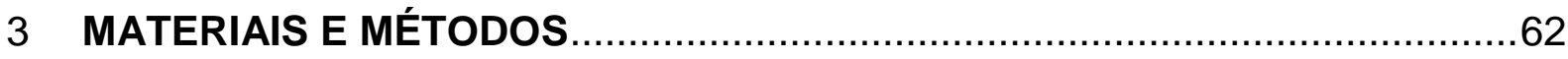

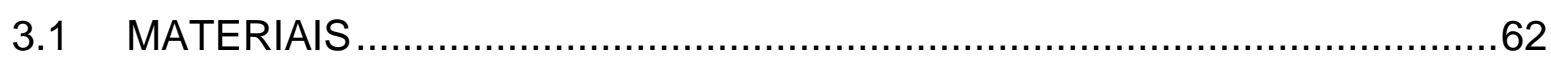

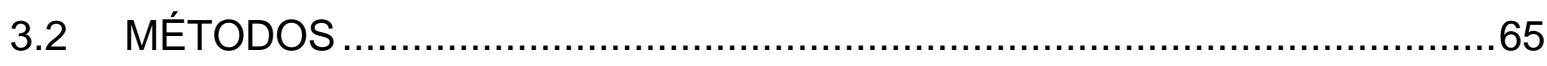

3.2.1 Determinação do modelo geral para previsão do torque ..................65

3.2.2 Avaliação do erro de modelo.......................................................73

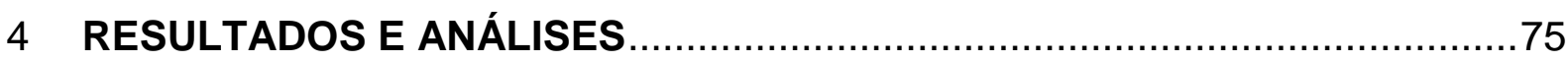

4.1 AVALIAÇÃO DO MODELO PARA SOLOS SILTOSOS E ARGILOSOS.......81

4.2 AVALIAÇÃO DO MODELO PARA ESTACAS COM 4 HÉLICES ..................82

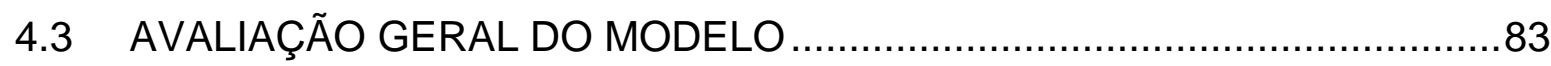

5 CONCLUSÕES E SUGESTÕES PARA TRABALHOS FUTUROS …...............84

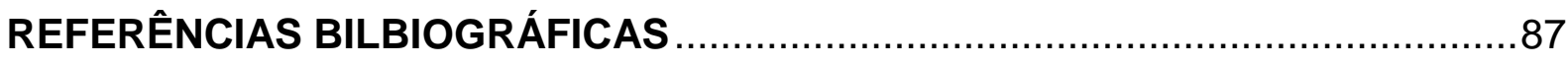

ANEXO A

APÊNDICE A

APÊNDICE B

APÊNDICE C

APÊNDICE D 




\section{INTRODUÇÃO}

O sistema estrutural utilizado em torres de transmissão de energia elétrica consiste, usualmente, em estruturas metálicas autoportantes ou estaiadas. Torres autoportantes são suportadas por montantes que compõem a estrutura principal da torre, através dos quais os esforços atuantes são transmitidos diretamente às fundações. Em torres estaiadas, a fundação recebe os esforços por meio de cabos metálicos conectados ao mastro da estrutura principal (Bentes, 2013). Nas duas situações, os elementos estruturais de fundações são solicitados por forças de tração originadas pela ação de forças de vento nos cabos condutores e na estrutura das torres (Gaaver, 2013).

As estacas helicoidais têm se tornado comuns nas fundações das torres de linhas de transmissão, principalmente por oferecem resistência à compressão e à tração. Além disso, este tipo de estaca oferece algumas vantagens interessantes para este tipo de obra, como: transporte fácil para locais remotos, possibilidade de serem instaladas em qualquer inclinação (caso de torres estaiadas), instalação rápida com equipamento relativamente pequeno (retroescavadeira); não necessita de serviços de concreto e forma; a capacidade da estaca correlaciona-se com o torque final de instalação e, portanto, pode ser controlada na fase de execução.

Segundo Hoyt e Clemence (1989) as estacas helicoidais são empregadas em diversas aplicações de engenharia inclusive em fundações de torres de transmissão de energia. Tsuha (2007) destaca que estacas metálicas helicoidais vêm sendo utilizadas em alguns países desde épocas anteriores à década de cinquenta e que no Brasil esse tipo de estaca passou a ser empregado próximo ao final dos anos 1990, principalmente em obras de linhas de transmissão e telecomunicação.

Dada a ocorrência de solicitações de vento, torna-se necessária, então, a determinação da capacidade de carga quanto à tração. Hoyt e Clemence (1989) consideram três metodologias principais de previsão: o método da superfície de cisalhamento, o método das capacidades de carga individuais e o método baseado no torque de instalação.

Ademais, Tsuha (2007) destaca que, na prática, grande parte do conhecimento relacionado às estacas helicoidais é baseado em observações empíricas quanto ao 
torque de instalação, pois esse valor é diretamente proporcional à capacidade de carga deste tipo de estaca. Por esta razão, algumas empresas pioneiras de estacas helicoidais apresentam tabelas com correlações empíricas entre torque de instalação e capacidade de carga da estaca, que variam de acordo com o modelo de estaca.

Tsuha (2007) desenvolveu um modelo teórico que fundamenta um procedimento de avaliação e controle da capacidade de carga de estacas helicoidais em solos arenosos com base no torque final de instalação.

Com base no modelo teórico proposto por Tsuha (2007) foi elaborado nesta dissertação um procedimento de previsão do torque de instalação baseado nos resultados de ensaios SPT.

\subsection{JUSTIFICATIVA}

A necessidade de construção de novas linhas de transmissão de energia elétrica no Brasil é iminente. A Agência Nacional de Energia Elétrica (ANEEL) licitou, em abril de 2016, vinte e seis lotes de novos empreendimentos correspondentes à instalação de cerca de $6.500 \mathrm{~km}$ de linhas de transmissão no país, com expectativas de investimentos de aproximadamente $R \$ 12,2$ bilhões e prazos para início de operação de 3 a 5 anos.

Construções com essas proporções são extremamente onerosas. Harikrishnan e Balagopal (2014) comentam que o sistema de ancoragem das torres pode equivaler a cerca de 20 a $35 \%$ do custo total de um empreendimento de linhas de transmissão de energia. Consequentemente, a otimização do projeto das fundações das torres pode contribuir substancialmente com a redução dos custos totais de implementação, o que incentiva o estudo dos métodos de previsão de capacidade de carga de fundações por estacas helicoidais.

Silva (2014) observa ainda um rápido crescimento da utilização de estacas helicoidais como fundação das torres de transmissão no Brasil e destaca a importância do desenvolvimento de procedimentos mais acurados para a previsão da capacidade de carga de fundações deste tipo. 
Deste modo, a possibilidade de estimar, na fase de projeto, os valores de torque de instalação de estacas helicoidais, com base em resultados de ensaio SPT (ensaio típico para a caracterização de subsolo no Brasil), traria os seguintes benefícios:

a) auxiliar na previsão do comprimento das estacas de torres de uma linha de transmissão com maior acurácia, evitando prejuízos (sobra de material) e problemas como falta de extensões de estaca na obra (em geral estas obras são feitas em locais de difícil acesso e a falta de material causa atrasos). No caso deste tipo de fundação, o critério de parada na instalação é o valor de torque; portanto, conhecendo-se a profundidade em que este valor é atingido é possível estimar-se o comprimento das estacas;

b) poder utilizar o método do torque na fase de projeto para se fazer a previsão de capacidade de carga. Existe uma relação direta entre torque final de instalação e a capacidade de carga à tração de estacas helicoidais, e, como não se conhece antecipadamente o valor do torque final de instalação, este não pode ser usado em projetos;

c) conhecer os valores de torque máximo para um dado modelo de estaca em um dado terreno, para se definir as características do motor necessário para a instalação;

d) verificar se valores de torque necessário para instalar a estaca ultrapassam o momento torçor de escoamento do aço da haste tubular da estaca. Deste modo, ajudaria na definição das dimensões de haste ideal (diâmetro externo e espessura da parede) para ser usada em uma obra.

e) verificar a viabilidade deste tipo de fundação em certos terrenos.

\subsection{OBJETIVOS}

O principal objetivo deste trabalho é elaborar um método semi-empírico para estimativa do torque de instalação de estacas helicoidais com base em resultados de resultados de sondagens de simples reconhecimento $\left(N_{S P T}\right)$. Esta necessidade se deve ao fato de que, no Brasil, as informações quanto às características do solo das torres de transmissão são normalmente obtidas por este tipo de ensaio de campo. 
A calibração e o ajuste do método serão feitos a partir de uma ampla base de dados obtidos em sondagens e relatórios de instalação de estacas helicoidais realizados durante a execução das torres que compõem o trecho LT 500 kV Cláudia - Paranatinga de uma linha de transmissão de energia. Os objetivos específicos são:

a) Organizar e digitalizar sistematicamente os relatórios de sondagem SPT e os protocolos de instalação das estacas helicoidais das torres autoportantes que compõem o banco de dados disponível para calibração do método de cálculo. Este banco de dados organizado em EXCEL poderá ser completado futuramente com novos resultados de sondagem SPT e torque de instalação de novas obras;

b) Avaliar diferentes hipóteses do efeito de instalação da estaca no solo penetrado para a elaboração e desenvolvimento do modelo. Este efeito afeta diretamente o torque resistido pela haste da estaca e pelas hélices superiores durante a instalação;

c) Verificar se o modelo calibrado para estimativa do torque de instalação com dados de torres que foram em sua maioria instaladas em solo arenoso também pode ser adequado para solos siltosos e argilosos. 


\section{REVISÃo BIBLIOGRÁFICA}

\subsection{ESTACAS HELICOIDAIS}

\subsubsection{Histórico}

Estacas helicoidais têm sido utilizadas por mais de 200 anos (Perko, 2009) e podem ser consideradas como um dos maiores avanços globais de engenharia da segunda metade do século XIX, que possibilitou a construção de torres de farol, pontes e embarcadouros em locais anteriormente improváveis (Lutenegger, 2011).

O primeiro registro da utilização de estacas helicoidais como um sistema de fundação aconteceu em 1836, introduzido pelo construtor irlandês Alexander Mitchell, que idealizou um sistema ainda embrionário de ancoragem helicoidal (Figura 1), dada a necessidade de fundações apropriadas para estruturas marinhas construídas sobre solos fracos (Lutenegger, 2011).

O termo screw pile (estaca parafuso, em tradução livre) foi inicialmente utilizado para denominar o sistema inicial criado por Mitchell, precursor das estacas helicoidais modernas (Perko, 2009).

Em 1838, Mitchell utilizou seu sistema de ancoragens helicoidais para construir as fundações do farol Maplin Sands, no rio Tâmisa, Inglaterra (Figura 2) e em 1848 Mitchell escreveu o primeiro artigo técnico referente à utilização de estacas helicoidais "On Submarine Foundations; particularly Screw-Piles and Moorings" publicado em Civil Engineering and Architects Journal (Perko, 2009).

Durante a segunda metade do século XIX a proposta inicial de Mitchell foi expandida e diversas foram as aplicações para as ancoragens helicoidais. Além de pontes, faróis e embarcadouros, obras menos convencionais como suporte para edificações sob efeito de subsidência e obras de proteção costeira também fizeram uso das estacas helicoidais (Lutenegger, 2011).

A primeira metade do século $X X$ foi marcada por um declínio do uso de estacas helicoidais, devido principalmente à mecanização da indústria da construção e pelo desenvolvimento de novos tipos de fundações profundas (Lutenegger, 2011), como as estacas Franki (Perko, 2009). 
Figura 1 - Componentes de amarração e da ancoragem helicoidal desenvolvida por Mitchell

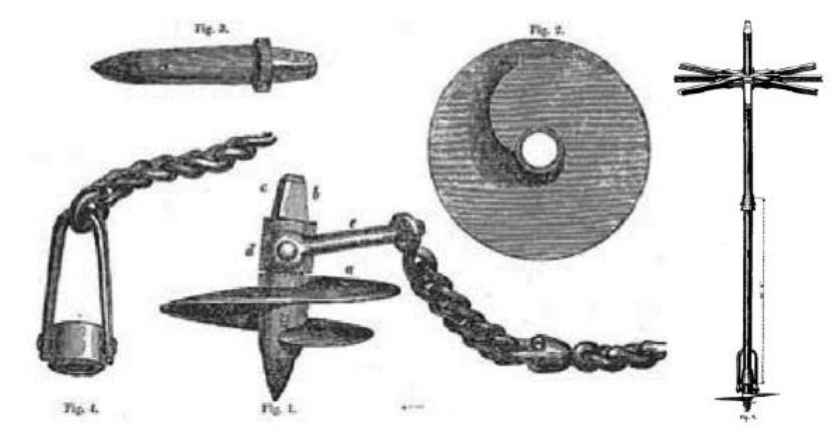

Figura 2 - Esquema do Farol Maplin Sands

Fonte: Lutenegger (2011).

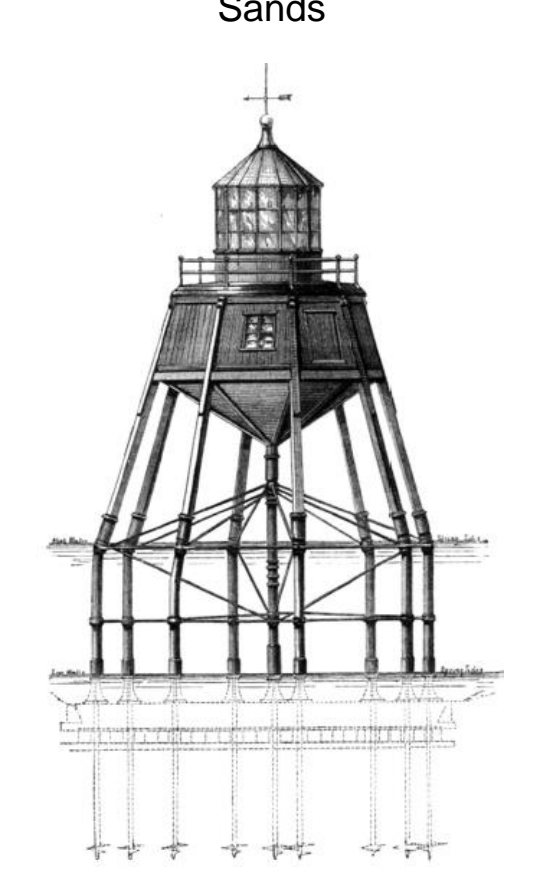

Fonte: Perko (2009).

A partir da década de 1980 nos Estados Unidos foram criadas várias novas patentes para ancoragens helicoidais, devido principalmente à quantidade significativa de obras de infraestrutura como barragens, rodovias interestaduais e linhas de transmissão de energia e à expansão imobiliária do fim daquela década (Perko, 2009).

No Brasil as estacas helicoidais modernas vêm sendo utilizadas em obras de torres de transmissão de energia principalmente a partir do final da década de 1990 (Tsuha, 2007).

\subsubsection{Definições e características principais}

Em Geotecnia o termo ancoragem refere-se a uma fundação projetada e construída com a finalidade de resistir a carregamentos de tração, ou seja, esforços que tendem a retirar do terreno o elemento resistente (Das, 1990). O autor estabelece um sistema de classificação para diferentes tipos de ancoragens através do agrupamento em categorias diversas, dentre as quais estão as ancoragens helicoidais. 
As estacas helicoidais (chamadas de ancoragens quando solicitadas somente em tração) são elementos estruturais instalados no solo pela aplicação de torque, até atingir a profundidade na qual o valor do torque aplicado seja igual ao valor especificado em projeto, que é equivalente à capacidade de carga requerida para a fundação. O valor do torque especificado para a estaca helicoidal é equivalente ao valor de "nega" especificado para a instalação de estacas cravadas, ambos parâmetros são adotados como critérios de paralisação da instalação.

Hoyt e Clemence (1989) citam que as estacas helicoidais consistem em uma ou mais placas circulares em forma de hélice fixadas a uma haste central (Figura 3), as quais são aparafusadas no solo através da aplicação de momento de rotação.

Udwari, Rogers e Singh (1979) descrevem um arranjo para um sistema de estaca com múltiplas hélices (Figura 4). Para os autores o sistema deve ser formado por uma seção guia com duas a quatro hélices de mesmo diâmetro ou diâmetro variável distantes de 30 polegadas, por seções de extensão da estaca com uma a quatro hélices, uma série de tubos de extensão ou hastes maciças conectadas com seção transversal quadrada ou circular e um adaptador para cabos na superfície.

Figura 3 - Estaca metálica helicoidal

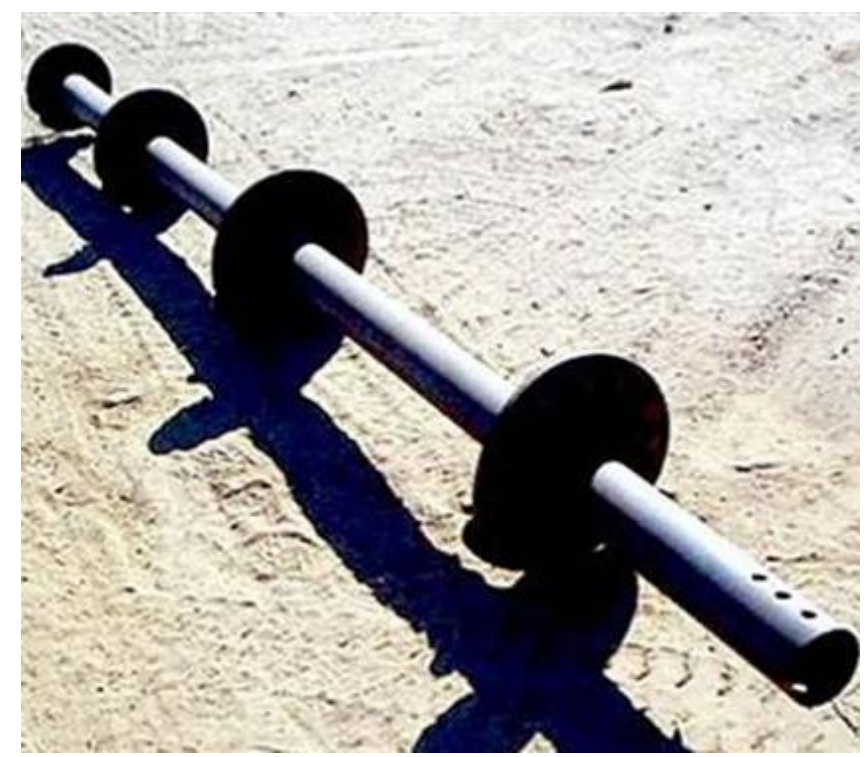

Fonte: Vértice Engenharia, 
Perko (2009) descreve uma série de elementos básicos que compõem uma estaca helicoidal, conforme Figura 5, dos quais a seção guia (com hélices soldadas) é a primeira seção da haste central a perfurar o solo; as extensões são seções adicionais com a finalidade de aumentar as profundidades atingidas; os engates ou ligações são os elementos de união entres seções adjacentes, geralmente formados por sistemas macho-fêmea aparafusados; às seções da haste central são fixadas placas helicoidais (hélices); o passo é a distância percorrida por uma rotação completa de uma hélice.

Figura 4 - Sistema de estaca com múltiplas hélices

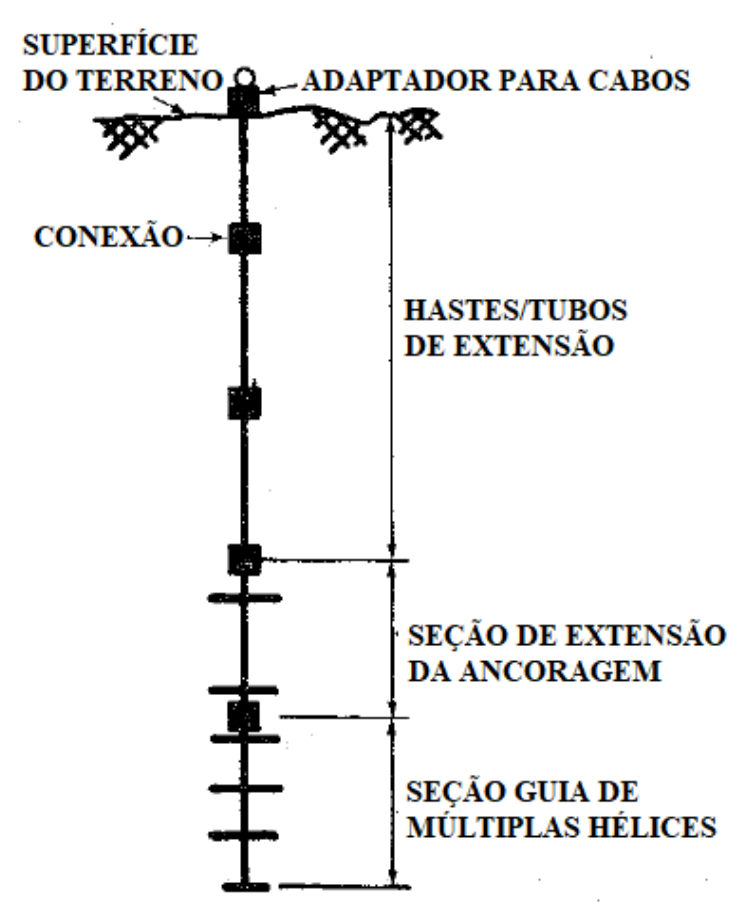

Fonte: Udwari, Rogers e Singh (1979).
Figura 5 - Estaca helicoidal básica

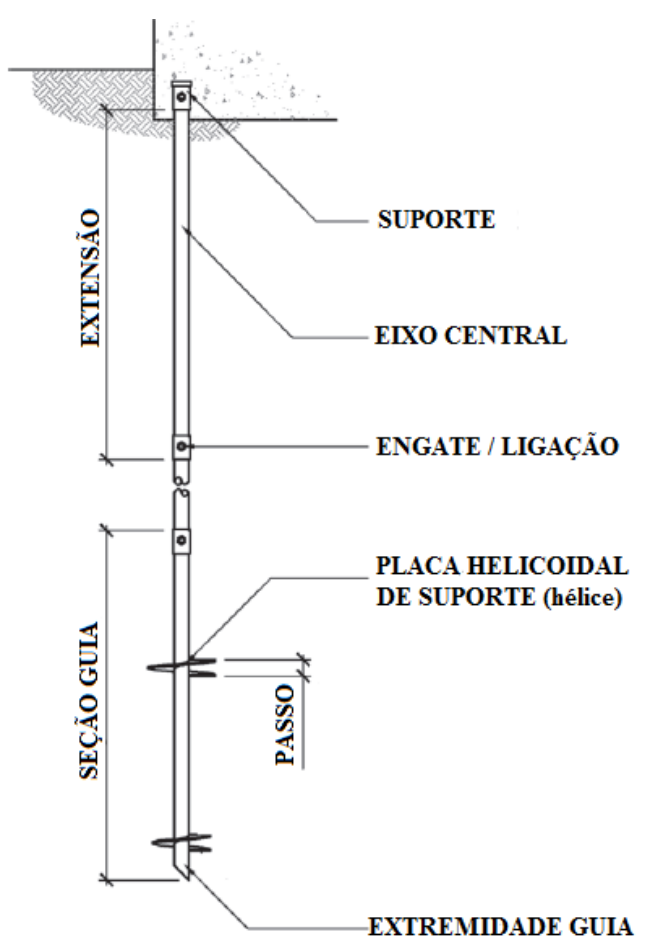

Fonte: Perko (2009).

Segundo Stephenson (2003) as estacas metálicas helicoidais modernas são compostas de dois elementos estruturais principais: a haste central e as placas helicoidais. A haste central pode ser construída com aço estrutural. As placas helicoidais podem também ser construídas com aço estrutural e são executadas cuidadosamente de forma a manter um passo que minimize a perturbação do solo durante a instalação. 
Filho (2014) destaca que no Brasil não existem normas específicas que regulamentem a fabricação de estacas helicoidais $e$, portanto, não existe padronização quanto às dimensões das hélices (diâmetro, passo, espessura) e observa que a definição dessas dimensões deve ser compatível com os esforços induzidos durante a instalação das estacas.

Perko, Stan e Rupiper (2000) destacam a importância da proteção dos materiais que constituem as estacas metálicas helicoidais contra a corrosão decorrente das propriedades eletroquímicas dos solos onde elas serão instaladas. A galvanização ou a proteção catódica controlada podem proteger o ferro e aço contra os efeitos da corrosão. Carvalho (2007) observa que no Brasil utiliza-se o Aço Corten na fabricação de estacas helicoidais para a mesma finalidade.

Estacas helicoidais podem ser utilizadas em diversas aplicações, são estruturas versáteis e podem ser instaladas com configurações variadas: podem ser executadas verticalmente ou inclinadas; podem suportar carregamento de compressão e de tração; podem apresentar hélice única ou múltiplas hélices com diâmetros variados (Perko, 2009).

O autor sugere ainda uma diferenciação dos termos "estaca helicoidal" e "ancoragem helicoidal", o primeiro é comumente utilizado como referência a fundações submetidas a esforços de compressão e tração, e o segundo indicado apenas para os casos de solicitações de tração.

\subsubsection{Vantagens e restrições}

O uso de estacas helicoidais tem aumentado nas últimas décadas, como observam Perko (2001), Tsuha (2007) e Silva (2014). A disseminação de seu uso é presumivelmente consequência de uma série de vantagens que fundações desse tipo apresentam.

Para Stephenson (2003) a vantagem mais evidente da utilização de estacas helicoidais é a sua confiabilidade; o autor afirma que quando instaladas adequadamente as estacas helicoidais podem atingir e até superar a capacidade prevista em projeto. 
Além disso, Perko (2009) reúne uma série de benefícios que estacas helicoidais apresentam em relação a outros tipos de fundações profundas:

a) resiste à degradação por fluxo e erosão, para utilização em pontes;

b) podem ser removidas em aplicações temporárias;

c) podem ser facilmente transportadas para locais remotos e instaladas com equipamentos compactos;

d) a capacidade de carga pode ser verificada a partir do torque de instalação;

e) podem ser instaladas abaixo do nível d'água;

f) podem ser instaladas rapidamente sem produzir grandes vibrações, ruídos ou perturbações em locais ambientalmente sensíveis;

g) elimina as formas para concreto e os procedimentos de cura e não produz resíduos de perfuração.

Outras vantagens observadas por Lutenegger (2011) são a possibilidade quase imediata de carregamento da fundação logo após a execução, as dimensões e os comprimentos podem ser facilmente adaptados às condições do terreno e fundações com estacas helicoidais podem constituir uma solução economicamente competitiva.

No entanto, alguns cuidados devem ser observados em relação à utilização de estacas helicoidais; Stephenson (2003) destaca algumas restrições:

a) deve-se evitar a instalação de estacas helicoidais em solos que podem danificar as hélices e a haste central ou que impossibilitem a instalação de um comprimento de ancoragem mínimo, principalmente em solos com quantidades excessivas de pedregulhos, matacões e resíduos de construção;

b) deve-se levar em consideração durante o projeto o efeito de flambagem quando a estaca estiver submetida à compressão em solos muito moles, geralmente com $N_{S P T}$ menor que 5 golpes;

c) estacas helicoidais não são efetivas quanto ao suporte de carregamentos laterais excessivos. 
Além disso, Tsuha, Filho e Santos (2016) observaram que a instalação de estacas helicoidais em solo estruturado não saturado pode provocar a desestruturação das camadas superiores de solo, causada pela penetração das hélices.

A perturbação verificada pelos autores produziu uma abertura que separou 0 solo da haste central das estacas até aproximadamente $3 \mathrm{~m}$ de profundidade (Figura $6)$.

Figura 6 - Espaço ao redor da haste central após a instalação da estaca

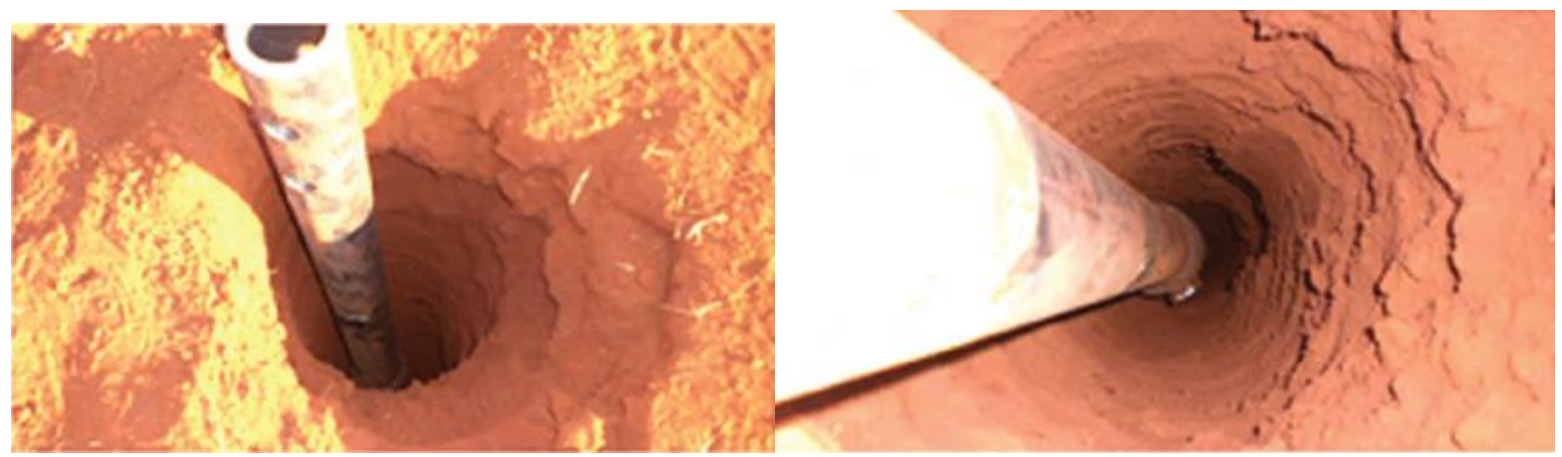

Fonte: Tsuha, Filho e Santos (2015).

\subsubsection{Instalação}

Segundo Hoyt e Clemence (1989) as estacas helicoidais são instaladas no terreno pela aplicação de rotação (aparafusamento) proporcionado por um caminhão padronizado ou por reboque equipado com sistema de instalação.

Para Ghaly e Clemence (1998) ancoragens helicoidais são instaladas no solo através da aplicação de rotação (torque) na haste central da estaca. Segundo os autores as placas helicoidais são autopropelidas e geram forças de arrasto que facilitam a penetração das estacas e os procedimentos de instalação são similares para ancoragens verticais e inclinadas.

Durante a instalação deve-se aplicar uma força paralela a haste central com sentido descendente, para substituir a ausência de sobrecarga, melhorar o contado entre os elementos helicoidais e o solo, garantir a direção de instalação para ancoragens inclinadas e minimizar a perturbação do solo. 
Perko, Stan e Rupiper (2000) especificam que a força axial aplicada sobre o eixo central durante a instalação também deve ser suficiente para garantir que a taxa de avanço da estaca no solo seja igual a um passo por rotação.

\subsubsection{Equipamento de instalação}

Perko (2009) afirma que uma estaca helicoidal é instalada no solo pela aplicação de torque através de um caminhão broca ou por um motor hidráulico de torque acoplado a uma retroescavadeira, empilhadeira, carregadeira, caminhão guindaste ou outro equipamento hidráulico compatível com o motor de torque (Figura 7). Equipamentos de instalação por percussão não são apropriados.

Figura 7 - Equipamento típico de instalação de estacas

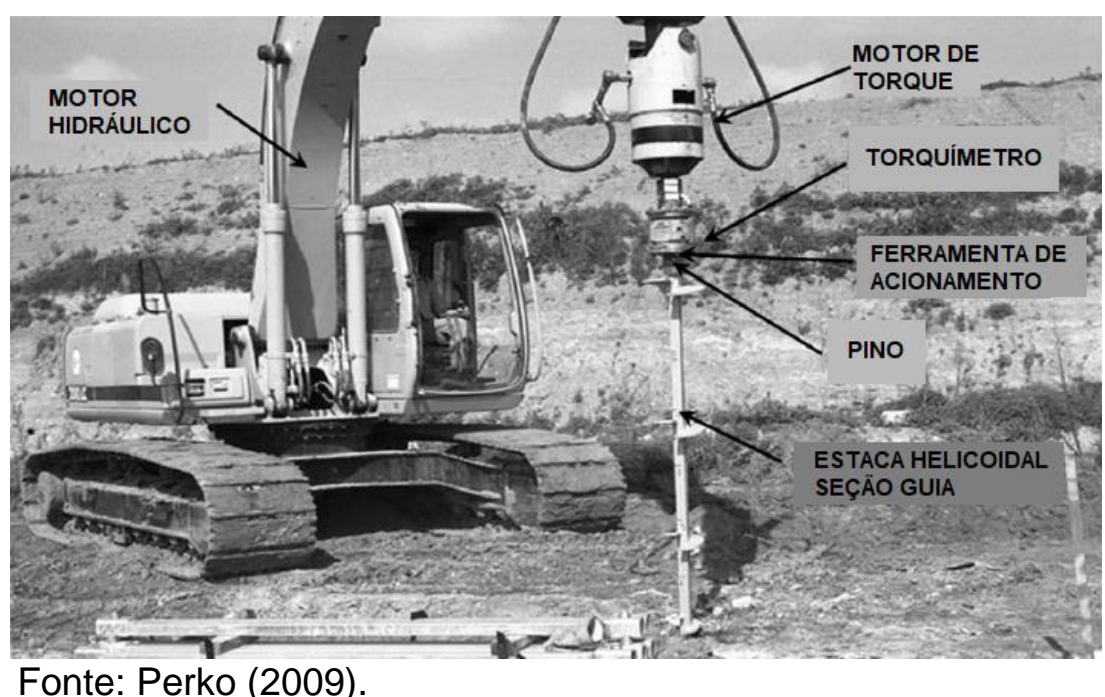

Fonte: Perko (2009).
Figura 8 - Torquímetro

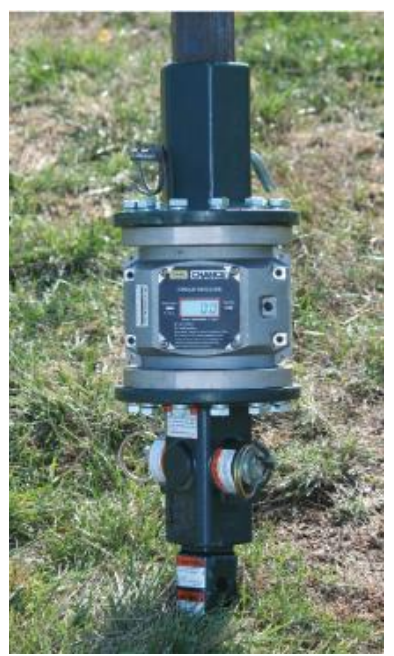

Fonte: A.B. Chance Co. (2013).

O principal equipamento para a instalação das estacas helicoidais é o motor de torque, utilizado para aplicar uma rotação no topo da haste central. Os motores devem apresentar capacidade de rotação horária e anti-horária com ajuste da quantidade de rotações por minuto. Os motores mais comuns utilizados para instalação das ancoragens têm capacidade de aplicar torques de 6.000 a $100.000 \mathrm{~N} \cdot \mathrm{m}$ ou superiores (Perko, 2009). 
Indicadores de torque ou torquímetros (Figura 8) devem ser utilizados para registro dos valores de torque aplicados durante a instalação. Os indicadores podem ser parte integrante do motor de torque ou podem ser externamente acoplados ao motor hidráulico. Devem ser calibrados em laboratório devidamente equipado e devem permitir a leitura dos valores de torque durante todo o procedimento de instalação (A.B. Chance Co., 2012).

Estacas helicoidais podem ser também instaladas utilizando-se motores de torque operados manualmente, principalmente quando o acesso ao local de instalação for dificultado, no entanto Perko (2009) ressalta que torques elevados não podem ser aplicados manualmente e por isso devem ser utilizadas barras de reação para evitar rotação do motor, além disso, nesses casos a aplicação da força axial na haste central não pode ser executada tão eficientemente.

\subsubsection{Procedimento de instalação}

Antes do iniciar a instalação da estaca todos os equipamentos devem ser inspecionados e partes faltantes ou com irregularidades devem ser substituídas, os equipamentos precisam ser calibrados e o local de instalação deve ser verificado quanto à existência de riscos à segurança da operação (A.B. Chance Co., 2013).

Perko (2009) fornece um guia de instalação e recomenda uma sequência de passos para proceder com a instalação adequada das estacas helicoidais:

a) vincular a seção guia da estaca ao motor de torque;

b) centralizar a haste da estaca sobre local especificado;

c) pressionar a extremidade guia até a primeira hélice encostar na superfície do terreno;

d) verificar o alinhamento da haste central;

e) verificar o alinhamento do motor de torque e dos elementos de ligação;

f) iniciar rotação com aplicação da força axial descendente;

g) continuar com o avanço da estaca e conferir o alinhamento (a verificação da inclinação da estaca deve ser periódica, sempre que necessária; 
h) registrar a profundidade e os valores de torque em intervalos especificados;

i) parar instalação na superfície do terreno;

j) adicionar seção de extensão conforme a necessidade;

k) continuar com o avanço da estaca e conferir o alinhamento;

l) parar a instalação ao atingir profundidade e o torque especificados;

m) cortar a seção de extensão até elevação final;

n) perfurar a haste para inserção de parafusos;

o) montar a seção de topo da estaca;

p) registrar o torque, a profundidade e a elevação finais.

As estacas helicoidais devem ser instaladas de modo que sejam atingidas as recomendações de projeto referentes a seu comprimento total, ao valor de torque final e ao valor de torque máximo fornecido pelo fabricante da estaca (torque que causa o escoamento do aço da haste central).

O torque fornecido pelo fabricante não deve ser excedido; se o torque máximo foi atingido antes do comprimento total especificado pode-se retroceder uma parte da estaca e tentar reinstalá-la com uma força axial reduzida, ou retirá-la completamente e instalar uma nova estaca com eixo central mais resistente e placas helicoidais menores, um pré-furo pode ser escavado antes da instalação da nova estaca. A estaca pode ser também realocada e instalada em local próximo (Perko, 2009).

\subsubsection{Previsão de capacidade de carga à tração}

Udwari, Rogers e Singh (1979) consideram que não existe uma única abordagem racional, baseada em princípios de engenharia, para a previsão de capacidade de carga de estacas helicoidais submetidas a esforços axiais de tração, qualquer que seja a condição do solo e a profundidade de assentamento da estaca.

A dificuldade em determinar uma abordagem específica pode ser atribuída ao problema de definição de uma superfície de ruptura adequada, que é uma função das configurações da estaca, da profundidade de assentamento e das condições gerais 
do solo. Udwari, Rogers e Singh (1979) enumeram diversos fatores que influenciam a capacidade de carga de estacas helicoidais:

a) propriedades de resistência e deformabilidade do solo;

b) não homogeneidade e estratificação do subsolo;

c) nível d'água e grau de saturação do solo;

d) efeitos ambientais sobre o comportamento do solo (congelamentodescongelamento; contração-inchamento; fissuração por secagem);

e) procedimento de instalação (taxa de avanço; força axial descendente; níveis de torque);

f) ângulo e profundidade de instalação;

g) tipo da ancoragem e suas configurações;

h) razão entre o diâmetro da haste central e o diâmetro da hélice superior;

i) capacidade estrutural das hélices, extensão da haste central e a configuração das conexões;

j) tipo e duração dos carregamentos;

k) efeito de grupo decorrente da instalação de estacas a pequenas distâncias;

l) sucção no solo;

De forma geral, as capacidades de carga de estacas helicoidais à tração e à compressão são tradicionalmente estimadas através de duas metodologias: o método do cilindro de atrito e o método das capacidades individuais (Hoyt e Clemence, 1989).

O método do cilindro considera que as múltiplas hélices de uma estaca resistem em grupo, e leva em conta a mobilização da resistência ao cisalhamento do solo ao longo de uma superfície circunjacente a todas as placas helicoidais, somada à resistência por atrito atuante na haste central e à resistência oferecida pelo solo acima da hélice superior. A utilização do termo cilindro é inadequada no caso de estacas de múltiplas hélices com diâmetros diferentes, portanto, decidiu-se utilizar neste texto a terminologia superfície de atrito. 
O método das capacidades individuais estima a capacidade de carga à tração como o somatório das forças resistentes atuantes em cada uma das hélices de uma estaca adicionado à resistência por atrito na haste (Perko, 2009).

A Figura 9 exibe diagramas esquemáticos das forças atuantes nas estacas helicoidais para o método da superfície de atrito e para o método das capacidades de carga individuais. Segundo Perko (2009), a capacidade de carga à tração $Q_{U}$ pode ser estimada pela equação (1) no caso do método da superfície de atrito, e pela equação (2) segundo o método das capacidades individuais.

Figura 9 - Métodos da superfície de atrito e das capacidades individuais
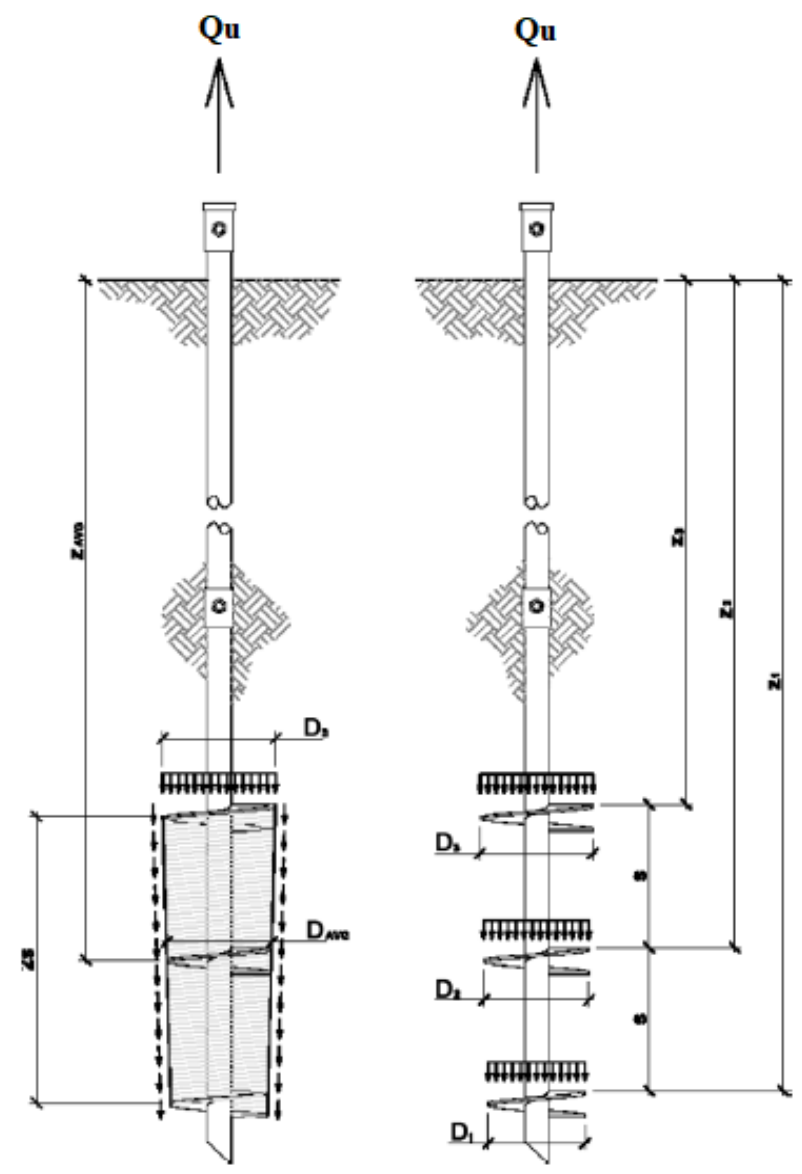

Fonte: Perko (2009).

$$
\begin{aligned}
Q_{U} & =q_{u l t} A_{T}+\tau(n-1) s \pi D_{A V G}+\alpha H_{e f f}(\pi d) \\
Q_{U} & =\sum_{n} q_{u l t} A_{n}+\alpha H_{e f f}(\pi d)
\end{aligned}
$$


Nas quais: $\quad q_{u l t}$ é tensão resistente na hélice;

$A_{T}$ é a área da hélice superior;

$A_{n}$ é a área da n-ésima hélice

$\tau$ é resistência ao cisalhamento do solo ao longo da distância entre a primeira e última hélice;

$D_{A V G}$ é o diâmetro médio das hélices;

$\alpha$ é adesão entre o solo e a haste central;

$H_{\text {eff }}$ é o comprimento da haste central acima da hélice superior;

$d$ é o diâmetro da haste central;

$(n-1) s$ é a distância entre distância entre a primeira e última hélice, onde $n$ e o número de hélices e $s$ o espaçamento entre duas hélices.

O espaçamento entre as placas helicoidais em estacas com múltiplas hélices é um indicativo de como a capacidade de carga da fundação se comporta. Se o espaçamento é pequeno existe uma tendência de comportamento conjunto, como propõe o método da superfície de atrito. Para espaçamentos maiores as hélices passam a oferecer resistência independentemente, conforme o método das capacidades individuais.

A proximidade ou afastamento relativo entre hélices depende da geometria da estaca helicoidal e das condições do solo circunjacente, assim, os resultados dos dois métodos devem ser avaliados pelo projetista. O espaçamento ideal é aquele que produz resultados convergentes nos dois procedimentos de cálculo, de forma que a haste central não seja excessivamente longo ou que não aconteça sobreposição das resistências de hélices adjacentes (Perko, 2009).

Hoyt e Clemence (1989) introduzem uma terceira metodologia que relaciona a capacidade de carga com o torque medido ao final da instalação da estaca, baseada em considerações empíricas, conforme equação (3). No procedimento indicado a capacidade de carga a tração pode ser obtida multiplicando-se o torque medido no final da instalação por um fator empírico que depende da forma e das dimensões da haste central. 


$$
Q_{U}=K_{T} \times T
$$

Em que: $\quad Q_{U}$ é a capacidade de carga à tração;

$K_{T}$ é o fator de torque (valor empírico recomendado pelos fabricantes das estacas);

$T$ é o torque final de instalação.

Segundo Hoyt e Clemence (1989) o valor de $K_{T}$ depende principalmente da geometria da haste central da estaca. Para estacas com haste de seção quadrada ou com seção circular de diâmetro menor que $89 \mathrm{~mm}$, os autores recomendam utilizar $K_{T}$ $=33 \mathrm{~m}^{-1}$; para seções circulares com diâmetro igual a $89 \mathrm{~mm}$ sugerem $K_{T}=23 \mathrm{~m}^{-1} \mathrm{e}$ para seções com diâmetro de $219 \mathrm{~mm}$ o valor recomendado é $K_{T}=9,8 \mathrm{~m}^{-1}$.

De acordo com o manual técnico da A. B. Chance Co. (2004) o valor de $K_{T}$ pode variar entre 10 e $66 \mathrm{~m}^{-1}$, dependendo das condições do solo, do projeto da estaca e principalmente do diâmetro da haste central da estaca.

A partir da comparação entre resultados obtidos por esse procedimento com as estimativas feitas através dos métodos da superfície e das capacidades individuais, Hoyt e Clemence (1989) indicam que o método do torque de instalação produziu resultados mais consistentes.

Perko, Stan e Rupiper (2000) aconselham que, sempre que possível, a decisão final do engenheiro deve ser baseada nos resultados dos três métodos, levando em consideração a confiabilidade dos dados de entrada.

\subsubsection{Relação entre capacidade de carga à tração e torque de instalação}

A relação entre capacidade de carga de uma estaca helicoidal e o torque aplicado durante a instalação tem sido utilizada como uma regra prática, desde a década de 60 (Perko, 2009), para o controle da capacidade de carga na fase de execução. 
No entanto, grande parte dos detalhes envolvendo a utilização dessa relação era mantida como propriedade dos fabricantes de estacas helicoidais, o que dificultou uma análise mais racional baseada em princípios da mecânica dos solos (Udwari, Rogers e Singh, 1979).

Hoyt e Clemence (1989) foram os primeiros a explicitar uma definição para essa relação tendo como base conceitos geotécnicos tradicionais (equação (3)). Os autores analisaram os resultados de 91 provas de carga para confirmar que as estimativas feitas a partir da relação torque-capacidade são mais adequadas que os métodos da superfície de atrito e das capacidades individuais.

Merifield (2011) afirma que a estimativa da capacidade de carga à tração de estacas helicoidais com múltiplas hélices é corriqueiramente baseada no valor final do torque de instalação através da relação empírica da equação (3). Diversos estudos referentes ao torque de instalação de estacas helicoidais foram publicados como Ghaly et al. (1991), Ghaly e Hanna (1991), Tsuha (2007), Gavin et al. (2013), Sakr (2015), Spagnoli (2017) e Al-Baghdali et al. (2017).

\subsection{Ghaly et al. (1991)}

Ghaly et al. (1991) conduziram um programa de investigação experimental no qual cinco modelos reduzidos de ancoragens helicoidais foram projetados para estudar o efeito da forma das hélices durante a instalação em areias. Os modelos eram diferentes quanto à quantidade, o diâmetro e o passo das hélices, conforme Figura 10.

A areia utilizada na investigação foi compactada de modo a atingir três condições de densidade distintas, particularmente nas condições fofa, medianamente compacta e compacta. A compactação aconteceu em camadas de $150 \mathrm{~mm}$ de espessura em um tanque de alvenaria com dimensões internas iguais a 1,00 $\times 0,70 \mathrm{~m}$ na base e $1,25 \mathrm{~m}$ de altura.

A Tabela 1 traz um resumo das características físicas e mecânicas da areia. 
Figura 10 - Diferentes configurações dos modelos reduzidos projetados por Ghaly et. al

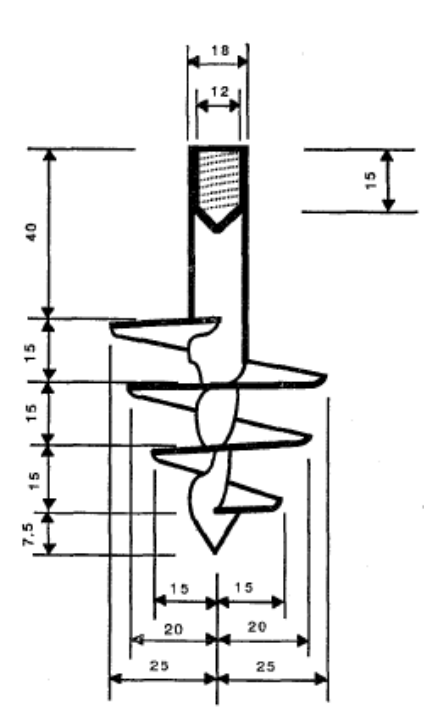
(1991) - dimensões em milímetro

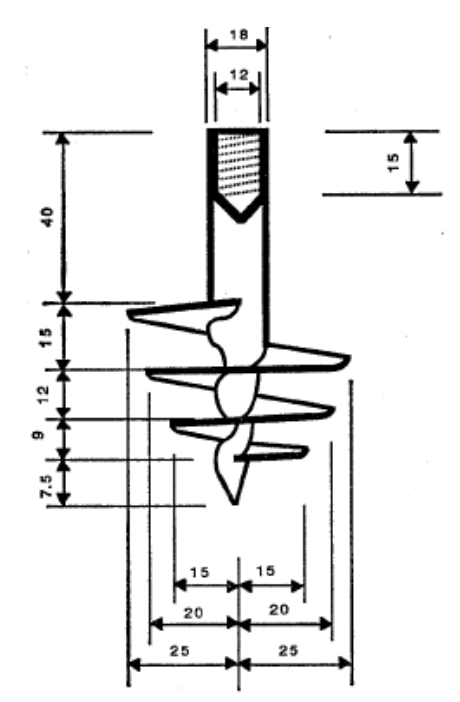

Tipo 2

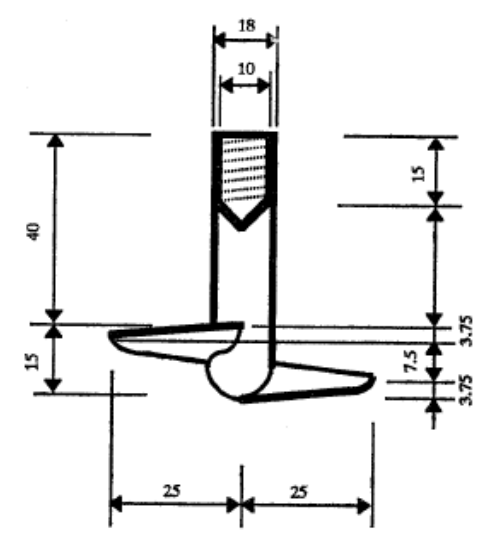

Tipo 1

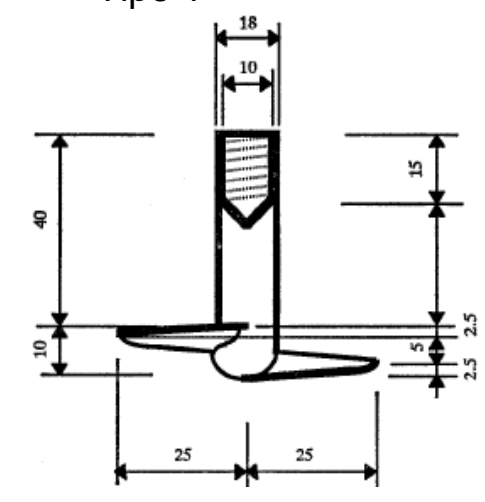

Tipo 4

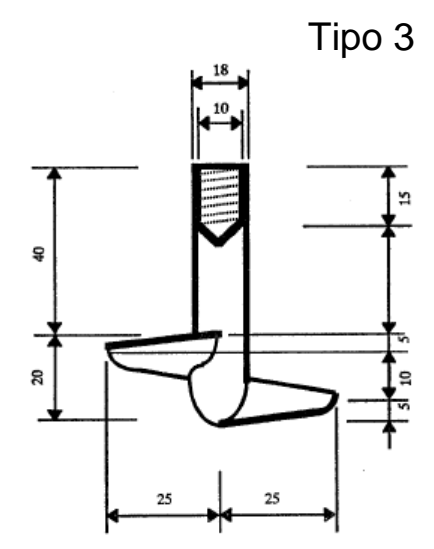

Tipo 5

Fonte: Ghaly et. al (1991).

Tabela 1 - Propriedades físicas e mecânicas da areia ensaiada

\begin{tabular}{rcc}
\hline \multicolumn{1}{c}{ Propriedades } & Valores \\
\hline Areia fofa: & Peso específico & $15,7 \mathrm{kN} / \mathrm{m}^{3}$ \\
& Ângulo de atrito & 300 \\
Densidade relativa & $35 \%$ \\
Areia medianamente compacta: & \\
Peso específico & $16,2 \mathrm{kN} / \mathrm{m}^{3}$ \\
Ângulo de atrito & 350 \\
Densidade relativa & $50 \%$ \\
Areia compacta: & $16,7 \mathrm{kN} / \mathrm{m}^{3}$ \\
Peso específico & $40^{\circ}$ \\
Ângulo de atrito & $80 \%$ \\
Densidade relativa & 2,67 \\
Densidade relativa & $($ continua $)$
\end{tabular}




\begin{tabular}{|c|c|}
\hline Propriedades & Valores \\
\hline & (continuação) \\
\hline$D_{10}$ & $0,11 \mathrm{~mm}$ \\
\hline$D_{30}$ & $0,19 \mathrm{~mm}$ \\
\hline$D^{50}$ & $0,23 \mathrm{~mm}$ \\
\hline Coeficiente de uniformidade, $\mathrm{C}_{\mathrm{u}}$ & 2,09 \\
\hline Coeficiente de curvatura, $\mathrm{C}_{\mathrm{c}}$ & 1,42 \\
\hline Forma das partículas & Angular \\
\hline
\end{tabular}

Fonte: Ghaly et. al (1991).

$\mathrm{Na}$ determinação de uma formulação teórica para relacionar o torque de instalação e capacidade de carga das ancoragens helicoidais, Ghaly et al. (1991) levaram em consideração a definição do formato de uma cunha na areia, mobilizada durante a solicitação por tração.

Os autores assumiram um sistema de forças atuantes durante a instalação nos casos de ancoragens rasas e profundas (Figura 11).

Figura 11 - Sistema de forças mobilizadas durante instalação das ancoragens helicoidais
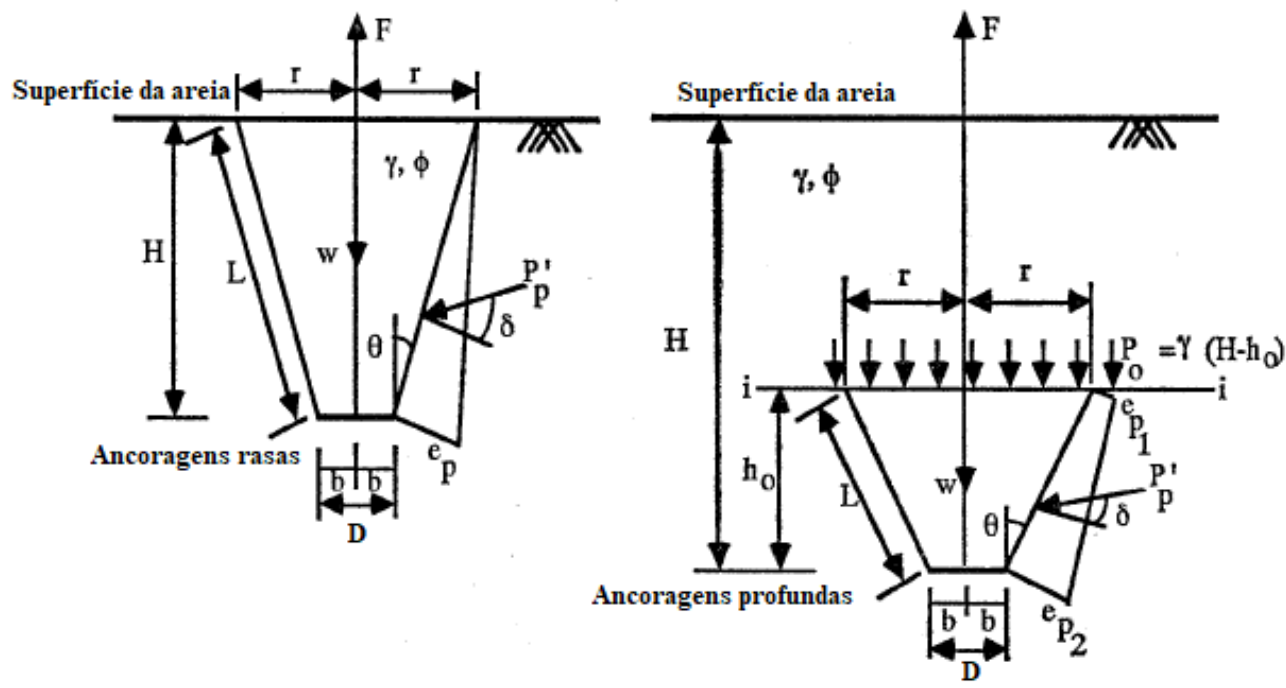

Fonte: Ghaly et. al (1991).

Na Figura 11 a força $F$ é resultante do impedimento do avanço descendente da estaca dentro da areia e é igual à força última contra o arrancamento da ancoragem e é igual à soma do peso de solo dentro da superfície de ruptura com as forças decorrentes de empuxo passivo, conforme equação (4). 


$$
F=W+P_{P}
$$

Em que: $\quad F$ é força última contra o arrancamento;

$W$ peso da areia dentro da superfície de ruptura;

$P_{p}$ são as forças de empuxo passivo.

Além disso, definiu-se um modelo esquemático das forças atuantes na superfície das placas helicoidais (Figura 12). As forças atuantes durante a rotação das hélices quando o avanço vertical é impedido são: $F$, força vertical; $\mu N$, força de atrito na superfície da hélice; $R$, força aplicada para contrapor o efeito do atrito e satisfazer o equilíbrio estático.

Figura 12 - Forças atuando na placa helicoidal

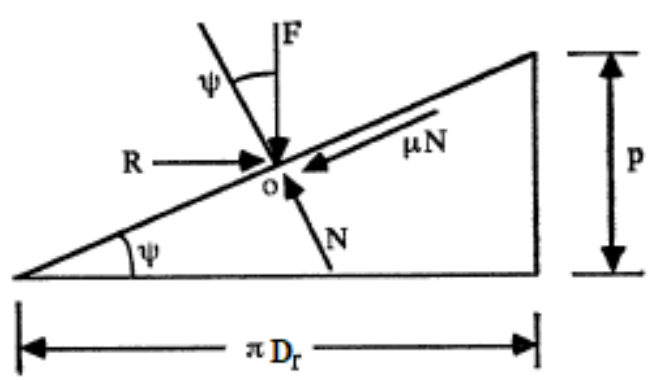

Fonte: Ghaly et. al (1991).
Figura 13 - Placa helicoidal (vista superior)

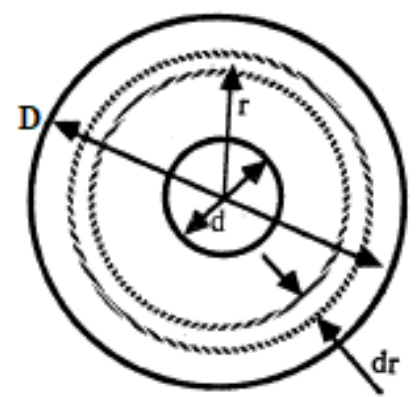

Fonte: Ghaly et. al (1991).

Em situação de equilíbrio estático o sistema de forças pode ser escrito conforme a equação (5). Por fim, com base na Figura 13, o torque $T$ de instalação para uma determina profundidade pode ser calculado a partir da equação (6).

$$
\left.\begin{array}{c}
R-N \sin \psi-\mu N \cos \psi=0 \\
F+\mu \sin \psi-N \cos \psi=0
\end{array}\right\} R=F\left[\frac{\tan \psi+\mu}{1-\mu \tan \phi}\right]
$$

Em que: $\quad N$ é a força normal ao plano inclinado da placa helicoidal; 
$R$ é a força aplicada para contrapor o efeito do atrito na superfície da placa helicoidal;

$\psi$ é o ângulo da placa helicoidal com a horizontal (Figura 12), igual a $\tan ^{-1}\left(\frac{p}{\pi D_{r}}\right)$;

$\mu$ é o coeficiente de atrito, igual a $\tan \lambda$, e $\lambda=0,6 \phi$, e que $\phi$ é ângulo de atrito interno.

$T=F \tan (\psi+\lambda)\left[\frac{D^{3}-d^{3}}{3\left(D^{2}-d^{2}\right)}\right]$

Em que: $\quad D$ é o diâmetro da placa helicoidal (Figura 13);

$d$ é o diâmetro da haste central (Figura 13);

O restante dos parâmetros foi definido anteriormente.

2.1.5.1.2 Ghaly e Hanna (1991)

Ghaly e Hanna (1991) desenvolveram um modelo teórico para estimativa do torque de instalação baseado no sistema de forças mobilizadas nas placas helicoidais e na haste central, quando a estaca penetra o solo por rotação.

Os autores mencionaram que o desempenho de estacas helicoidais durante a instalação é influenciado por vários fatores como: diâmetro da placa helicoidal, passo e ângulo da hélice, diâmetro da haste, configuração geral da estaca (estacas com uma hélice, estacas com várias hélices de mesmo diâmetro, estacas com várias hélices de diâmetros crescentes, hélices com ângulo variável, etc.), espessura das placas, espessura e forma da aresta cortante na exterminada das placas, método utilizado na construção da estaca (montada, soldada, parafusada, rebitada, etc.), material da estaca e sua rugosidade.

O modelo proposto por Ghaly e Hanna (1991) para estimar o torque requerido para instalar estacas helicoidais com uma hélice em areia é dado pela equação (7). 


$$
T=T_{1}+T_{2}+T_{3}+T_{4}+T_{5}+T_{6}+T_{7}
$$

Em que: $\quad T_{1}$ é o momento resistente mobilizado na haste central;

$T_{2}$ e $T_{3}$ são momentos resistentes mobilizados na placa helicoidal;

$T_{4} \mathrm{e} T_{5}$ são os momentos resistentes mobilizados nas superfícies superior e inferior da placa helicoidal, devido à ação de tensões ativas e passivas, respectivamente;

$T_{6}$ é o momento resistente devido à força que atua em todo o comprimento do passo da hélice;

$T_{7}$ é o momento resistente mobilizado em todo o perímetro externo da espessura da placa helicoidal;

Os valores desses momentos podem ser calculados através das equações (8) a (14).

$$
\begin{aligned}
& T_{1}=0,5 \gamma H^{2} \cos \delta K_{P}^{\prime} K_{f}(\pi d)(d / 2) \\
& T_{2}=0,5 \gamma H^{2} \sin \delta K_{P}^{\prime} \tan (\delta+\theta)(\pi d)(d / 2) \\
& T_{3}=0,5 \gamma H^{2} \sin \phi K_{P}^{\prime} \tan (\delta+\theta)(\pi D)(D / 2) \\
& T_{4}=\gamma H K_{A} A_{t} \tan (\delta+\theta)\left[\left(D+D_{0}\right) / 4\right] \\
& T_{5}=\gamma H K_{P} A_{b} \tan (\delta+\theta)\left[\left(D+D_{0}\right) / 4\right] \\
& T_{6}=F\left[\left(D-D_{O}\right)^{2} / 8\right] \\
& T_{7}=\gamma H K_{P} K_{f}(\pi D)(D / 2) \mathrm{t}
\end{aligned}
$$

Nas quais: $\quad \gamma$ é peso específico da areia;

$H$ é a profundidade de instalação;

$\delta$ é o ângulo de atrito entre o material da hélice e a areia adjacente;

$K_{f}=\tan \delta$ é o coeficiente de atrito entre o material da hélice e a areia adjacente; 
$\phi$ é o ângulo de atrito interno da areia;

$K_{P}=(1+\sin \phi) /(1-\sin \phi)$ é o coeficiente de empuxo passivo;

$K_{P}^{\prime}=0,3 \times K_{P}$ é o coeficiente de empuxo passivo modificado, para considerar os efeitos de instalação;

$K_{A}=(1-\sin \phi) /(1+\sin \phi)$ é o coeficiente de empuxo ativo;

$\theta$ é o ângulo entre a hélice e a horizontal;

$d$ é o diâmetro da haste;

$B$ é o diâmetro externo da placa helicoidal;

$B_{0}$ é o diâmetro interno da placa helicoidal;

$A_{t}$ e $A_{b}$ são, respectivamente, as áreas reais das superfícies superior e inferior da placa helicoidal.

\subsection{Tsuha (2007)}

Tsuha (2007) desenvolveu um modelo teórico que relaciona o torque de instalação de estacas helicoidais profundas (profundidade de instalação 5 vezes maior que o diâmetro da hélice superior) com a capacidade de carga à tração para estacas instaladas em solos arenosos, levando em consideração a contribuição decorrente da mobilização do atrito na haste da estaca.

O modelo proposto assume que o torque necessário para instalar uma estaca metálica helicoidal é igual à soma do momento resistente nas placas helicoidais com o momento resistente na superfície da haste central, conforme as equações (15) e (16). A Figura 14 apresenta os modelos com as hipóteses assumidas por Tsuha (2007).

$$
\begin{aligned}
& T=T_{h}+T_{S} \\
& T_{h}=\sum_{i=1}^{N} T_{h \mathrm{i}}
\end{aligned}
$$


Nas quais: $T$ é o torque de instalação;

$T_{h}$ é o momento resistente nas placas helicoidais;

$T_{S}$ é o momento resistente na haste da estaca;

$T_{h \mathrm{i}}$ é o momento resistente na i-ésima hélice das $N$ placas em uma estaca;

Figura 14 - Esquema das hipóteses assumidas por Tsuha (2007): (a) momentos resistentes durante a instalação; (b) forças resistentes ao arrancamento

(a)

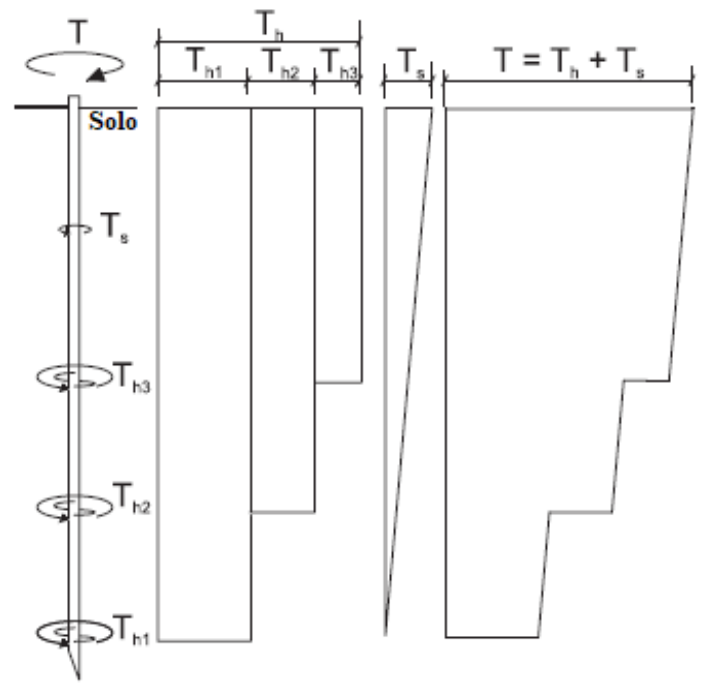

(b)

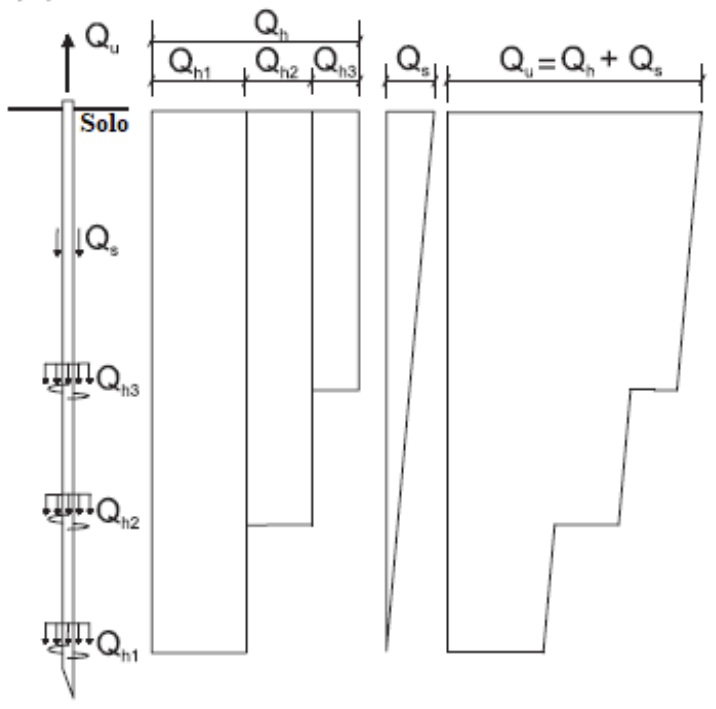

Fonte: Tsuha (2007).

O modelo teórico foi desenvolvido com base no método das capacidades de carga individuais, ou seja, a capacidade de carga à tração é formada por uma parcela mobilizada independentemente em cada uma das placas helicoidais, e uma parcela decorrente do atrito na haste central, conforme as equações (17) e (18).

$$
\begin{aligned}
& Q_{U}=Q_{h}+Q_{s} \\
& Q_{h}=\sum_{i=1}^{N} Q_{h \mathrm{i}}
\end{aligned}
$$

Nas quais: $Q_{U}$ é a capacidade de carga; 
$Q_{h}$ é a parcela de capacidade de carga à tração nas hélices;

$Q_{S}$ é a resistência por atrito lateral na haste da estaca;

$Q_{h i}$ é a parcela de capacidade de carga na i-ésima hélice das $N$ placas em uma estaca;

Para uma estaca com haste central com diâmetro externo igual a $d$ e atrito lateral mobilizado em sua superfície, o valor de $T_{S}$ é igual à força resistente por atrito $Q_{S}$ multiplicada pelo raio igual $d / 2$, como na equação (19).

$$
T_{S}=Q_{S} \times \frac{d}{2} \rightarrow Q_{S}=\frac{2 T_{S}}{d}
$$

Em que: $\quad d$ é o diâmetro externo da haste central da estaca.

Figura 15 - Esquema das forças atuantes na superfície das placas helicoidais

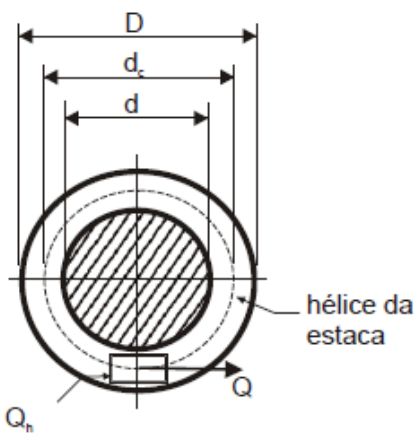

a) Vista superior da hélice da estaca b) (onde as forças resistentes se concentram durante a instalação da estaca)

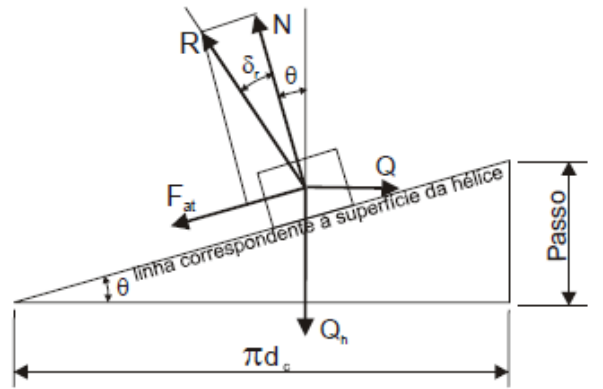

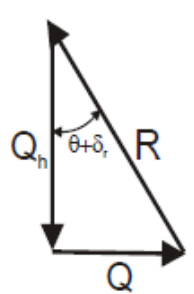

c) Triângulo de forças correspondente $a \mathrm{~b}$ )

Fonte: Tsuha (2007).

Na definição da relação entre $T_{h}$ e $Q_{h}$ Tsuha (2007) leva em consideração a carga movida durante a rotação das hélices, igual à força $F$ do modelo proposto por Ghaly et al. (1991), correspondente à carga $Q_{h}$ na Figura 15. O torque necessário para girar uma placa helicoidal contra a carga $Q_{h}$ pode ser determinado pela equação (20), com raciocínio análogo ao da equação (19). 


$$
\begin{aligned}
T_{h} & =Q \times \frac{d_{c}}{2} \\
Q_{h} & =\frac{Q}{\tan \left(\theta+\delta_{r}\right)}
\end{aligned}
$$

Em que: $\quad d_{c}$ é o diâmetro do círculo correspondente à área resistente da placa helicoidal (Figura 15).

$Q$ é a força necessária para mover a carga $Q_{h}$;

$\theta$ é o ângulo entre a hélice e a horizontal (Figura 15)

$\delta_{r}$ é o ângulo de atrito residual na interface entre o material da placa helicoidal e a areia circunjacente.

A medida $d_{c}$ representa o diâmetro de um círculo cuja área corresponde à superfície da hélice onde se concentram as forças resistentes durante a instalação da estaca e $\theta$ é o ângulo entre esse círculo e a horizontal. Os valores de $d_{c}$ e $\theta$ são dados pelas equações (22) e (23).

$$
\begin{aligned}
& d_{c}=\frac{2}{3}\left(\frac{D^{3}-d^{3}}{D^{2}-d^{2}}\right) \\
& \theta=\tan ^{-1}\left(\frac{p}{\pi d_{c}}\right)
\end{aligned}
$$

Partindo da das equações (20) e (21) pode-se determinar a relação entre a parcela de torque $T_{h}$ necessário para contrapor a resistência $Q_{h}$ oferecida pelas hélices, através da equação (24).

$$
Q_{h}=\frac{2 T_{h}}{d_{c} \tan \left(\theta+\delta_{r}\right)}
$$

Substituindo então as equações (19) e (24) na equação (15) encontra-se a relação entre o torque de instalação $T$ e a capacidade de carga à tração $Q_{U}$ de uma 
estaca helicoidal, em termos de $Q_{s}$ e $Q_{h}$, conforme equação (25). No caso de estacas com $N$ hélices, o torque de instalação pode ser estimado através da equação (26).

$$
\begin{aligned}
& T=\frac{Q_{s} d}{2}+\frac{Q_{h} d_{c} \tan \left(\theta+\delta_{r}\right)}{2} \\
& T=\frac{Q_{s} d}{2}+\frac{\sum_{i=1}^{N} Q_{h i} d_{c i} \tan \left(\theta_{i}+\delta_{r i}\right)}{2}
\end{aligned}
$$

\subsection{Gavin et al (2013)}

Gavin et al. (2013) descreveram um modelo simples para estimativa do torque necessário para instalar estacas helicoidais, baseado em uma forma modificada do modelo teórico proposto por Tsuha (2007), que associa o torque de instalação com a capacidade de carga de à tração de uma estaca com uma hélice instalada em areia, em termos do atrito lateral $f_{s}$ e da resistência de ponta $q_{c}$ do Cone Penetration Test (CPT).

Os autores realizaram um programa experimental em que cinco estacas helicoidais com uma hélice de $400 \mathrm{~mm}$ foram instaladas. Uma estaca foi instrumentada para realização de prova de carga à tração. Com base nos resultados dos ensaios e na equação (25), Gavin et al. (2013) apresentaram a equação (27).

$$
T=\frac{Q_{s} d}{2}+\frac{Q_{h} D\left(\theta+\delta_{r}\right)}{2}
$$

Em que: $\quad D$ é o diâmetro da hélice; os outros parâmetros da equação (27) foram definidos na seção 2.1.5.1.2.

Para prever o torque de instalação Gavin et al. (2013) substituíram $Q_{s}$ e $Q_{h}$ da equação (27) pelas equações (28) e (29). 


$$
\begin{aligned}
& Q_{s}=q_{s a v} \cdot \pi \cdot d \cdot L \\
& Q_{h}=q_{u p} \cdot \pi \cdot D^{2}
\end{aligned}
$$

Em que: $\quad q_{s a v}$ é a resistência ao atrito média, mobilizada na haste, é igual a $\alpha \cdot f_{s}$; $q_{u p}$ é a capacidade de carga mobilizada na hélice, é igual a $\beta \cdot q_{c}$ $d$ e $L$ são, respectivamente, o diâmetro e o comprimento da haste central da estaca; $\alpha$ e $\beta$ são iguais 0,6 e 0,065 , respectivamente.

\subsection{Sakr (2015)}

Sakr (2015) propôs um modelo teórico para estimar o torque de instalação de estacas helicoidais em solos não coesivos. O modelo é similar ao método proposto por Ghaly e Hanna (1991), como descrito no item 2.1.5.1.2.

As duas diferenças principais entre os modelos são: (1) Sakr (2015) utiliza a abordagem de tensões efetivas enquanto o modelo de Ghaly e Hanna (1991) é baseado na abordagem de tensões totais; (2) Ghaly e Hanna (1991) utilizaram um coeficiente reduzido de empuxo passivo $\left(K_{P}^{\prime}=0,3 \times K_{P}\right)$ e Sakr (2015) não reduziu o valor de $K_{P}$ em seu modelo.

\subsection{Spagnoli (2017)}

Sapagnoli (2017) apresentou algumas modificações no modelo de Gavin et al. (2013). O autor utilizou o modelo original de Tsuha (2007) (equação (25)) para correlacionar o torque de instalação com a capacidade de carga de estacas helicoidais com uma hélice instaladas em areia. 
Spagnoli (2017) utilizou as equações (30) e (31) para estimar os valores de $Q_{s}$ e $Q_{h}$ da equação (25). Os parâmetros das equações (30) e (31) foram definidos nas seções anteriores.

$$
\begin{aligned}
Q_{s} & =q_{s a v} \cdot \pi \cdot d \cdot L \\
Q_{h} & =q_{u p} \cdot \pi \cdot\left(D^{2}-d^{2}\right) / 4
\end{aligned}
$$

O procedimento foi testado e comparado com os resultados dos ensaios de laboratório e de campo, em uma faixa de valores de torque de instalação variando entre 10 e $400 \mathrm{k} \cdot \mathrm{Nm}$. Os resultados dos ensaios de laboratório sugerem que a resistência mobilizada nas placas helicoidais tem a maior influência sobre o valor do torque de instalação.

\subsection{Al-Baghdadi et al. (2017)}

Al-Baghdadi et al. (2017) apresentaram um procedimento de projeto baseado no CPT para a estimativa do torque de instalação de estacas helicoidais em areia. $O$ torque necessário para instalar uma estaca é a soma dos torques mobilizados por atrito na haste central $\left(T_{s}\right)$ e na base da estaca $\left(T_{b}\right)$ e o torque exercido devido à resistência da hélice $\left(T_{h}\right)$.

O torque de instalação pode ser estimado através das equações (32) a (38).

$$
\begin{aligned}
& T=T_{S}+T_{b}+T_{h} \\
& T_{S}=a q_{c a} \tan (\delta \pi L) \frac{d^{2}}{2} f_{1} \\
& T_{b}=\frac{q_{b} \tan \left(\delta \pi d^{3}\right)}{12} f_{2} \\
& T_{h}=T_{h 1}+T_{h 2}+T_{h 3}
\end{aligned}
$$




$$
\begin{aligned}
& T_{h 1}=a q_{c a} \tan (\delta) \frac{\pi\left(D^{3}-d^{3}\right)}{12 k_{0}} \\
& T_{h 2}=a q_{c a} t_{h} \tan (\delta) \frac{\pi D^{2}}{2} \\
& T_{h 2}=q_{c a} t_{h} \frac{D^{2}-d^{2}}{8}
\end{aligned}
$$

Nas quais: $\quad a=R_{f} / \tan \delta$ é o índice de redução de tensão. $R_{f}$ é a razão de atrito do CPT.

$q_{c a}$ é a resistência de ponta média do CPT;

$f_{1}=0,75$ e $f_{2}=0,70$ são fatores de redução da resistência por atrito na haste e na base da estaca, respectivamente, decorrentes da rotação durante a instalação;

$q_{b}$ é a resistência de ponta da estaca, é igual a $0,6 \cdot q_{s a v}$ (eq. (28)) para estacas com extremidade fechada.

$k_{0}=1-\sin \phi^{\prime}$ é o coeficiente de empuxo no repouso em solos normalmente adensados;

$t_{h}$ é a espessura da placa helicoidal;

Os demais parâmetros foram definidos para equações anteriores.

2.1.5.2 Relação entre capacidade de carga à tração e resultados de ensaio SPT

2.1.5.2.1 Kanai (2007)

Com base em resultados de provas de carga executadas em campo em quatro estacas helicoidais Kanai (2007) observou uma semelhança entre os perfis dos valores de torque e de $N_{S P T}$ ao longo da profundidade.

A partir dos resultados dos ensaios o autor propôs uma relação entre a capacidade de carga das estacas e os valores $N_{S P T}$. Kanai (2007) considera que a 
capacidade de carga é composta da soma das resistências oferecidas pelas hélices e da resistência de atrito mobilidade na superfície da haste central da estaca. A partir dessas considerações o autor elaborou a equação (39).

$$
Q_{U}=\sum q_{u l t, i} \cdot A_{T, i}+U \sum L \cdot \tau
$$

Em que: $\quad Q_{U}$ é a capacidade de carga à tração;

$q_{u l t, i}$ é a resistência (em tensão) unitária da hélice i, é igual a $a \cdot N_{S P T}$;

$A_{T, i}$ é a área efetiva da hélice $\mathrm{i}$;

$U$ é o perímetro da haste central;

$L$ é o comprimento efetivo da haste central onde é mobilizada a resistência por atrito;

$\tau$ é a resistência por atrito mobilizada na haste central, igual a $b \cdot N_{S P T}$;

$a$ e $b$ são coeficiente de ajuste da capacidade de carga.

\subsection{Silva (2014)}

A partir de uma base de dados com 76 estacas helicoidais ensaiadas à tração, Silva (2014) desenvolveu um procedimento de cálculo semi-empírico para relacionar a capacidade de carga de estacas helicoidais com os resultados do ensaio SPT.

Silva (2014) recomenda a utilização dessa metodologia para solos argilosos, silto-argilosos, silto-arenosos e arenosos. O método proposto considera que a capacidade de carga à tração de estacas helicoidais é o resultado da soma das capacidades individuais em cada hélice com a resistência por atrito mobilizada na haste central da estaca, conforme equação (40).

$$
Q_{U}=\sum_{i=1}^{N} Q_{h \mathrm{i}}+Q_{s}
$$


Em que: $\quad Q_{U}$ é a capacidade de carga à tração;

$Q_{h i}$ é a resistência à tração de cada hélice i;

$Q_{S}$ é a resistência à tração mobilizada na superfície da haste central;

A capacidade à tração oferecida por cada uma das hélices resulta da multiplicação da área efetiva pela média dos valores de $N_{S P T}$ na profundidade de interesse e nas posições imediatamente acima e abaixo, e por um coeficiente referente ao solo acima da hélice.

A parcela de capacidade referente ao atrito na haste central pode ser calculada multiplicando-se o perímetro da haste da estaca pelo comprimento de camada em que está inserido, o que resulta em uma área de ação da resistência por atrito lateral, a área é então multiplicada pelo valor de $N_{S P T}$ correspondente à camada considerada e por um coeficiente referente à resistência unitária por atrito lateral.

Assim, O valor de $Q_{U}$ pode ser encontrado a partir da equação (41).

$$
Q_{u}=\sum_{i=1}^{N} \alpha_{S i} A_{e h i} N_{S P T i}+U \sum_{i=1}^{n} l_{j} \beta_{S j} N_{S P T j}
$$

Em que: $\quad Q_{u}$ : capacidade de carga à tração da ancoragem helicoidal;

$N$ : número de hélices;

$i$ : índice relativo à posição da hélice, varia de $1 \mathrm{a} N$;

$n$ : número de camadas de solo ao longo da haste central;

$j$ : índice relativo ao número de camadas de solo ao longo da haste central, varia de 1 a $n$;

$A_{\text {ehi }}$ : área projetada da hélice i;

$N_{S P T i}:$ NSPT do solo na hélice i;

$N_{S P T j}:$ NSPT do solo na camada j; 
$l_{j}$ : espessura da camada j ao longo da haste central;

$\alpha_{S i}$ : resistência unitária da camada de solo na posição da hélice i;

$\beta_{S j}$ : resistência unitária por atrito lateral da camada de solo j;

\subsection{6 $O$ ângulo de atrito residual na interface hélice-solo $\left(\delta_{r}\right)$.}

O ângulo de atrito $\delta$ mobilizado na interface entre materiais de construção com o solo adjacente é um parâmetro importante da engenharia geotécnica. Forças de atrito são consideradas em obras geotécnicas como muros de contenção, paredes diafragmas e estacas (Rinne, 1989).

Na prática, vários projetistas têm considerado $\delta$ igual a 2/3 do ângulo de atrito interno do solo $(\phi)$, no entanto, sabe-se que o valor de $\delta$ pode variar em casos de atrito de um mesmo solo em contato com materiais distintos (Aksoy, Gör e Inal, 2016). Segundo Randolph et al. (apud Yu e Yang, 2012) os valores de $\delta$ variam entre 0,6 e 0,7 vezes o valor de $\phi$.

A tensão de atrito $\tau_{f}$ na interface pode ser relacionada com $\delta$ através da equação (42), assumindo o critério de ruptura de Coulomb e analisando separadamente as tensões normais efetivas e os coeficientes de atrito atuantes na ruptura (Jardine, Lehane e Everton, 1993).

$$
\tau_{f}=\sigma_{r f}^{\prime} \tan \delta^{\prime}
$$

Em que: $\quad \sigma_{r f}^{\prime}$ é a tensão radial efetiva na ruptura;

$\delta^{\prime}$ é ângulo de atrito efetivo na interface estaca-solo.

Apesar da simplicidade da equação (42), Jardine, Lehane e Everton (1993) e Yu e Yang (2012) indicam que existem incertezas devido à falta de conhecimento 
adequado para a avaliação o valor de $\sigma_{r f}^{\prime}$. O valor de $\delta$ pode ser obtido através de ensaios de cisalhamento direto.

A metodologia de projeto de estacas UWA-05 desenvolvida em The University of Western Australia recomenda a utilização da equação (42) substituindo-se $\delta^{\prime}$ por $\delta_{c v}$, referente ao ângulo de atrito na interface a volume constante (Lehane, Schneider e Xu, 2005). Caso não seja possível obter medidas em laboratório do parâmetro $\delta_{c v}$, a recomendação da UWA-05 é utilizar a relação gráfica da Figura 16, com limite superior do valor de $\tan \delta_{c v}=0,55$.

Figura 16 - Variação de $\delta_{c v}$ com $\mathrm{D}_{50}$

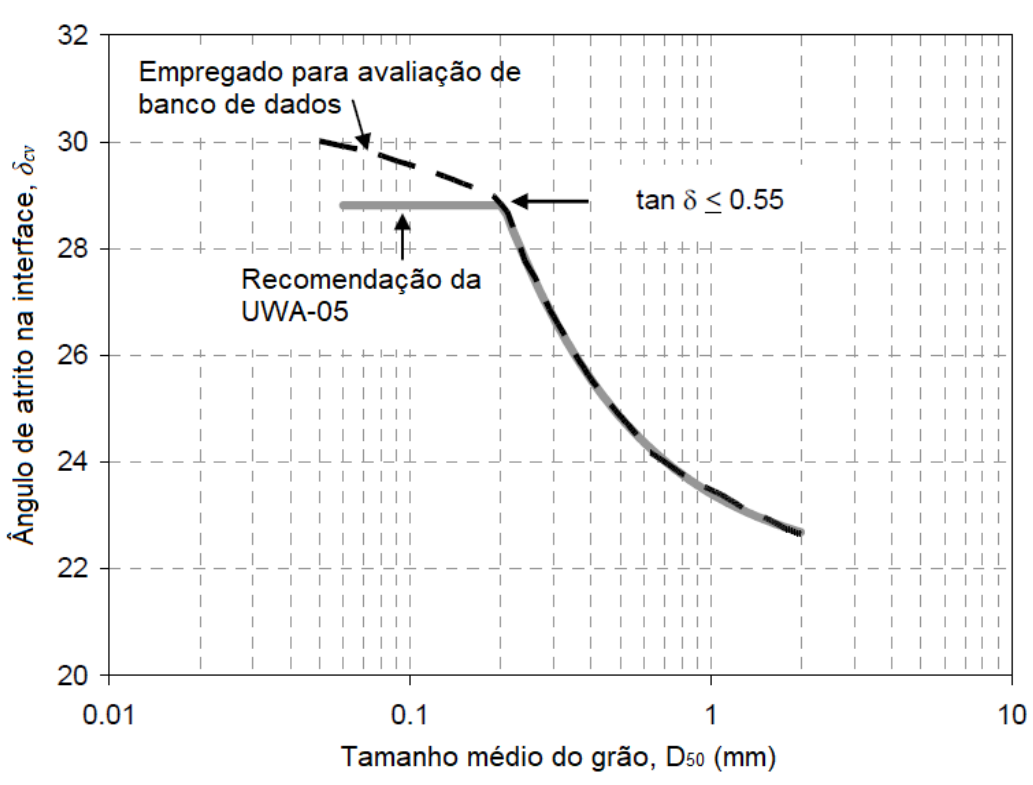

Fonte: Lehane, Schneider e Xu, 2005.

Aksoy, Gör e Inal (2016) propuseram uma relação gráfica (Figura 17) para estimativa do valor de $\delta$ com base em ensaios de cisalhamento direto na interface entre várias amostras de areias argilosas em contato com madeira, polímero reforçado com fibra (FRP) e aço ST37. Para compor as amostras de areia argilosa os autores utilizaram misturas de areia com diferentes proporções de argila (Tabela 2). 
Figura 17 - Gráfico de atrito na interface para aço, FRP e madeira

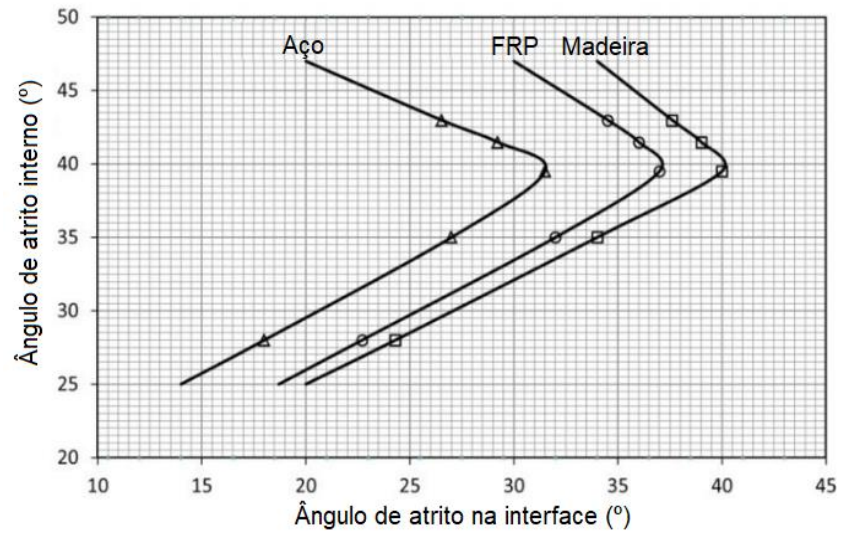

Fonte: Aksoy, Gör e Inal (2016).
Tabela 2 - Ensaios de cisalhamento direto no solo e na interface

\begin{tabular}{|c|c|c|c|c|}
\hline \multirow{2}{*}{$\begin{array}{c}\% \\
\text { Argila }\end{array}$} & \multirow{2}{*}{$\begin{array}{l}\text { Ângulo de atrito } \\
\text { interno, } \phi\left({ }^{\circ}\right)\end{array}$} & \multicolumn{3}{|c|}{$\begin{array}{c}\text { Ângulo de atrito na } \\
\text { interface, } \delta(\stackrel{\circ}{)})\end{array}$} \\
\hline & & FRP & Aço & Madeira \\
\hline 0 & 43,0 & 34,5 & 26,5 & 37,6 \\
\hline 20 & 39,5 & 37,0 & 31,5 & 40,0 \\
\hline 30 & 41,5 & 36,0 & 29,2 & 39,0 \\
\hline 40 & 35,0 & 32,0 & 27,0 & 34,0 \\
\hline 45 & 28,0 & 22,7 & 18,0 & 24,3 \\
\hline
\end{tabular}

Fonte: Aksoy, Gör e Inal (2016).

Como a instalação de estacas helicoidais é um fenômeno cinemático, o ângulo de atrito mobilizado entre a hélice e o solo arenoso pode ser considerado o valor residual $\left(\delta_{r}\right)$. Deste modo, Tsuha (2007) realizou ensaios de cisalhamento direto na interface aço/areia para determinar os valores de $\delta_{r}$. Os ensaios foram realizados em areias com diâmetros médios $\left(D_{50}\right)$ e densidade relativa $\left(D_{r}\right)$ diferentes, conforme Tabela 3. A chapa de aço utilizada nestes ensaios foi a mesma que a usada na fabricação de estacas helicoidais no Brasil, para reproduzir a mesma condição de rugosidade.

Tabela 3 - Medidas de $\delta_{r}$ na interface do material da hélice e as amostras de areia de diferente $D_{50}$

\begin{tabular}{|c|c|c|c|}
\hline Tipo de areia & $D_{50}(\mathrm{~mm})$ & $\begin{array}{c}\text { Densidade relativa, } \\
D_{r}(\%)\end{array}$ & $\delta_{r}(\stackrel{\circ}{)}$ \\
\hline \multirow{4}{*}{ Areia 01} & & 25 & 18,8 \\
\hline & 0,13 & 55 & 19,8 \\
\hline & & 85 & 20,7 \\
\hline & & 25 & 19,0 \\
\hline \multirow[t]{3}{*}{ Areia 02} & 0,29 & 55 & 21,9 \\
\hline & & 85 & 22,9 \\
\hline & & 25 & 15,9 \\
\hline \multirow[t]{4}{*}{ Areia 03} & 0,52 & 55 & 19,0 \\
\hline & & 85 & 20,6 \\
\hline & & $\begin{array}{l}\text { Valor médio de } \delta_{r}: \\
\text { Desvio padrão: }\end{array}$ & $\begin{array}{c}19,8^{\circ} \\
20\end{array}$ \\
\hline & & 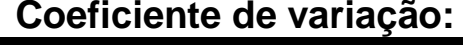 & $10 \%$ \\
\hline
\end{tabular}

Fonte: Tsuha (2007). 


\subsection{ANÁLISE DE REGRESSÃO LINEAR}

A análise de regressão é uma das técnicas estatísticas mais amplamente utilizadas para investigar e modelar a relação entre variáveis. Modelos de regressão linear são equações que relacionam variáveis de entrada ou variáveis regressoras com as respostas de interesse ou variáveis dependentes em um problema. De forma geral, a resposta pode depender de $k$ variáveis regressoras, conforme a equação (43) (Montgomery, Peck e Vining, 2006).

$$
y=\beta_{0}+\beta_{1} x_{1}+\beta_{2} x_{2}+\cdots+\beta_{k} x_{k}+\varepsilon
$$

Em que: $\quad y$ é a variável resposta (variável dependente);

$\beta_{j}, j=0,1, \ldots, k$, são os coeficientes de regressão;

$x_{j}, j=0,1, \ldots, k$, são as variáveis regressoras (variáveis independentes);

$\varepsilon$ é o erro estatístico do modelo, é uma variável aleatória referente à falha do modelo em ajustar os dados de forma exata.

Um modelo de regressão linear simples utiliza apenas uma variável regressora e pode ser equacionado da forma $y=\beta_{0}+\beta_{1} x+\varepsilon$. O modelo que envolve mais de uma regressora é chamado de modelo de regressão linear múltipla.

Modelos de regressão linear múltipla são comumente utilizados como modelos empíricos ou funções de aproximação, ou seja, a relação funcional entre $y$ e $x_{j}$ é desconhecida. Contudo, dentro de um determinado intervalo das variáveis regressoras o modelo de regressão linear é uma aproximação adequada da verdadeira função desconhecida (Montgomery, Peck e Vining, 2006).

Um dos objetivos das análises de regressão é estimar os valores dos coeficientes $\beta_{j}$ pelo ajuste do modelo de regressão aos dados disponíveis do problema. O método dos mínimos quadrados pode ser empregado com essa finalidade. Depois de ajustado, o modelo pode ser utilizado para estimar o valor da 
variável resposta a partir das variáveis independentes, neste caso a equação (43) pode ser reescrita como a equação (44).

$$
\hat{y}=\hat{\beta}_{0}+\hat{\beta}_{1} x_{1}+\hat{\beta}_{2} x_{2}+\cdots+\hat{\beta}_{k} x_{k}
$$

Em que: $\quad \hat{y}$ é a variável resposta ajustada ou estimada;

$\hat{\beta}_{j}, j=0,1, \ldots, k$, são os coeficientes de regressão ajustados aos dados de entrada;

\subsubsection{Estimativa dos coeficientes de regressão pelo método dos mínimos quadrados}

O método dos mínimos quadrados é utilizado para estimar os coeficientes de regressão $\beta_{j}$ da equação (43) de modo que o somatório dos quadrados das diferenças entre as observações $y_{i}$ e a reta estimada por $\hat{y}$ seja mínimo, ou seja, de modo a minimizar o somatório dos quadrados dos resíduos ou erros: $\min \left(S S_{\text {Res }}\right)=$ $\min \sum\left(y_{i}-\hat{y}_{i}\right)^{2}$.

Pode-se escrever para uma amostra o modelo de regressão correspondente à equação (43), de modo que $i=1,2, \ldots, n$ para os $n$ pontos pertencentes à amostra, conforme equação (45).

$$
\begin{aligned}
y_{i} & =\beta_{0}+\beta_{1} x_{i 1}+\beta_{2} x_{i 2}+\cdots+\beta_{k} x_{i k}+\varepsilon_{i} \\
& =\beta_{0}+\sum_{j=1}^{k} \beta_{j} x_{i j}+\varepsilon_{i} \rightarrow \varepsilon_{i}=y_{i}-\beta_{0}-\sum_{j=1}^{k} \beta_{j} x_{i j}
\end{aligned}
$$

Então, a função dos mínimos quadrados pode ser definida como a equação (46). A função $S$ deve ser minimizada em relação a $\beta_{1}, \beta_{2}, \ldots, \beta_{k}$ e seus estimadores devem satisfazer as equações (47) e (48), para $j=1,2, \ldots, k$. 


$$
\begin{gathered}
S\left(\beta_{0}, \beta_{1}, \ldots, \beta_{k}\right)=\sum_{i=1}^{n}\left(y_{i}-\beta_{0}-\sum_{j=1}^{k} \beta_{j} x_{i j}\right)^{2}=\sum_{i=1}^{n} \varepsilon_{i}^{2} \\
\left.\frac{\partial S}{\partial \beta_{0}}\right|_{\widehat{\beta}_{0}, \widehat{\beta}_{1}, \ldots, \widehat{\beta}_{k}}=-2 \sum_{i=1}^{n}\left(y_{i}-\hat{\beta}_{0}-\sum_{j=1}^{k} \hat{\beta}_{j} x_{i j}\right)=0 \\
\left.\frac{\partial S}{\partial \beta_{j}}\right|_{\widehat{\beta}_{0}, \widehat{\beta}_{1}, \ldots, \widehat{\beta}_{k}}=-2 \sum_{i=1}^{n}\left(y_{i}-\hat{\beta}_{0}-\sum_{j=1}^{k} \hat{\beta}_{j} x_{i j}\right) x_{i j}=0
\end{gathered}
$$

Simplificando as equações (47) e (48) são encontradas as equações normais dos mínimos quadrados, equação (49).

Existem $k+1$ equações normais, uma para cada um dos estimadores dos coeficientes de regressão. A solução das equações normais serão os valores dos estimadores $\hat{\beta}_{0}, \hat{\beta}_{1}, \ldots, \hat{\beta}_{k}$ (Montgomery, Peck e Vining, 2006).

$$
\begin{aligned}
& \sum_{i=1}^{n} y_{i}=n \hat{\beta}_{0}+\hat{\beta}_{1} \sum_{i=1}^{n} x_{i 1}+\hat{\beta}_{2} \sum_{i=1}^{n} x_{i 2}+\cdots+\hat{\beta}_{k} \sum_{i=1}^{n} x_{i k} \\
& \sum_{i=1}^{n} x_{i 1} y_{i}=\hat{\beta}_{0} \sum_{i=1}^{n} x_{i 1}+\hat{\beta}_{1} \sum_{i=1}^{n} x_{i 1}^{2}+\hat{\beta}_{2} \sum_{i=1}^{n} x_{i 1} x_{i 1}+\cdots+\hat{\beta}_{k} \sum_{i=1}^{n} x_{i 1} x_{i k} \\
& \sum_{i=1}^{n} x_{i k} y_{i}=\hat{\beta}_{0} \sum_{i=1}^{n} x_{i k}+\hat{\beta}_{1} \sum_{i=1}^{n} x_{i k} x_{i 1}+\hat{\beta}_{2} \sum_{i=1}^{n} x_{i k} x_{i 2}+\cdots+\hat{\beta}_{k} \sum_{i=1}^{n} x_{i k}^{2}
\end{aligned}
$$

\subsubsection{Análise de variância e coeficiente de determinação}

Uma análise de variância, baseada no particionamento da variabilidade total da variável resposta, pode ser empregada como teste de significância da regressão. Para obter o particionamento utiliza-se a equação (50), em que $\bar{y}$ é a média de $y_{i}$. 
$\sum_{i-1}^{n}\left(y_{i}-\bar{y}\right)^{2}=\sum_{i-1}^{n}\left(\hat{y}_{i}-\bar{y}\right)^{2}+\sum_{i-1}^{n}\left(y_{i}-\hat{y}_{i}\right)^{2}$

O lado esquerdo da equação (50) refere-se à soma corrigida dos quadrados das observações, $\left(S S_{T}\right)$ e mede a variabilidade total das observações. Os dois componentes de $S S_{T}$ medem, respectivamente, a quantidade de variabilidade de $y_{i}$ contabilizada pela regressão $\left(S S_{R}\right)$ e a variação residual não contabilizada pela linha de regressão $\left(S S_{R e s}\right)$ (Montgomery, Peck e Vining, 2006).

A equação (50) pode ser simbolicamente reescrita na forma da equação (51).

$$
S S_{T}=S S_{R}+S S_{\text {ReS }}
$$

O coeficiente de determinação $\left(R^{2}\right)$ é habitualmente referido como a proporção de variação explicada pelas variáveis regressoras e pode ser obtido através da normalização da equação (51), conforme equação (52).

$$
R^{2}=\frac{S S_{R}}{S S_{T}}=1-\frac{S S_{R e s}}{S S_{T}}
$$

Como $0 \leq S S_{R e s} \leq S S_{T}$ é válido que $0 \leq R^{2} \leq 1$. Quando os valores de $R^{2}$ estão próximos de 1 entende-se que a maior parte da variabilidade em $y$ é contabilizada pelo modelo de regressão.

O valor $R^{2}$ deve ser avaliado com cautela, já que é possível tornar $R^{2}$ grande ao adicionar-se termos suficiente ao modelo. Além disso, $R^{2}$ não mede a adequação de um modelo linear, pois $R^{2}$ será frequentemente grande mesmo em casos em que $y \mathrm{e}$ $x$ não se relacionam linearmente 0 que implica que 0 modelo não será necessariamente um bom estimador (Montgomery, Peck e Vining, 2006). 


\section{MATERIAIS E MÉTODOS}

\subsection{MATERIAIS}

O material disponível para auxiliar esta pesquisa consiste em uma base de dados fornecida pela Vértice Engenharia, empresa de Belo Horizonte - MG atuante no projeto e execução de fundações em estacas metálicas helicoidais. Os dados foram obtidos durante a execução das fundações das torres de um trecho de $350 \mathrm{~km}$ de extensão de uma linha de transmissão de energia elétrica com tensão de $500 \mathrm{kV}$ e circuito duplo ( $\mathrm{C} 1$ e $\mathrm{C} 2$ ), entre os municípios Cláudia e Paranatinga, no estado de Mato Grosso. O Apêndice B apresenta uma síntese dos principais dados disponíveis.

\subsubsection{Síntese da geomorfologia, geologia e pedologia da região entre Cláudia e Paranatinga}

A maior parte da região considerada pertence à parcela centro-norte do estado do Mato Grosso e faz parte da Folha SD.21 Cuiabá no encarte cartográfico internacional. Diversas unidades geomorfológicas foram identificadas na Folha: Planalto Residual do Alto Guaporé; Planalto dos Parecis; Planalto do Guimarães; Província Serrana; Depressão Interplanáltica de Paranatinga; Depressão do Paraguai; Depressão do Guaporé; Planícies e Pantanais do Alto Guaporé (Barros et al., 1981).

A região apresenta um quadro geológico bastante diversificado. Na parte norte predominam os sedimentos arenosos do Grupo Parecis parcialmente cobertos por uma camada argilo-arenosa. Os sedimentos arenosos estão sobre as rochas da Plataforma Guaporé. Na parte sul ocorrem desde rochas antigas a sedimentos mais novos, sendo encontrados sedimentos do Grupo Aguapel, rochas do Complexo Basal, litologias do Grupo Alto Paraguai, rochas do Grupo Cuiabá e sedimentos da Bacia do Paraná (Ross e Santos, 1981).

A diversificação das unidades geomorfológicas e das litologias é responsável pela grande variedade de solos encontrados nessa região, onde predominam Latossolos, Terra Roxa Estruturada, Podzólico Eutrófico, Cambissolo, Laterita 
Hidromórfica, Glei Pouco Húmico, Areias Quartzosas, Solos Aluviais, Solos Litólicos e Solos Concrecionários (Barros et al., 1981).

\subsubsection{Base de dados}

A base de dados consiste em relatórios de investigação de campo com os resultados de sondagens com realização de SPT, protocolos de instalação de estacas em estais e em torres autoportantes, protocolos de testes e planilhas de escavação (para torres autoportantes). O Anexo A traz um exemplo de um protocolo de instalação de torres autoportantes e de um relatório de sondagem, disponíveis na base de dados.

Para cada torre existe apenas um relatório de sondagem (Apêndice A). Em condições ideais, as sondagens foram realizadas nas coordenadas do centro da projeção da torre sobre o terreno. Caso houvesse alguma impossibilidade executiva a sondagem era deslocada de modo a ficar o mais próximo possível da posição central. Foram desconsiderados nesta dissertação os casos em que as sondagens não atingiram profundidade suficiente, ou seja, todas as torres em que o perfil de investigação era mais curto que a profundidade final de instalação das estacas.

$\mathrm{Na}$ maior parte dos terrenos os solos encontrados pelas sondagens foram areias argilosas finas e médias, eventualmente intercaladas por camadas de areia siltosa, silte ou argila, exceto no local da torre 191/1 onde o perfil observado é inteiramente composto de argila arenosa e argila siltosa e no terreno da torre 202/1, onde a maior parte do perfil é de silte argiloso.

Das 107 torres, 33 são estaiadas e o restante é autoportante. Decidiu-se inicialmente pela desconsideração das torres estaiadas, uma vez que a distância entre os apoios dos estais e o centro da torre é muito maior do que nas torres autoportantes, nesses casos as estacas estariam mais afastadas do local da sondagem, o que agregaria mais incertezas aos resultados. Por fim, foram selecionadas para análise um total de 24 torres autoportantes; a Tabela 4 apresenta um resumo das composições e quantidades de estacas por torre.

A fundação de cada torre autoportante é composta de 28 ou 36 estacas helicoidais, distribuídas igualmente em quantidade para cada pé da estrutura da torre. 
Em todas as estacas existe registro do torque aplicado durante a instalação para cada metro instalado. As estacas foram executadas com diferentes inclinações, os ângulos utilizadas foram $0^{\circ}, 5^{\circ}, 18^{\circ}, 20^{\circ}$ e $23^{\circ}$ em relação à vertical.

Tabela 4 - Composições e quantidades das estacas por torre ${ }^{(1)}$

\begin{tabular}{ccc|ccc}
\hline Torre & $\begin{array}{c}\text { Composição } \\
\text { (hel/estaca) }\end{array}$ & $\begin{array}{c}\text { Quantidade de } \\
\text { estacas por } \\
\text { torre }\end{array}$ & Torre & $\begin{array}{c}\text { Composição } \\
\text { (hel/estaca) }\end{array}$ & $\begin{array}{c}\text { Quantidade de } \\
\text { estacas por } \\
\text { torre }\end{array}$ \\
\hline $36 / 1$ & 4 ou 6 & 36 & $204 / 2$ & 6 & 36 \\
$47 / 2$ & 4 ou 6 & 36 & $205 / 2$ & 6 & 36 \\
$114 / 1$ & 6 & 28 & $219 / 1$ & 6 & 28 \\
$114 / 2$ & 6 & 36 & $220 / 1$ & 6 & 28 \\
$137 / 2$ & 6 & 36 & $221 / 1$ & 4 ou 6 & 28 \\
$177 / 1$ & 6 & 28 & $222 / 1$ & 4 ou 6 & 28 \\
$184 / 2$ & 6 & 28 & $223 / 1$ & 4 ou 6 & 28 \\
$191 / 1$ & 6 & 36 & $226 / 1$ & 6 & 28 \\
$199 / 2$ & 6 & 28 & $226 / 2$ & 4 & 36 \\
$200 / 1$ & 6 & 28 & $245 / 1$ & 6 & 36 \\
$201 / 2$ & 6 & 36 & $245 / 2$ & 6 & 36 \\
$202 / 1$ & 6 & 36 & $246 / 1$ & 6 & 36 \\
\hline
\end{tabular}

(1) Foram excluídas das análises as estacas com menos de 6,0m de comprimento. A quantidade total considerada é igual a 769.

Fonte: do autor.

As estacas foram construídas com estrutura e composição padronizadas. Há estacas com 4 ou 6 hélices, todas em configuração cônica (hélice crescente a partir da ponta) com os diâmetros das hélices iguais a 254-305-366-366 mm (estacas com 4 hélices) e 254-305-366-366-366-366 mm (estacas com 6 hélices). O diâmetro da haste central das estacas é $d=101,60 \mathrm{~mm}$ e o passo das hélices é $p=9,0 \mathrm{~cm}$. A distância entre hélices consecutivas é igual a 3 vezes o diâmetro da hélice inferior. 


\subsection{MÉTODOS}

Este trabalho teve como um de seus objetivos principais definir uma metodologia baseada nos valores de $\mathrm{N}_{S P T}$ para estimativa do torque final necessário para instalar estacas helicoidais.

Depois de determinado o modelo, análises de regressão linear múltipla foram implementadas a fim de encontrar os coeficientes de regressão que produzissem o melhor ajuste do modelo ao banco de dados descrito anteriormente.

Então, com base nos erros dos modelos de regressão, correções matemáticas foram propostas para aproximar os valores medidos dos valores estimados do torque final de instalação.

É importante destacar que em nenhum dos casos as informações referentes à eficiência energética dos ensaios SPT estavam disponíveis, portanto, nenhuma correção de energia foi realizada.

\subsubsection{Determinação do modelo geral para previsão do torque}

O modelo teórico da equação (26), proposto por Tsuha (2007), foi empregado como base das equações utilizadas nas análises de regressão. Para calcular os valores de $Q_{s}$ e $Q_{h}$ utilizou-se a equação (39), que relaciona diretamente a capacidade de carga à tração com o $\mathrm{N}_{S P T}$, reescrita nas equações (53) e (54).

$$
\begin{aligned}
& Q_{S}=\left(\alpha_{S} \pi d\right) \sum_{j=1}^{N} \Delta l_{j} N_{j} \\
& Q_{h}=\alpha_{h} \sum_{k=1}^{n} A_{e h, k} N_{k}
\end{aligned}
$$

Em que: $\quad \alpha_{S}$ e $\alpha_{h}$ são os coeficientes de regressão do modelo, referentes à resistência por atrito na haste e à resistência mobilizada nas hélices, respectivamente; 
$\Delta l_{j}$ é a espessura da camada de solo $j$ em contato com a haste da estaca, onde ocorre $N_{j}$;

$N_{j}$ e $N_{k}$ são os valores de $N_{S P T}$, respectivamente, na camada de solo $j$ e na profundidade da hélice $k$, em uma estaca com $n$ hélices;

$A_{e h, k}$ é área efetiva da hélice $k$.

Ao substituir as equações (53) e (54) na equação (26), encontra-se a equação (55) que expressa o modelo geral de previsão do torque final de instalação.

$$
T=T_{s}+T_{h}=\frac{d^{2}}{2}\left[\left(\alpha_{S} \pi\right) \sum_{j=1}^{N} \Delta l_{j} N_{j}\right]+\alpha_{h} \sum_{k=p}^{n} A_{e h, k} N_{k} \frac{d_{c, k} \tan \left(\theta_{k}+\delta_{r, k}\right)}{2}
$$

Os índices $j$ e $k$ da equação (55) referem-se, respectivamente, à camada $j$ de um perfil de solo com $N$ camadas e à hélice $k$ em uma estaca com $n$ hélices, dado que $k=p, 1,2 \cdots n$, sendo $p$ o índice relativo à hélice da ponta.

\subsubsection{Pressupostos fundamentais do modelo}

Para desenvolver o modelo proposto na equação (55) algumas hipóteses foram consideradas, com relação:

a) ao valor do ângulo de atrito residual na interface entre o material das hélices e o solo adjacente $\left(\delta_{r}\right)$;

b) ao efeito da perturbação do solo, provocado pela penetração das hélices durante a instalação, no valor de torque resistente mobilizado na haste central;

c) à influência da perturbação causada por hélices inferiores no torque mobilizado nas hélices superiores;

d) à quantidade de hélices na estaca; 


\subsubsection{1 Ângulo de atrito residual na interface hélice-solo $\left(\delta_{r}\right)$}

Primeiramente, com base em trabalhos da literatura sobre ângulo de atrito residual de interface, como o de Jardine et al. (1993) entre outros, as análises foram feitas separadamente para dois valores de $\delta_{r}$. Em cada caso assumiu-se que $\delta_{r}$ tem valor único para todas as hélices, visto que a rugosidade do aço é a mesma.

Com base nos resultados de Tsuha (2007) decidiu-se adotar $\delta_{r}=20^{\circ}$, próximo ao valor médio encontrado pela autora (Tabela 3). Alternativamente, adotouse $\tan \delta_{r}=0,55 \rightarrow \delta_{r}=29^{\circ}$, conforme a recomendação da UWA-05 (Figura 16), que é próximo ao valor intermediário encontrado para aço por Aksoy, Gör e Inal (2016) (Tabela 2).

Além desta hipótese, também foi testado o caso em que o valor de $\delta_{r}$ varia de acordo com o valor de $N_{S P T}$ da areia em contato com a hélice. Para este caso, foram assumidas as relações $\phi=15^{\circ}+\sqrt{24 \times N_{S P T}}$ (Teixeira, 1996 apud Schnaid e Odebrecht, 2012) e $\delta_{r}=(2 / 3) \times \phi$. No entanto, sabe-se pela literatura que o valor "residual" do ângulo de atrito de interface independe da compacidade relativa da areia, mas depende principalmente da rugosidade do aço e do tamanho do grão (Jardine et al. 1993, Lehane, Schneider e Xu 2005, e outros).

\subsection{Efeito da instalação no torque resistente mobilizado na haste central}

Quatro hipóteses diferentes foram consideradas para análise do efeito da perturbação do solo na estimativa da parcela $T_{s}$ do modelo geral, referente ao torque resistido pelo atrito na superfície da haste central.

Considerou-se na primeira hipótese que o torque desenvolvido na haste é mobilizado ao longo de todo o comprimento $L$ e pode ser expresso pela equação (56), levando em conta os valores de $N_{S P T}$ medidos durante a investigação, sem qualquer tipo de correção.

$\mathrm{Na}$ segunda hipótese assumiu-se que a perturbação provocada pela penetração de várias hélices consecutivas levaria o solo adjacente à haste a uma condição em que o valor de $N_{\mathrm{SPT}}$ se tornaria residual $\left(N_{\mathrm{r}}\right)$. Foi arbitrado neste caso o 
valor $N_{\mathrm{r}}=4$, e considerou-se que o torque é mobilizado ao longo de $L$, conforme equação (57).

A terceira hipótese é análoga à segunda, a única diferença é que foi considerado que o torque é mobilizado ao longo do comprimento livre da haste (acima da hélice superior (equação (58)).

$\mathrm{Na}$ quarta hipótese foi considerado que o torque é mobilizado ao longo do comprimento livre da haste, levando em conta os valores de $N_{S P T}$ medidos durante a investigação (sem correção) neste trecho.

$$
\begin{aligned}
& T_{s 1}=\frac{d^{2}}{2}\left(\alpha_{S} \pi\right) \sum_{j=1}^{N} \Delta l_{j} N_{j} \\
& T_{s 2}=\frac{d^{2}}{2}\left(\alpha_{S} \pi\right) L N_{r} \\
& T_{S 3}=\frac{d^{2}}{2}\left(\alpha_{S} \pi\right) L_{f} N_{r} \\
& T_{S 4}=\frac{d^{2}}{2}\left(\alpha_{S} \pi\right) \sum_{j=1}^{N} \Delta l_{j} N_{j} \text { (assumindo-se } L \text { igual a } L_{f} \text { ) }
\end{aligned}
$$

Em que: $\quad L_{f}$ é o comprimento livre da haste, medido a partir da hélice superior até o topo da estaca, sem considerar o comprimento entre as hélices.

Em todos os casos foi desconsiderada a resistência por atrito relativa ao comprimento de haste inserido nos $2 \mathrm{~m}$ inicias de profundidade do solo (medidos verticalmente a partir da superfície do terreno). Essa decisão foi fundamentada na observação feita por Tsuha, Filho e Santos (2016), em relação à formação de um espaço vazio entre a haste e o solo nos primeiros metros abaixo da superfície.

\subsection{Influência da perturbação causada por hélices inferiores no torque resistido em hélices superiores}

Durante a instalação de estacas com múltiplas hélices o solo penetrado é primeiramente perturbado por hélices mais inferiores. Então, o torque resistido pelas 
hélices superiores, durante a instalação da estaca em uma determinada camada de solo, deve ser menor que o torque resistido pela hélice da ponta ao penetrar a mesma camada.

Dessa forma, a parcela referente a $T_{h}$ na equação (55) foi desmembrada em três componentes avaliadas separadamente, de acordo com a posição das hélices na estaca, conforme equação (59).

$$
T_{h}=T_{h, p}+T_{h, \text { int }}+T_{h, \text { sup }}
$$

A primeira componente $T_{h p}$ é referente ao torque resistido pela hélice da ponta. A componente $T_{\text {hint }}$ refere-se ao torque resistido em hélices intermediárias, onde existe variação de diâmetro. Para diâmetros distribuídos de forma crescente, o perímetro externo de hélices maiores penetra uma parcela de solo não perturbada diretamente pela hélice anterior. No caso das estacas disponíveis para este estudo foram consideradas como intermediárias as duas hélices imediatamente acima da hélice da ponta, com diâmetros de 12 e 14 polegadas.

A componente de $T_{h, \text { sup }}$ refere-se ao torque resistido nas hélices superiores, onde não há diferenciação de diâmetro. Para as estacas com quatro hélices, $T_{h s u p}$ contabiliza apenas o efeito da quarta hélice.

As expressões para as componentes $T_{h, p}, T_{h, \text { int }}$ e $T_{h, \text { sup }}$ são encontradas em (60), (61) e (62).

$$
\begin{aligned}
& T_{h, p}=\alpha_{h, p} A_{e h, p} N_{p} \frac{d_{c, p} \tan \left(\theta_{p}+\delta_{r, p}\right)}{2} \\
& T_{h, \text { int }}=\alpha_{h, \text { int }} \sum_{k=1}^{3} A_{e h, k} N_{k} \frac{d_{c, k} \tan \left(\theta_{k}+\delta_{r, k}\right)}{2} \\
& T_{h, \text { sup }}=\alpha_{h, \text { sup }} \sum_{k=4}^{n} A_{e h, k} N_{k} \frac{d_{c, k} \tan \left(\theta_{k}+\delta_{r, k}\right)}{2}
\end{aligned}
$$

Em algumas análises uma versão alternativa foi considerada, com os torques resistidos nas hélices intermediárias e superiores agrupados em uma mesma parcela de $T_{h}$. 
3.2.1.1.4 Influência da quantidade de hélices na previsão do torque

Como considerado no item anterior, o torque resistido por hélices inferiores tende a ser maior que o torque mobilizado nas hélices superiores. Então, decidiu-se averiguar se a parcela de torque resistida pelas hélices superiores produziria algum efeito significativo no valor final do torque de instalação.

Dessa forma, duas abordagens foram testadas. No primeiro caso foi desconsiderada a contribuição de torque resistido nas duas últimas hélices de estacas com seis hélices. No segundo caso a contribuição das três últimas hélices foi desconsiderada.

Nas duas situações, $T_{s 3}$ foi assumido como a parcela de torque resistido pelo atrito da haste, com $L_{f}$ medido a partir da quarta hélice, no primeiro caso, e a partir da terceira hélice, no segundo caso.

\subsubsection{Análise de regressão linear}

Para implementar as análises de regressão as equações de $T_{h}$ e $T_{s}$ foram substituídas no modelo geral da equação (55), de acordo com a abordagem considerada.

Para facilitar o processamento do problema, os coeficientes de regressão $\alpha_{S}$, $\alpha_{h, p}, \alpha_{h, \text { int }}$ e $\alpha_{h, \text { sup }}$ foram isolados de modo que todos os dados conhecidos ficaram agrupados nas variáveis regressoras $X_{i}$, conforme as equações de (63) até (69). Substituindo os termos correspondentes na equação (55) por $X_{i}$, encontrou-se o modelo final simplificado da equação (70).

Algumas considerações devem ser observadas:

a) o modelo geral da equação (70) foi utilizado em todos os casos; $X_{S}$ foi selecionado entre as equações de (63) e (66) de acordo com abordagem ou hipótese considerada; 
b) as notações $X_{s 3,2}$ e $X_{s 3,3}$, foram utilizadas no lugar de $X_{s 3}$ nos casos em que 2 ou 3 hélices superiores foram desconsideradas.

c) no caso em que as 3 hélices superiores foram desconsideradas o termo $\alpha_{h, \text { sup }} X_{h, \text { sup }}$ da equação (70) tornou-se nulo;

$$
\begin{aligned}
& X_{s 1}=\frac{d^{2} \pi}{2} \sum_{j=1}^{N} \Delta l_{j} N_{j} \\
& X_{s 2}=\frac{d^{2} \pi}{2} L N_{r} \\
& X_{s 3}=\frac{d^{2} \pi}{2} L_{f} N_{r} \\
& X_{s 4}=\frac{d^{2} \pi}{2} \sum_{j=1}^{N} \Delta l_{j} N_{j} \\
& X_{h, p}=0,5 A_{e h, p} N_{p} d_{c, p} \tan \left(\theta_{p}+\delta_{r, p}\right) \\
& X_{h, \text { int }}=0,5 \sum_{k=1}^{3} A_{e h, k} N_{k} d_{c, k} \tan \left(\theta_{k}+\delta_{r, k}\right) \\
& X_{h, \text { sup }}=0,5 \sum_{k=4}^{n} A_{e h, k} N_{k} d_{c, k} \tan \left(\theta_{k}+\delta_{r, k}\right) \\
& T=\alpha_{S} X_{S}+\alpha_{h, p} X_{h, p}+\alpha_{h, \text { int }} X_{h, \text { int }}+\alpha_{h, \text { sup }} X_{h, \text { sup }}
\end{aligned}
$$

A Figura 18 apresenta um esquema simplificado de um modelo típico das estacas de seis hélices. A figura indica também os comprimentos de haste considerados nas estimativas de $T_{S}$ para cada hipótese assumida e a distribuição dos torques mobilizados nas hélices.

As análises de regressão linear foram realizadas através das Ferramentas de Análise do Microsoft Excel 2013. O nível de confiança escolhido foi de 95\% e a interseção definida como zero. O módulo de regressão do Microsoft Excel utiliza o método dos mínimos quadrados para fazer o ajuste do modelo ao banco de dados de entrada. 
A qualidade dos modelos de regressão foi avaliada inicialmente através do valor do coeficiente de determinação $R^{2}$, do valor do erro padrão associado ao ajuste e do coeficiente de variação do erro. No entanto, em todos os casos os modelos resultantes da regressão linear foram corrigidos com base no erro de modelo.

Figura 18 - Esquema básico de uma estaca típica de seis hélices

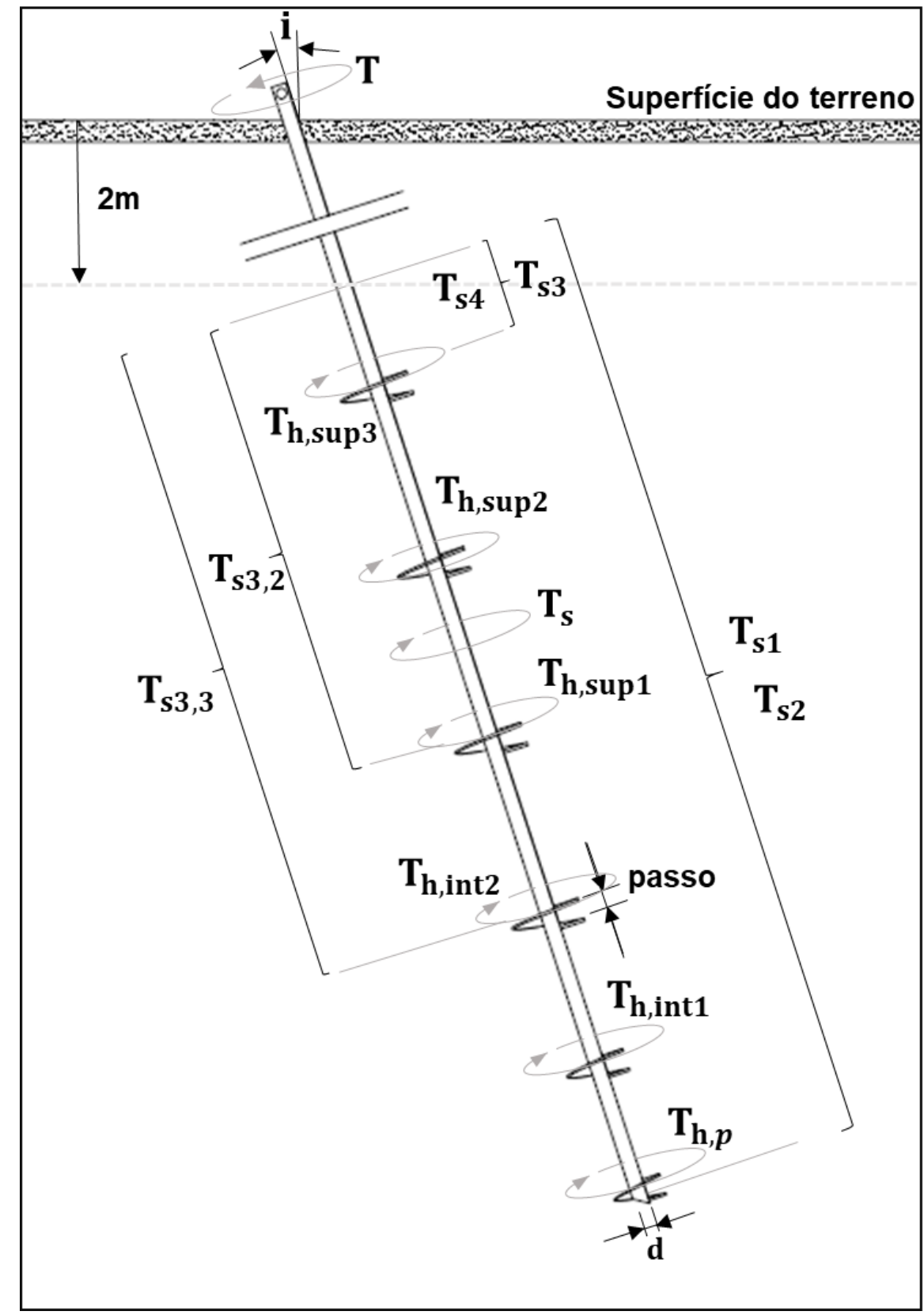

Fonte: do autor. 


\subsubsection{Avaliação do erro de modelo}

Uma avaliação da qualidade do ajuste baseada apenas no coeficiente de determinação pode ser insuficiente e o modelo de regressão obtido pode não funcionar como um bom estimador.

Portando, decidiu-se examinar também a variável denominada aqui como erro de modelo $(E M)$, que corresponde ao quociente do valor medido de torque e o valor estimado pelos modelos de regressão.

$$
E M=T / \widehat{T}
$$

Em que: $\quad E M$ é a variável erro de modelo;

$T$ é o valor de torque de instalação medido em campo;

$\widehat{T}$ é o valor de torque de instalação estimado pelos modelos de regressão.

Os valores de $E M$ foram calculados para todas as estacas, então foi possível verificar graficamente se algum parâmetro considerado nos modelos exercia alguma influência no comportamento de $E M$. O comprimento $L$ e os valores $N_{j}$ são variáveis independentes que variam de estaca para estaca, então foram considerados nas avaliações de erro.

Foram traçados os gráficos $E M \times L$ e $E M \times N_{j}$ e correções matemáticas foram aplicadas para ajustar os valores de EM quando verificadas tendências de comportamento do erro de modelo provocadas pelos outros parâmetros. Antes de aplicar as correções foram removidos os pontos que se apresentavam fora da curva preferencial (outliers).

As correções consistiram em multiplicar $\widehat{T}$ pela função que expressa a relação entre $E M$ e o parâmetro observado - função que corresponde ao valor esperado $E[E M]$ 
do erro de modelo. A multiplicação resulta em $\widehat{T}$ corrigido ou valor esperado do torque previsto, $E[\widehat{T}]$.

Ao substituir $\hat{T}$ por $E[\hat{T}]$ na equação (71), novos valores de $E M$ são encontrados, com o quais as mesmas verificações de tendência devem ser realizadas. A determinação das correções deve acontecer de maneira iterativa até que não serem observadas tendências de comportamento entre os parâmetros e os novos valores de $E M$.

Os modelos finais corrigidos foram expressos na forma geral da equação (72).

$$
T\left(L, N_{j}\right)=\left(\alpha_{s} X_{s}+\alpha_{h, p} X_{h, p}+\alpha_{h, \text { int }} X_{h, \text { int }}+\alpha_{h, \text { sup }} X_{h, \text { sup }}\right) \times C(L) \times C\left(N_{j}\right)
$$

Em que: $\quad T\left(L, N_{j}\right)$ é o valor de torque corrigido em termos dos parâmetros $L$ e $N_{j}$;

$C(L)$ e $C(N)$ são as funções de correção baseadas nos valores de $L$ e $N_{j}$; 


\section{RESULTADOS E ANÁLISES}

Os resultados das análises de regressão com todas as hipóteses de modelo testadas são apresentados no Apêndice C. As tabelas apresentam as estatísticas de regressão, os coeficientes de regressão de cada análise, as equações das correções propostas e as estatísticas da variável erro de modelo antes e depois das correções.

O Apêndice D apresenta todas os gráficos $E M \times L$ e $E M \times N_{j}$ antes e depois de cada correção. Na maior parte dos casos, duas correções sucessivas foram aplicadas ao modelo de regressão original, exceto onde indicado. As notações $E M^{*}$ e $E M^{* *}$ indicam os valores do erro de modelo após uma e duas correções, respectivamente.

Os resultados não mostraram diferenças significativas entre análises realizadas para $\delta_{r}=20^{\circ}$ e $\delta_{r}=29^{\circ}$. Algumas diferenças podem ser observadas entre os valores dos coeficientes de regressão, o que é esperado pois os valores das variáveis $X_{h}$ (onde $\delta_{r}$ é empregado) são diferentes. Ainda assim, as estatísticas de regressão ficaram aproximadamente iguais, o que sugere que $X_{h}$ teve comportamentos muito parecidos nos dois casos.

No entanto, deve-se ressaltar que apesar dos modelos terem sido ajustados para esses valores de $\delta_{r}$, análises mais aprofundadas devem ser realizadas a fim de determinar valores mais representativos do ângulo de atrito na interface hélice-solo.

As análises baseadas na primeira hipótese, relativa ao torque resistido na haste (de acordo com o item 3.2.1.1.2), produziu os piores resultados. Nas duas situações os coeficientes de determinação foram os menores encontrados, igual 0,80 para $\delta_{r}=$ $20^{\circ}$ e 0,79 para $\delta_{r}=29^{\circ}$ e os valores do erro padrão do ajuste ficaram acima dos demais casos. Mesmo após as correções, o desvio padrão e coeficiente de variação da variável EM ficaram maiores que o das outras hipóteses. Este resultado indica que a resistência por atrito lateral ao longo da haste da estaca durante a instalação não varia de acordo com os valores de $N_{S P T}$ do solo em seu entorno.

Os resultados das análises com base na terceira hipótese de $T_{S}$, que assume um valor de $N_{S P T}$ residual e único no solo ao longo da haste, ficaram melhores que a anterior, no entanto, no caso de $X_{s 3}$ os valores de coeficiente de variação após as correções ficaram relativamente elevados, iguais a 0,253 e 0,184 para $\delta_{r}$ igual a $20^{\circ}$ e $29^{\circ}$, respectivamente. Para $X_{s 3,2}$ e $X_{s 3,3}$ os resultados foram ainda melhores, gerando 
bons estimadores após as correções. Nesses casos os valores do coeficiente de variação ficaram abaixo de 0,20 , concordando com alguns limites praticados em geotecnia.

A pequena melhora de resultados quando utilizou-se $X_{s 3,2}$ e $X_{s 3,3}$ em comparação a $X_{s 3}$ indica que as hélices superiores têm menor influência no torque necessário para instalar estacas helicoidais. Matematicamente os ajustes ficaram melhores quando as hélices foram desconsideradas, maiores evidências são necessárias para confirmar essa constatação.

O melhor ajuste matemático aconteceu para a segunda hipótese $T_{s 2}$, então uma análise mais detalhada desta situação é apesentada. Neste caso, os coeficientes de determinação ficaram iguais a 0,90 para ambos os valores de $\delta_{r}$, com baixos coeficiente de variação da variável erro de modelo. Contudo, a análise de regressão gerou valores negativos para o coeficiente $\alpha_{h, \text { sup }}$ e um valor baixo para $\alpha_{h, \text { sup }}$, o que é fisicamente inconsistente.

Então, uma modificação foi feita nos componentes de $T_{h}$. Decidiu-se considerar conjuntamente o efeito de todas as hélices acima da hélice da ponta, de modo que 0 modelo simplificado foi alterado para $T=\alpha_{s} X_{s}+\alpha_{h, p} X_{h, \text { sup }}$, com $X_{h, \text { sup }}$ contabilizando o efeito de todas as hélices exceto a da ponta. Os resultados das análises para esse caso estão apresentados na Tabela 5.

Na nova consideração, os valores de $\alpha_{s}$ ficaram muitos próximos dos valores encontrados antes da modificação mas 0 valores de $\alpha_{h, p}$ aumentaram consideravelmente, o que garante maior influência das hélice da ponta no valor do torque de instalação. O modelo modificado apresentou uma boa concordância entre os valores de campo e os valores previstos depois das correções, com bom ajuste para maioria das estacas

A Tabela 5 mostra que as médias de $E M$ são iguais a 1,268 e 1,270 e os coeficientes de variação são 0,359 e 0,361 . Como $E M=T / \widehat{T}$, médias maiores do que 1,0 indicam que o modelo é conservador. Os coeficientes de variação são bastante grandes, mas realistas para um modelo semi-empírico. Esta tabela mostra que o valor adotado para o ângulo de atrito residual não afeta o resultado corrigido. 
Tabela 5 - Resumo dos resultados das análises de regressão e das correções do erro de modelo para os dois valores de $\delta_{r}$

\begin{tabular}{|c|c|c|}
\hline \multicolumn{3}{|c|}{ Estatísticas de regressão } \\
\hline & $\delta_{r}=20^{\circ}$ & $\delta_{r}=29^{\circ}$ \\
\hline $\mathrm{R}^{2}$ & 0,89 & 0,89 \\
\hline Erro padrão & 5,09 & 5,10 \\
\hline \multicolumn{3}{|c|}{ Coeficiente de regressão } \\
\hline$\alpha_{\mathrm{s}}$ & 15,47 & 15,57 \\
\hline$\alpha_{h, p}$ & 38,19 & 26,78 \\
\hline$\alpha_{\mathrm{h}, \mathrm{sup}}$ & 10,22 & 6,98 \\
\hline \multicolumn{3}{|c|}{ Correções } \\
\hline 1’a correção & $\mathrm{C} 1(\mathrm{~L})=-0,1139 \times(\mathrm{L})+2,6826$ & $C 1(L)=-0,1146 \times(L)+2,6937$ \\
\hline $\mathrm{R}^{2}$ & 0,80 & 0,80 \\
\hline $2^{a}$ correção & $\mathrm{C} 2(\mathrm{~Np})=-0,0174 \times(\mathrm{Np})+1,2161$ & $\mathrm{C} 2(\mathrm{~Np})=-0,0172 \times(\mathrm{Np})+1,2136$ \\
\hline $\mathrm{R}^{2}$ & 0,37 & 0,36 \\
\hline \multicolumn{3}{|c|}{ Estatísticas do erro de modelo antes da primeira correção } \\
\hline Média & 1,268 & 1,270 \\
\hline Desvio padrão & 0,455 & 0,458 \\
\hline Coeficiente de variação & 0,359 & 0,361 \\
\hline no de estacas (sem outliers) & 752 & 752 \\
\hline \multicolumn{3}{|c|}{ Estatísticas do erro de modelo depois das correções } \\
\hline Média & 1,000 & 1,000 \\
\hline Desvio padrão & 0,141 & 0,141 \\
\hline Coeficiente de variação & 0,141 & 0,141 \\
\hline $\mathrm{n}^{0}$ de estacas (sem outliers) & 752 & 752 \\
\hline
\end{tabular}

A Figura 19 (feita para corrigir o modelo de alguma tendência) indica que para estacas com comprimento instalado inferior a $15 \mathrm{~m}$ o modelo é conservador e para estacas com comprimento instalado maior do que $15 \mathrm{~m}$ o modelo proposto superestima os valores de torque.

Essa tendência acontece provavelmente porque, em estacas mais longas, o aumento do torque resistente na estaca em relação à profundidade dever ser reduzido. Por outro lado, para estacas mais curtas o modelo subestima o torque de instalação, indicando alguma influência de tensões geostáticas nos resultados, o que deve ser melhor investigado em trabalhos futuros a fim de melhorar a o modelo original. 
Figura 19 - Relação entre o erro de modelo e o comprimento instalado $\boldsymbol{L}$

(a) $\delta_{r}=20^{\circ}$

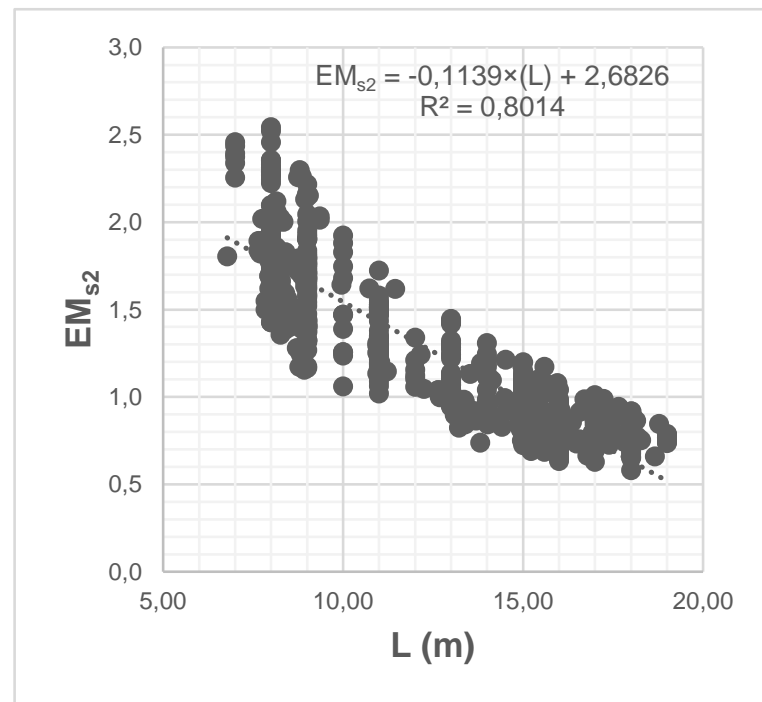

(b) $\delta_{r}=29^{\circ}$

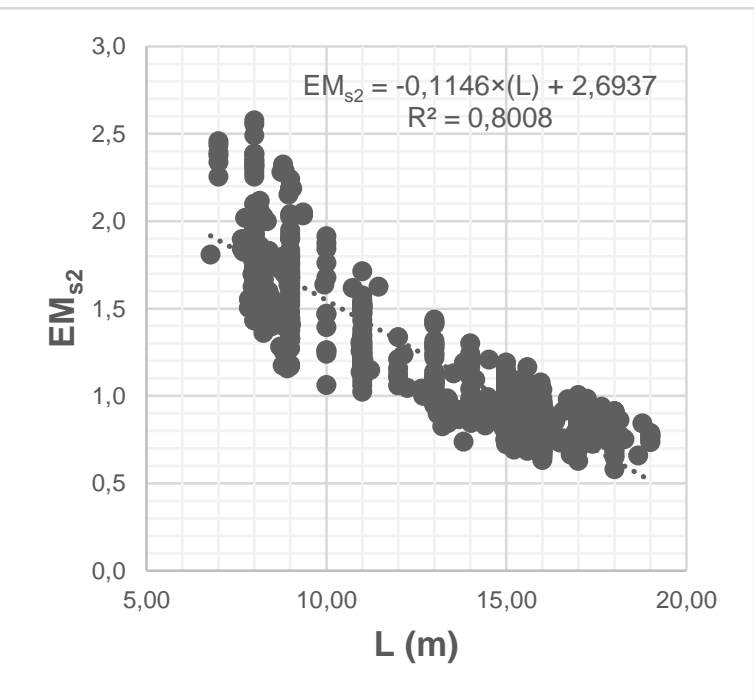

Fonte: do autor.

A Figura 20 apresenta uma correlação menor entre $E M^{*}$ e valor do $N_{S P T}$ na profundidade da hélice da ponta. A figura indica que para estacas com $h p$ instalada em solo com $N$ menor do que 10 golpes/30cm os modelos subestimam ligeiramente o torque de instalação, e quando $h p$ está instalada em solo com $N$ maior do que 10 golpes $/ 30 \mathrm{~cm}$ os valores de torque são superestimados.

O resultado mostrado na Figura 20 indica existe uma leve tendência de que 0 aumento ou diminuição do torque resistido na hélice da ponta da estaca durante a instalação não é tão sensível ao aumento ou diminuição do valor de $N_{S P T}$ do solo atravessado.

Portanto, o efeito do comprimento instalado da estaca (ou sua profundidade) e o valor do $N_{S P T}$ na hélice $h p$ devem ser considerados em trabalhos posteriores para melhorar as suposições iniciais do modelo. 
Figura 20 - Relação entre o erro de modelo após a primeira correção e o valor do $\boldsymbol{N}_{\boldsymbol{S P T}}$ na hélice $\mathrm{n}^{01}$

(a) $\delta_{r}=20^{\circ}$

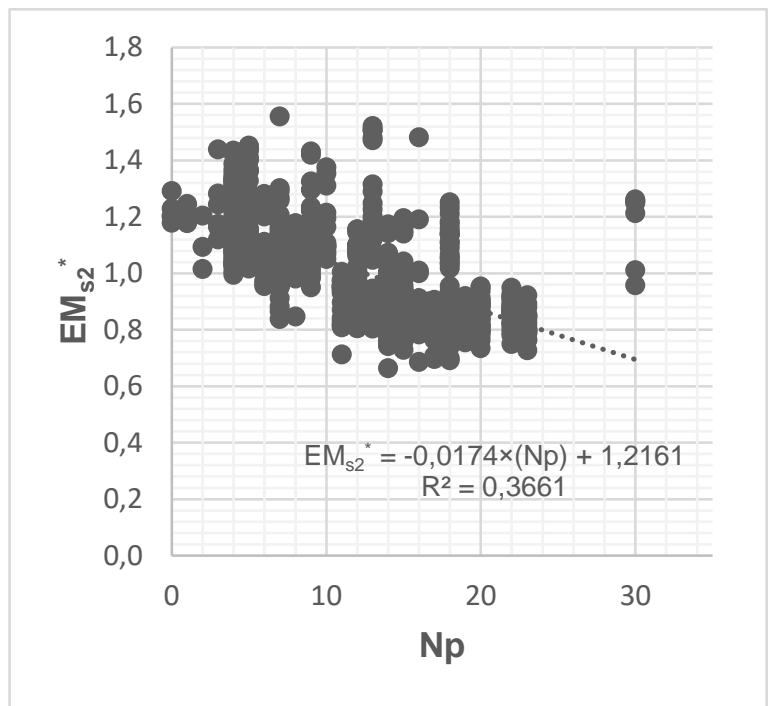

(b) $\delta_{r}=29^{\circ}$

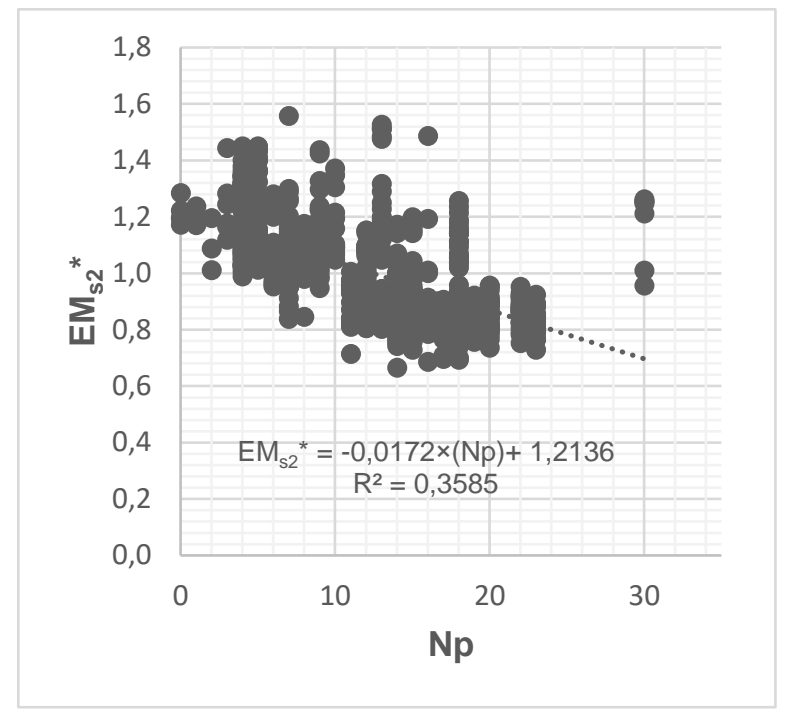

Fonte: do autor.

Depois de aplicadas as correções, o torque final de instalação pode ser estimado pelo modelo simplificado da equação (73), adotando-se um valor de $\delta_{r}$ igual a 20․․ Este ângulo escolhido, como mostra os resultados de coeficiente de variação do erro do modelo na Tabela 5, apresentou ligeiramente um melhor ajuste.

$$
T\left(L, N_{j}\right)=\left(15,47 X_{s}+38,19 X_{h, p}+10,22 X_{h, \text { sup }}\right) \times C 1(L) \times C 2\left(N_{p}\right)
$$

Em que:

$$
\begin{aligned}
& C 1(L)=2,6826-0,1139 L \text { e } C 2(N 1)=1,2161-0,0174 N p \text { para } \\
& \delta_{r}=20^{\circ} \\
& X_{s 2}=\frac{d^{2} \pi}{2} L N_{r} \\
& X_{h, p}=0,5 A_{e h, p} N_{p} d_{c, p} \tan \left(\theta_{p}+\delta_{r, p}\right) ; \\
& X_{h, \text { sup }}=0,5 \sum_{k=1}^{n} A_{e h, k} N_{k} d_{c, k} \tan \left(\theta_{k}+\delta_{r, k}\right) .
\end{aligned}
$$


A Figura 21 e a Figura 22 mostram as distribuições dos erros de modelo para cada estaca antes e depois das correções, para os dois casos avaliados de $\delta_{r}$. As figuras evidenciam a melhora provocada pelas correções, mostrando a aproximação de $E M$ ao valor 1,0 e a diminuição do coeficiente de variação.

Figura 21 - Erro de modelo antes e depois das correções para $\boldsymbol{\delta}_{\boldsymbol{r}}=\mathbf{2 0 ^ { \circ }}$. .
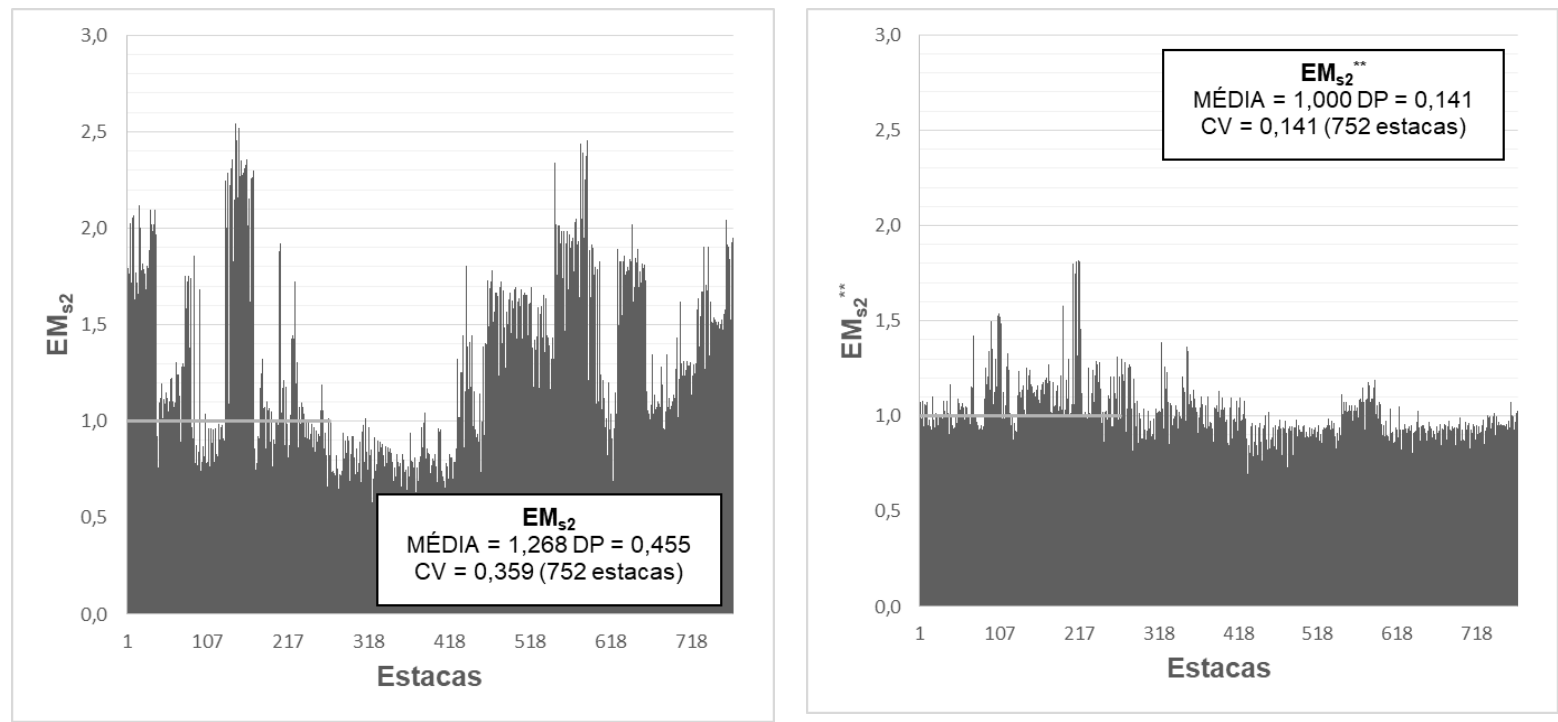

Fonte: do autor.

Figura 22 - Erro de modelo antes e depois das correções para $\boldsymbol{\delta}_{\boldsymbol{r}}=\mathbf{2 9}^{\circ}$.
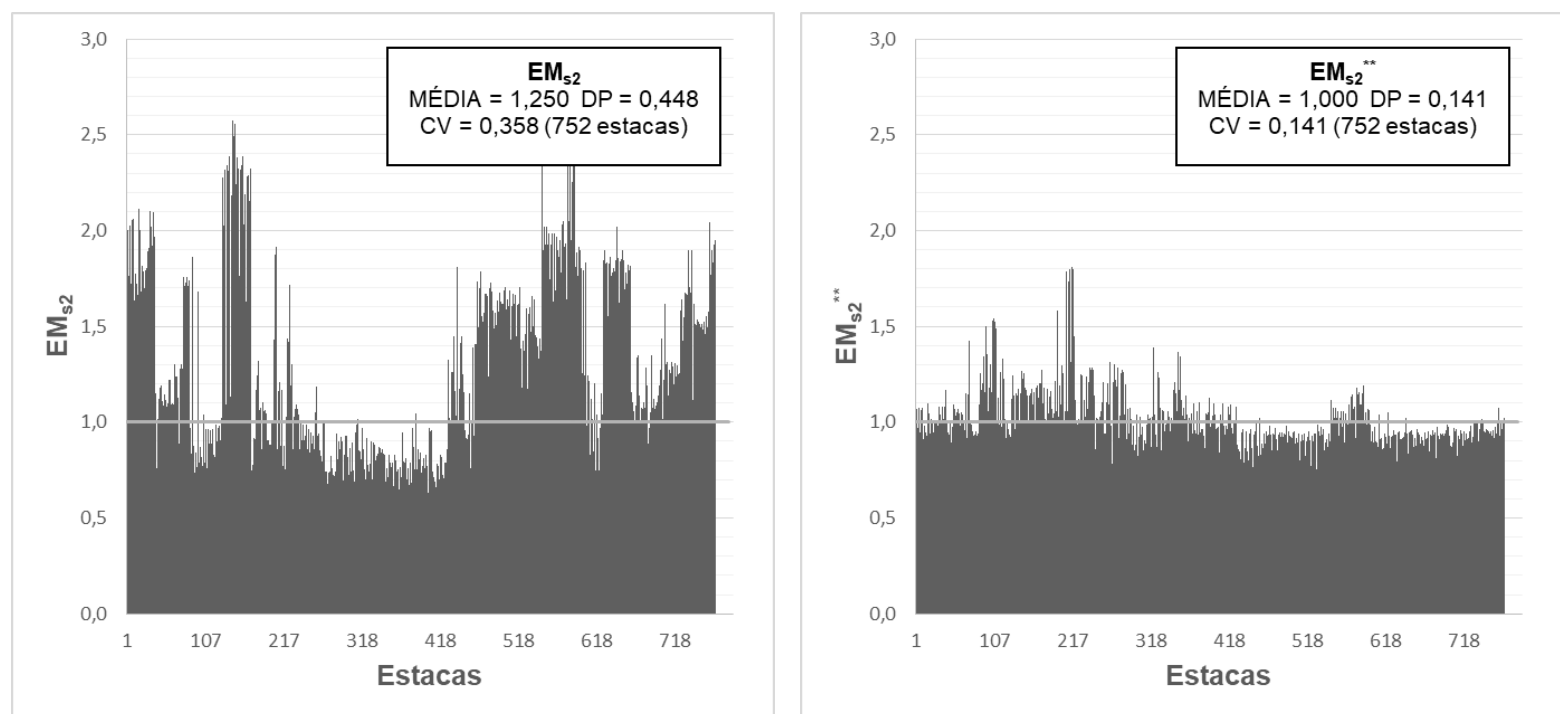

Fonte: do autor. 


\subsection{AVALIAÇÃO DO MODELO PARA SOLOS SILTOSOS E ARGILOSOS}

Das 752 estacas consideradas nas análises apresentadas na Tabela 5, 35 foram instaladas em argila siltosa (torre 191/1) e 36 foram instaladas em silte argiloso (torre 202/1).

Portanto, para avaliar se o modelo proposto descrito na equação (73) pode ser utilizado para estimar o torque de instalação de estacas helicoidais em solos siltosos e argilosos, visto que quase todos os dados de estacas usados na calibração do modelo foram de solos arenosos, uma comparação entre os valores medidos estimados para esses locais foi apresentada na Figura 23.

Figura 23 - EM após correções para estacas em argila siltosa e em silte argiloso.
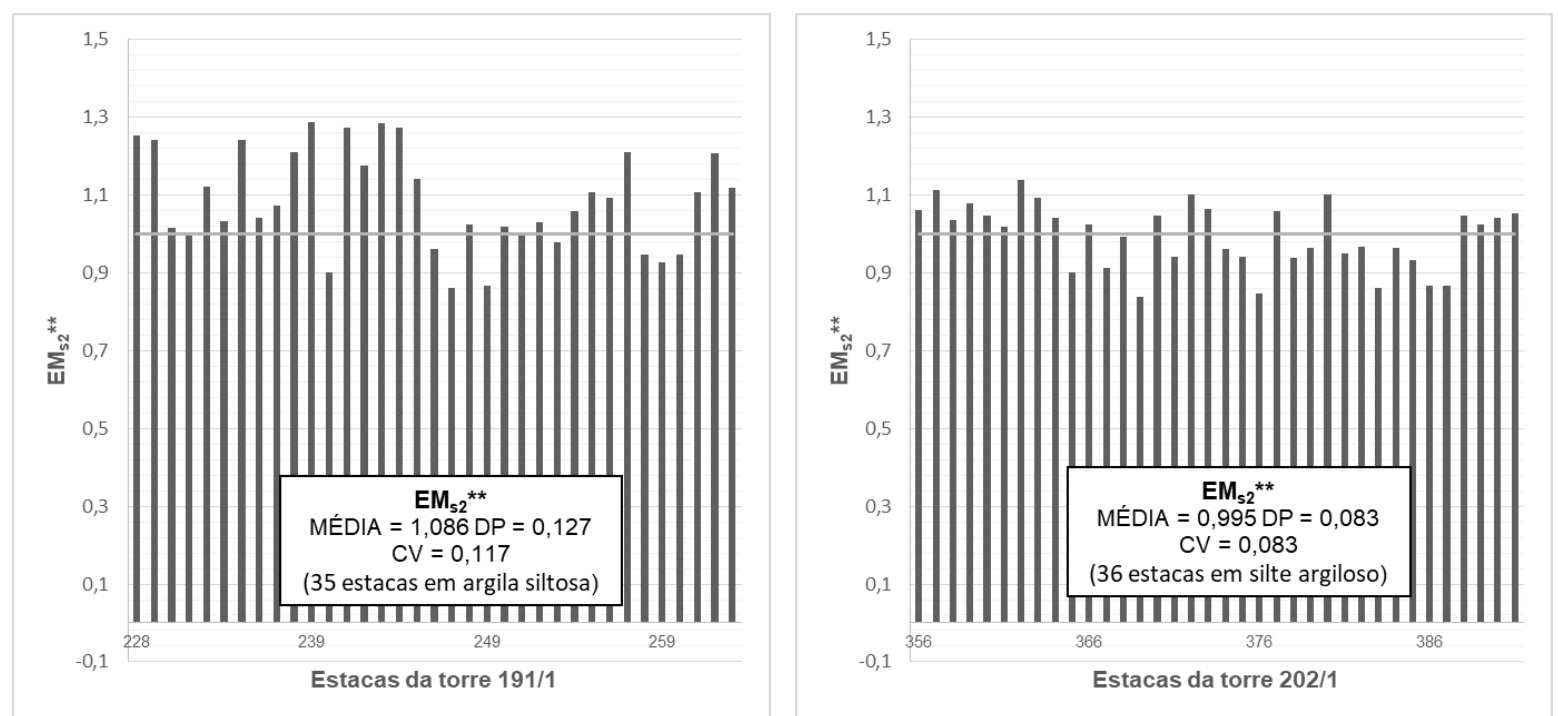

Fonte: do autor.

A figura indica que apesar de os métodos terem sido ajustados com valores de torque de estacas instaladas majoritariamente em areias finas argilosas, os modelos corrigidos também apresentaram grande aproximação entre os valores medidos e calculados do torque instalação em solos siltosos e argilosos.

Provavelmente, isso acontece porque as pressuposições do método podem ser apropriadas para estacas helicoidais instaladas nesses tipos de solo. Contudo, uma 
avaliação mais aprofundada deste método, utilizando estacas instaladas em solos siltosos e argilosos, é necessária para confirmar essa interpretação.

\subsection{AVALIAÇÃO DO MODELO PARA ESTACAS COM 4 HÉLICES}

O banco de dados utilizado neste estudo é composto de 690 estacas com 6 hélices e apenas 62 estacas com 4 hélices, instaladas em seis locais diferentes. Portanto, para avaliar se os modelos são adequados para o menor número de casos de estacas com 4 hélices, uma comparação entre os valores medidos e calculados para as 62 estacas Figura 24.

Figura 24 - Erro de modelo após correções para estacas com 4 hélices

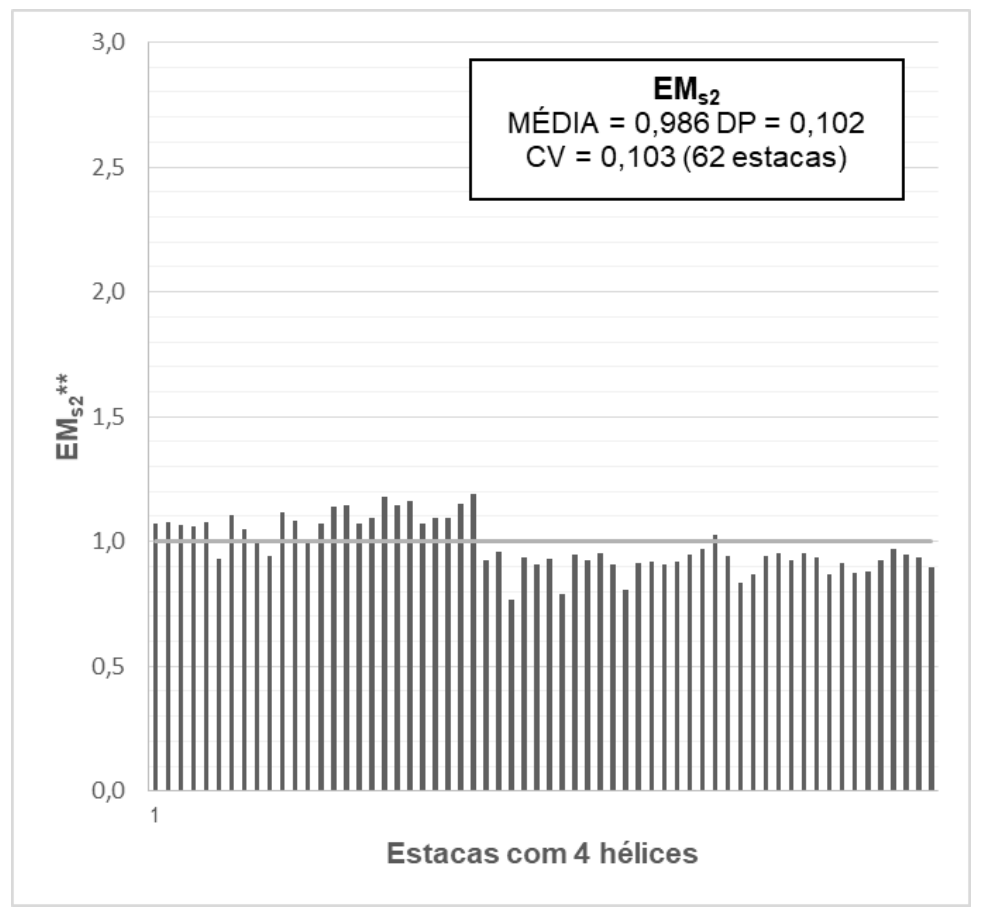

A comparação mostra que apesar de os modelos terem sido predominantemente calibrados com torque de instalação medido em estacas com 6 hélices, a metodologia apresentou boa concordância com o torque medido em estacas com 4 hélices nos seis terrenos diferentes. Portanto, os modelos podem ser recomendados para estacas com 4 a 6 hélices. 


\subsection{AVALIAÇÃO GERAL DO MODELO}

Devido à variabilidade do solo, efeitos de instalação, investigações precárias nos locais de instalação e outras razões, a precisão de métodos de previsão empregados em projetos de fundação geralmente é baixa.

Portanto, considerando-se que o modelo proposto (após as correções), testado em 752 estacas helicoidais instaladas em 24 locais diferentes, com comprimentos variando entre 6,0 e 23,0 metros, apresentou um valor de erro de modelo $E M=T / \widehat{T}$ (valor medido/ valor calculado) igual a 1,000 em média, com coeficiente de variação de $14,1 \%$, é possível constatar que o modelo desenvolvido pode ser utilizado para previsão do torque de instalação de estacas helicoidais de múltiplas hélices em condições similares às do banco de dados utilizado.

A concordância entre os comportamentos previstos e observados sugerem que as suposições iniciais do modelo são adequadas. Portanto, os resultados indicam que:

a) o solo ao longo da haste central da estaca pode ser representado em termos de um único valor residual de $N_{S P T}$; as condições de perturbação do solo em contato com a haste é similar ao longo de todo o comprimento da estaca;

b) os resultados encontrados para os coeficientes de regressão $\alpha_{h, p} \mathrm{e}$ $\alpha_{h, \text { sup }}$ mostram que o momento resistente mobilizado na hélice da ponta durante a instalação da estaca helicoidal é muito maior do que o momento resistente em hélices superiores; isso ocorre porque durante a instalação a hélice da ponta penetra solo intacto, enquanto as hélices superiores penetram camadas de solos previamente perturbadas pela penetração da hélice da ponta. 


\section{CONCLUSÕES E SUGESTÕES PARA TRABALHOS FUTUROS}

A principal proposta desta dissertação foi a elaboração de um modelo semiempírico para a previsão do valor do torque final de instalação de estacas helicoidais com múltiplas hélices levando-se em consideração os resultados de sondagens de simples reconhecimento. Através de análises de regressão linear o modelo foi ajustado e corrigido a partir de valores de torque de instalação medidos em estacas de torres de uma linha de transmissão de energia. As principais conclusões desta pesquisa e algumas sugestões para trabalhos futuros são apresentados nas próximas seções.

\subsection{CONCLUSÕES}

As informações da instalação de 752 estacas com múltiplas hélices em 24 locais diferentes foram usadas para calibrar e avaliar o desempenho de um método simplificado para prever o torque final de instalação de estacas helicoidais em solos arenosos usando dados de ensaio SPT.

Usando-se o modelo simplificado proposto, foram estimados os valores de torque de instalação de estacas de múltiplas hélices (com 4 ou 6 hélices), com diferentes comprimentos (de 6 a $23 \mathrm{~m}$ ), predominantemente instaladas em areias argilosas. As avaliações apresentadas indicam que as medições do torque de instalação em campo apresentam boa concordância com os resultados do modelo proposto. Com base no trabalho aqui descrito, as principais conclusões foram formadas:

a) a hipótese para $T_{S}$ (torque resistido na haste da estaca durante a instalação) que proporcionou melhores resultados considera que, durante a instalação da estaca, a resistência por atrito lateral é mobilizada na haste inteira (a partir de $2 \mathrm{~m}$ de profundidade), adotandose um valor residual de $N_{S P T}$ para todo o solo ao longo de seu comprimento. Este fato indica que o solo em contato com a haste da estaca em todo seu comprimento encontra-se em uma única condição 
(residual) devido à perturbação causada pela instalação prévia das hélices.

b) Apenas 71 das estacas do banco de dados foram instaladas em solos siltosos ou argilosos e, para esses casos, os valores calculados de torque pelo modelo proposto também ficaram próximos dos valores medidos em campo; isso indica que o modelo apresentado nesta dissertação pode ser também indicado para esses tipos de solo; no entanto, investigações adicionais em solos siltosos e argilos devem sem implementadas antes de se chegar a uma conclusão final.

c) O bom ajuste que o método apresentou com os valores medidos em campo validam algumas das hipótese assumidas durante a elaboração do modelo, como: (i) durante a instalação de uma estaca com várias hélices, a resistência por atrito na interface solo-haste apresenta uma condição residual e única ao longo de toda a haste, decorrente da perturbação do solo provocada pela instalação prévia das hélices; (ii) a fração de torque resistido pela hélice da ponta durante a instalação é muito mais importante do que nas outras hélices, porque a hélice da ponta atravessa solo intacto e as hélices superiores atravessam solo perturbado;

\subsection{SUGESTÕES PARA TRABALHOS FUTUROS}

a) o ângulo de atrito residual $\delta_{r}$ entre o solo e o material da estaca é um parâmetro fundamental do modelo teórico utilizado nesta pesquisa, contudo, a literatura especializada ainda carece de uma melhor caracterização de $\delta_{r}$. Portanto, recomenda-se a execução de ensaios de laboratório para aprimorar o conhecimento referente a este parâmetro, levando em consideração os materiais mais comuns utilizados na fabricação das estacas e tentando abranger diferentes tipos de solo; além disso, pode-se investigar, em ensaios de campo, a influência das tesões verticais no valor de $\delta_{r}$;

b) alguns resultados desta pesquisa sugerem que as hélices superiores, em estacas com múltiplas hélices, têm menor influência no valor final do 
torque de instalação, nesse sentido, estudos de campo podem ser realizados com estacas instrumentadas para averiguar, de forma mais adequada, os valores de torque resistido pelas hélices relacionados a sua posição ao longo do comprimento da estaca;

c) as leituras de torque durante a instalação de estacas helicoidais geralmente são realizadas a cada metro de estaca instalado, assim, pode-se tentar propor um modelo para previsão de torque aplicado ao longo do comprimento da estaca, o que possibilita a estimativa de um perfil de torques de instalação;

d) A forte correlação entre os valores do erro de modelo com o comprimento das estacas e a correlação menos significativa entre o erro de modelo e os valores de $N_{S P T}$ na profundidade da hélice da ponta, indicam que as suposições iniciais para os modelos sem correções podem ser melhoradas em trabalhos futuros, considerando-se os efeitos desses parâmetros no torque de instalação de estacas helicoidais. 


\section{REFERÊNCIAS BILBIOGRÁFICAS}

A.B. CHANCE CO. (2004). Technical manual. Bulletin 01-9601. Centralia, USA.

A.B. CHANCE CO. (2012). Guide to model specification - helical piles for structural support. Centralia, USA.

A.B. CHANCE CO. (2013). Encyclopedia of anchoring. Centralia, USA.

AKSOY, H.S.; GÖR, M.; INAL, E. A new design chart for estimating friction angle between soil and pile materials. Geomechanics and Engineering, v. 10, n. 3, p. 315324, 2016.

AL-BAGHDADI, T.A.; DAVIDSON, C,; BROWN, M.J.; KNAPPETT, J.A.;BRENNAN, A.; AUGARDE, C.; COOMBS, W.; WANG, L.; RICHARDS, D.; BLAKE, A. CPT based design procedure for installation torque prediction for screw piles installed in sand. 8th Int. Conf. on Offshore Site Investigation \& Geotechnics, 2017.

BARROS, A. M.; SILVA, R. H.; CARDOSO, O. R. F. A.;FREIRE, F. A.;SOUZA JÚNIOR, J. J.; RIVETTI, M.; LUZ, D. S. PALMEIRA, R. C. B.; TASSINARI, C. C. G. Geologia. Projeto Radam Brasil. Folha SD.21, 1981.

BENTES, J.L. Análise dinâmica da ruptura de cabos em torres autoportante e estaiadas de linhas de transmissão. 2013. 165f. Dissertação (Mestrado em Engenharia de Estruturas) - Universidade Federal do Rio Grande do Sul, Porto Alegre, 2013.

CARVALHO, I. P. G. Estudo teórico-experimental da capacidade de carga à tração e compressão de estacas metálicas helicoidais. 2007, 205f. Dissertação (Mestrado em engenharia de estruturas) - Universidade Federal de Minas Gerais, 2007.

DAS, B. M. Earth Anchors. New York: Elsevier Science Publisher, 1990. 241p.

FILHO, J. M. S. M,. Efeito de instalação de estacas helicoidais em solo tropical. 2014. 121f. Dissertação (Mestrado em Geotecnia) - Universidade de São Paulo, Escola de Engenharia de São Carlos, São Carlos, 2014.

GAAVER, K.E. Uplift capacity of single piles and pile groups embedded in cohesionless soil. Alexandria engineering journal, v.52, p.365-372, 2013

GAVIN, K.G.; DOHERTY, P.; SPAGNOLI, G. Prediction of installation torque resistance of large diameter helical piles in dense sand. Proceedings of 1st International Geotechnical Symposium of Helical Foundations, 2013.

GHALY, A. HANNA, A. Experimental and theoretical studies on installation torque of screw anchors. . Canadian geotechnical journal, v. 28, p. 353-364, 1991

GHALY, A.M.; HANNA, A.; HANNA, M. Installation toque of screw anchors in dry sand. Soils and foundations, v. 31, n. 2, p. 77-92, 1991. 
GHALY, A.M.; CLEMENCE, S. P. Pullout performance of inclined helical screw anchors in sand. Journal of geotechnical and geoenvironmental engineering, $v$. 124, n. 7, p. 617-627, 1998.

HARIKRISHNAN, M.; BALAGOPAL, R. Time-cost benefit analysis for anchor type foundation in transmission towers. International conference on advance in civil engineering and chemistry of innovative materials, 2014. SRM University, Chennai, India, 2014.

HOYT R. M.; CLEMENCE, S.P. Uplift capacity of helical anchors in soil. Proceedings of the twelfth international conference on soil mechanics and foundation engineering, v. 2, p. 1019-1022, 1989.

JARDINE, R. J., LEHANE, B. M., EVERTON, S. J. (1993). Friction coefficients for piles in sands and silts. In: ARDUS D.A., CLARE D., HILL A., HOBBS R., JARDINE R.J., SQUIRE J.M. Offshore site investigation and foundation behavior. Advances in Underwater Technology, Ocean Science and Offshore Engineering. Dordrecht: Springer, 1993. vol. 28. p. 661-677.

JARDINE, R.J.; LEHANE, B.M.; EVERTON, S.J. Friction coefficients for piles in sands and silts. Offshore site investigation and foundation behavior, v. 28, n. 3, p. 315324, 2016.

KANAI, S. A seismic retrofitting application by means of multi-helix micropiles. Proceedings of the 23 U.S. - Japan Bridge Engineering Workshop, Tsukuba Japan.

LEHANE, B.M.; SCHNEIDER, J.; XU, X. A Review of Design Methods for Offshore Driven Piles in Siliceous Sand. UWA REPORT GEO05358, The University of Western Australia, 2005, 102p.

LUTENEGGER, A. J. Historical Development of Iron Screw-Pile Foundations: 18361900. The international journal for the history of engineering \& technology, v. 81 , n. 1, p. 108-128, 2011.

MONTGOMERY, D.C.; PECK, E.A.; VINING, G.G. Introduction to linear regression analysis. 4ed. Hoboken, New Jersey: John Wiley and Sons. 2006. 612p.

PERKO, H. A. Energy method for predicting installation torque of helical foundations and anchors. New Technological and Design Developments in Deep Foundations, Geotechnical special publications, ASCE, 2000. Revisado em 2001.

PERKO, H. A.; STAN, J.; RUPIPER, P. E. Helix pier engineering - handbook. Ingal Precision Foundation, INC. Worldwide Helix Pier Distributors, 2000.

PERKO, H. A. Helical piles: a practical guide to design and installation. Hoboken, New Jersey: John Willey and Sons, 2009, 512p.

RINNE, N. F. Evaluation of interface friction between cohesionless soil and common construction materials. 1989, 90f. Dissertação (Mestrado em ciência 
aplicada) - University of British Columbia, Department of Civil Engineering, 1989.

ROSS, J. L.; SANTOS, L. M Geomorfologia. Projeto Radam Brasil. Folha SD.21, 1981.

SCHNAID, F.; ODEBRECHT, E. Ensaios de campo e suas aplicações à engenharia de fundações. $2^{\underline{a}}$ ed. São Paulo: Oficina de textos, 2012.

SAKR, M. Relationship between installation torque and axial capacities of helical piles in cohesionless soils. Canadian geotechnical journal, v. 52, p. 747-759, 2015.

SILVA, B. C. Estimativa de capacidade de carga à tração de estacas helicoidais com base no ensaio SPT. 2014, 361f. Dissertação (Mestrado em geotecnia) Universidade de São Paulo, Escola de Engenharia de São Carlos, São Carlos, 2014.

SPAGNOLI, G. A CPT-based model to predict the installation torque of helical piles in sand. Marine georesources and geotechnology, v. 35, n. 4, p. 578-585, 2017.

STEPHENSON, R.W. Design and Installation of Torque Anchors for Tiebacks and Foundations. University of Missouri-Rolla, 2003;

TSUHA, C. H. C. Modelo teórico para controle de capacidade de carga à tração de estacas metálicas helicoidais em solo arenoso. 2007. 275f. Tese (Doutorado em Geotecnia) - Universidade de São Paulo, Escola de Engenharia de São Carlos, São Carlos, 2007.

TSUHA, C. H. C. FILHO; J. M. S. M.; SANTOS, T.C. Helical piles in unsaturated soils: a case study. Canadian geotechnical journal, v. 53, p. 103-117, 2016.

UDWARI, J. J.; ROGERS, T.E.; SINGH, B. A rational approach to the design of high capacity multi-helix screw anchors. Transmission and Distribution Conference and Exposition, p. $606-610,1979$.

YU, F. YANG, J. Improved Evaluation of Interface Friction on Steel Pipe Pile in Sand. Journal of performance of constructed facilities, v. 26, p. 170-179, 2012. 


\section{ANEXO A - Exemplo dos protocolos de instalação de torres autoportantes e dos relatórios de sondagem disponíveis na base de dados}

Figura 25 - Exemplo de protocolo de instalação de estacas em torres autoportantes

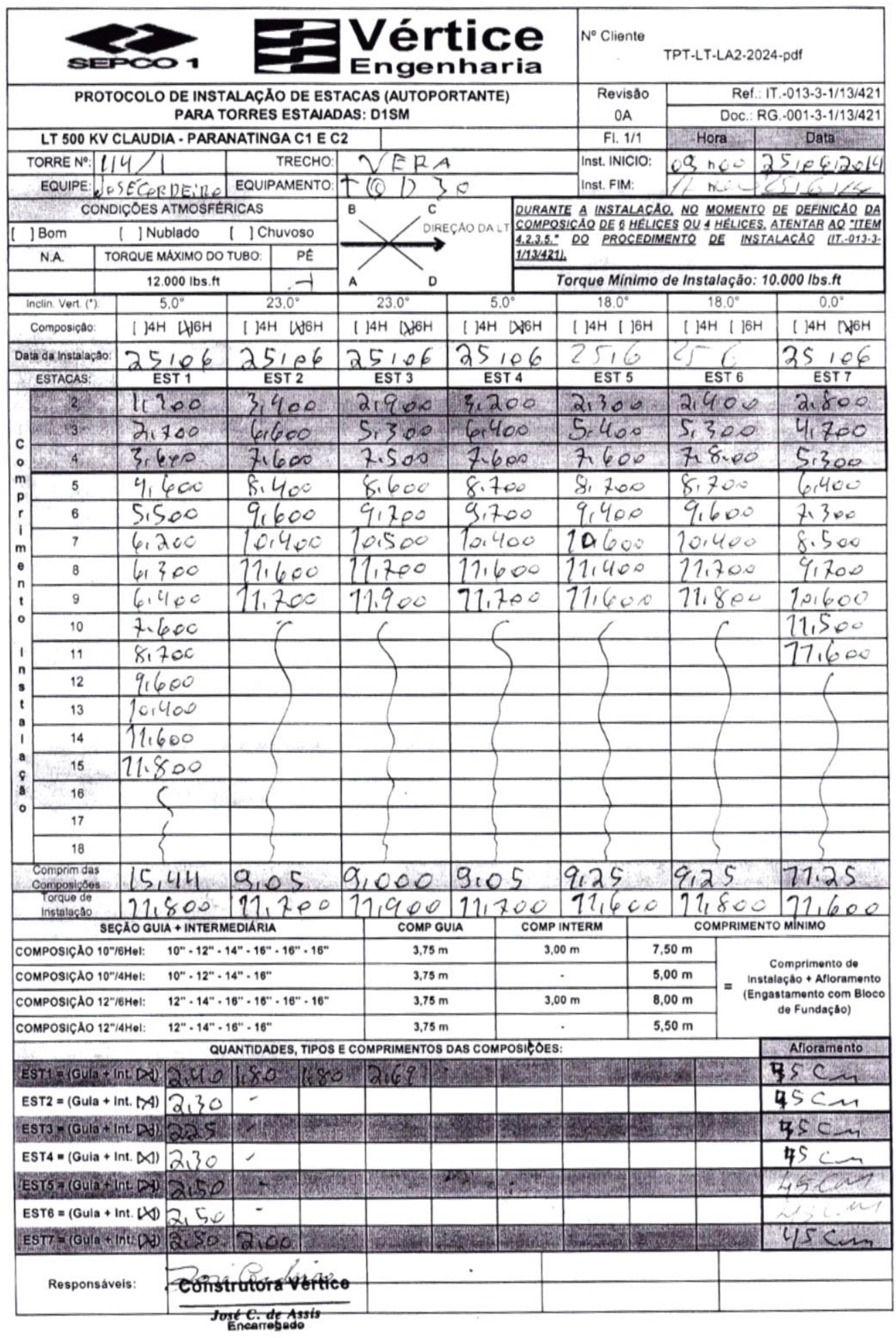

Fonte: Vértice Engenharia 
Figura 26 - Exemplo de relatório de sondagem com SPT
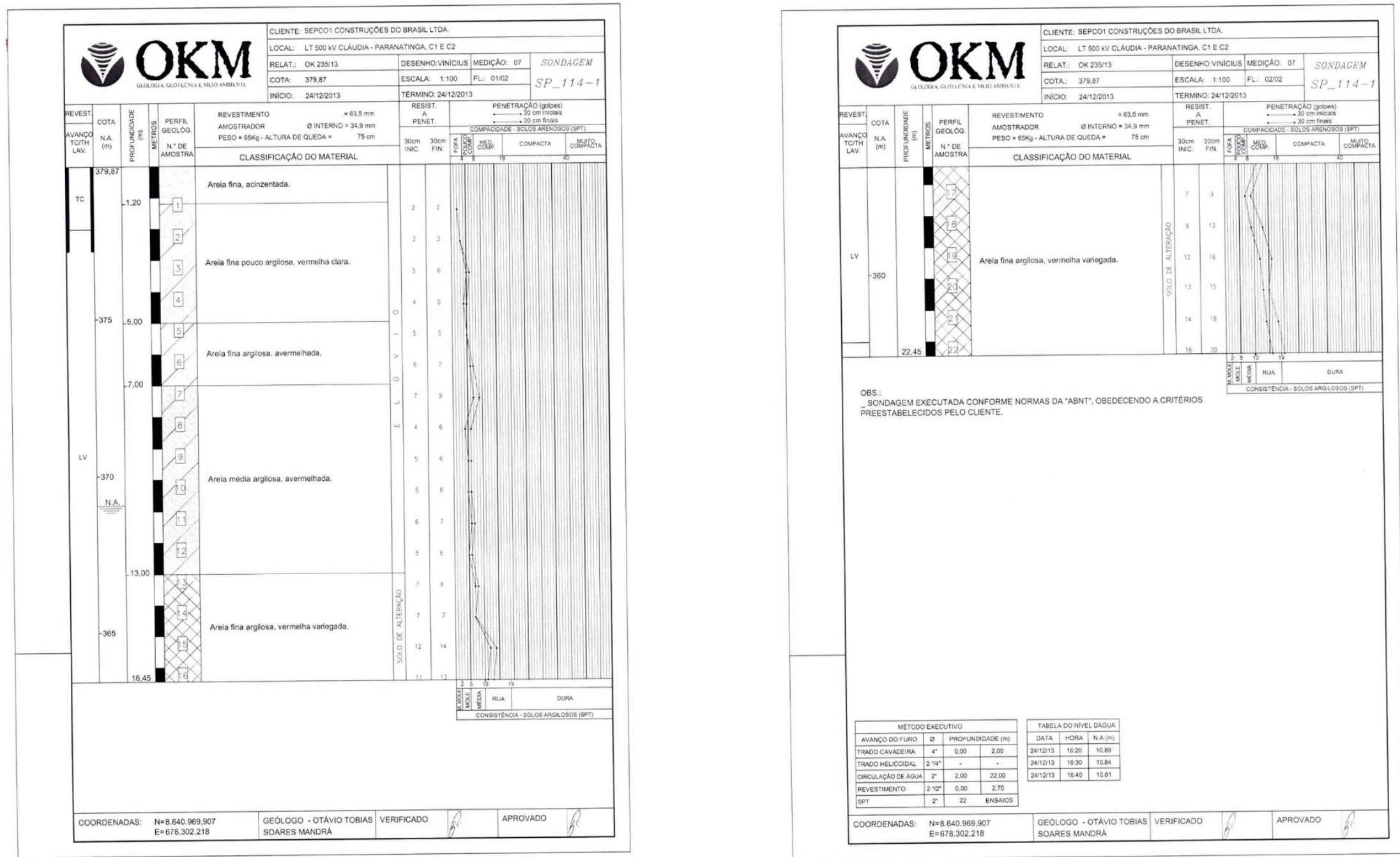

Fonte: Vértice Engenharia. 


\section{APÊNDICE A - síntese dos resultados das sondagens SPT}

Tabela 6 - Resultados das sondagens SPT para as torres 36/1 até 114/2

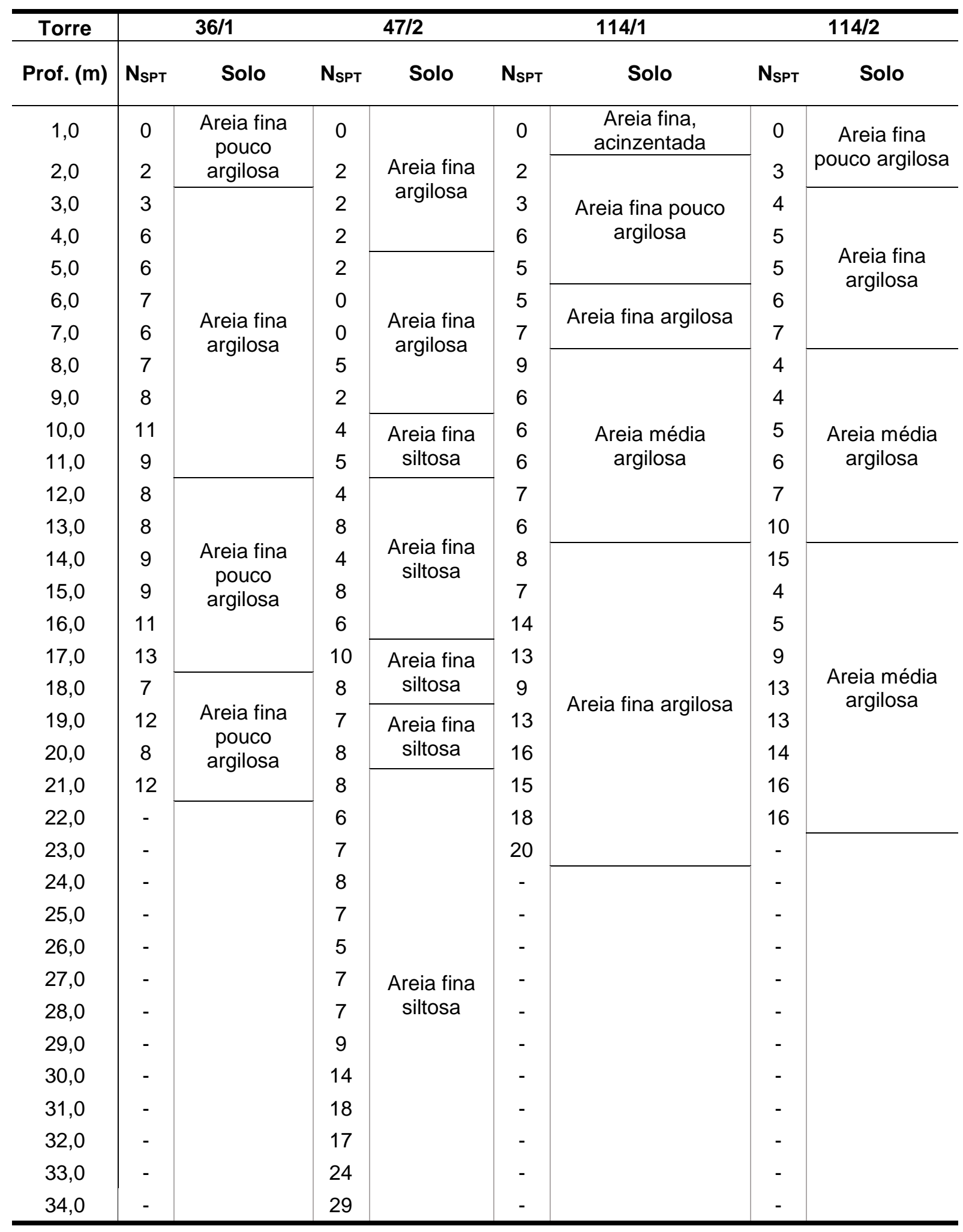


Tabela 7 - Resultados das sondagens SPT para as torres 137/2 até 200/1

\begin{tabular}{|c|c|c|c|c|c|c|c|c|c|c|c|c|}
\hline \multirow{2}{*}{$\begin{array}{c}\text { Torre } \\
\text { Prof. } \\
\text { (m) }\end{array}$} & \multicolumn{2}{|r|}{$137 / 2$} & \multicolumn{2}{|r|}{$177 / 1$} & \multicolumn{2}{|r|}{$184 / 2$} & \multicolumn{2}{|r|}{$191 / 1$} & \multicolumn{2}{|r|}{$199 / 2$} & \multicolumn{2}{|r|}{$200 / 1$} \\
\hline & $N_{\text {SPT }}$ & Solo & $\mathbf{N}_{\text {SPT }}$ & Solo & $\mathbf{N}_{\text {SPT }}$ & Solo & $\mathbf{N}_{\text {SPT }}$ & Solo & $\mathrm{N}_{\mathrm{SPT}}$ & Solo & $\mathbf{N}_{\text {SPT }}$ & Solo \\
\hline 1,0 & 0 & \multirow{22}{*}{$\begin{array}{c}\text { Areia argilosa, } \\
\text { pouco siltosa, } \\
\text { fofa a pouco } \\
\text { compacta }\end{array}$} & 0 & Areia fina & 0 & \multirow{3}{*}{$\begin{array}{c}\text { Areia fina } \\
\text { argilosa }\end{array}$} & \multirow{5}{*}{$\begin{array}{l}0 \\
0 \\
2\end{array}$} & \multirow{5}{*}{$\begin{array}{c}\text { Argila arenosa, } \\
\text { pouco siltosa, } \\
\text { muito mole }\end{array}$} & \multirow{3}{*}{$\begin{array}{l}0 \\
7 \\
8\end{array}$} & \multirow{3}{*}{$\begin{array}{l}\text { Areia fina } \\
\text { argilosa }\end{array}$} & 0 & \multirow{2}{*}{ Areia fina argilosa } \\
\hline 2,0 & 2 & & 3 & pouco argilosa & 2 & & & & & & 4 & \\
\hline 3,0 & 4 & & 0 & \multirow{2}{*}{$\begin{array}{l}\text { Areia fina } \\
\text { argilosa }\end{array}$} & 2 & & & & & & 6 & $\begin{array}{l}\text { Argila pouco } \\
\text { arenosa }\end{array}$ \\
\hline 4,0 & 5 & & 1 & & 8 & Argila arenosa & & & 11 & \multirow{4}{*}{$\begin{array}{c}\text { Argila } \\
\text { avermelhada }\end{array}$} & 8 & \multirow{4}{*}{$\begin{array}{l}\text { Argila pouco } \\
\text { arenosa }\end{array}$} \\
\hline 5,0 & 5 & & 1 & \multirow{5}{*}{$\begin{array}{c}\text { Areia fina } \\
\text { argilosa }\end{array}$} & 7 & \multirow{4}{*}{ Argila arenosa } & & & 13 & & 8 & \\
\hline 6,0 & 5 & & 0 & & 3 & & \multirow{3}{*}{$\begin{array}{l}8 \\
7 \\
7\end{array}$} & \multirow{15}{*}{$\begin{array}{l}\text { Argila siltosa, } \\
\text { mole a média }\end{array}$} & 12 & & 9 & \\
\hline 7,0 & 4 & & 0 & & 1 & & & & 12 & & 8 & \\
\hline 8,0 & 4 & & 1 & & 0 & & & & 9 & \multirow{2}{*}{$\begin{array}{l}\text { Areia fina } \\
\text { argilosa }\end{array}$} & 10 & \multirow{9}{*}{ Areia fina argilosa } \\
\hline 9,0 & 4 & & 1 & & 0 & \multirow{5}{*}{ Argila arenosa } & 5 & & 10 & & 10 & \\
\hline 10,0 & 4 & & 3 & \multirow{3}{*}{$\begin{array}{l}\text { Areia fina } \\
\text { argilosa }\end{array}$} & 1 & & 4 & & 11 & & 13 & \\
\hline 11,0 & 4 & & 2 & & 2 & & 2 & & 7 & \multirow{8}{*}{$\begin{array}{l}\text { Areia fina } \\
\text { argilosa }\end{array}$} & 14 & \\
\hline 12,0 & 3 & & 4 & & 1 & & 2 & & 6 & & 16 & \\
\hline 13,0 & 2 & & 4 & \multirow{7}{*}{$\begin{array}{l}\text { Areia fina } \\
\text { argilosa }\end{array}$} & 1 & & 2 & & 8 & & 15 & \\
\hline 14,0 & 3 & & 9 & & 0 & \multirow{2}{*}{$\begin{array}{l}\text { Areia fina } \\
\text { argilosa }\end{array}$} & 2 & & 14 & & 18 & \\
\hline 15,0 & 3 & & 10 & & 0 & & 4 & & 14 & & 19 & \\
\hline 16,0 & 3 & & 14 & & 10 & \multirow{2}{*}{ Nível laterítico } & 5 & & 16 & & \multirow{2}{*}{$\begin{array}{c}22 \\
-\end{array}$} & \\
\hline 17,0 & 3 & & 13 & & 30 & & 5 & & 15 & & & \\
\hline 18,0 & 3 & & 16 & & - & & 5 & & 18 & & - & \\
\hline 19,0 & 3 & & 15 & & - & & 5 & & - & & - & \\
\hline 20,0 & 4 & & - & & - & & 34 & & - & & - & \\
\hline 21,0 & 5 & & - & & - & & 46 & Argila siltosa, & - & & - & \\
\hline 22,0 & 10 & & - & & - & & 56 & dura & - & & - & \\
\hline
\end{tabular}


Tabela 8 - Resultados das sondagens SPT para as torres 201/2 até 221/1

\begin{tabular}{|c|c|c|c|c|c|c|c|c|c|c|c|c|c|c|}
\hline \multirow{2}{*}{$\begin{array}{c}\text { Torre } \\
\text { Prof. } \\
\text { (m) }\end{array}$} & \multicolumn{2}{|r|}{$201 / 2$} & \multicolumn{2}{|c|}{$202 / 1$} & \multicolumn{2}{|r|}{$204 / 2$} & \multicolumn{2}{|r|}{$205 / 2$} & \multicolumn{2}{|r|}{$219 / 1$} & \multicolumn{2}{|r|}{$220 / 1$} & \multicolumn{2}{|c|}{$221 / 1$} \\
\hline & $\mathbf{N}_{\mathrm{SPT}}$ & Solo & $N_{\text {SPT }}$ & Solo & $N_{S P T}$ & Solo & $\mathrm{N}_{\text {SPT }}$ & Solo & $\mathrm{N}_{\text {SPT }}$ & Solo & $\mathrm{N}_{\mathrm{SPT}}$ & Solo & $\mathbf{N}_{\text {SPT }}$ & Solo \\
\hline 1,0 & 0 & $\begin{array}{l}\text { Areia fina } \\
\text { pouco }\end{array}$ & 0 & Areia & 0 & & 0 & $\begin{array}{c}\text { Areia fina } \\
\text { pouco argilosa }\end{array}$ & 0 & $\begin{array}{c}\text { Areia fina } \\
\text { pouco } \\
\text { argilosa }\end{array}$ & 0 & $\begin{array}{c}\text { Areia fina } \\
\text { pouco argilosa }\end{array}$ & 0 & \\
\hline 2,0 & 4 & argilosa & 1 & $\begin{array}{c}\text { fina } \\
\text { pouco }\end{array}$ & 1 & $\begin{array}{l}\text { Arela tina pouco } \\
\text { argilosa }\end{array}$ & 2 & $\begin{array}{c}\text { Areia fina } \\
\text { argilosa }\end{array}$ & 3 & Areia fina & 3 & & 2 & $\begin{array}{c}\text { Areia fina } \\
\text { argilosa }\end{array}$ \\
\hline 3,0 & 4 & $\begin{array}{c}\text { Areia fina } \\
\text { argilosa }\end{array}$ & 2 & argilosa & 2 & & 4 & & 5 & argilosa & 4 & $\begin{array}{c}\text { Areia fina } \\
\text { arqilosa }\end{array}$ & 5 & \\
\hline 4,0 & 6 & Araila & 2 & & 4 & & 6 & & 5 & & 6 & & 6 & \\
\hline 5,0 & 8 & Argila & 5 & & 6 & & 10 & Argila pouco & 7 & & 9 & & 10 & \\
\hline 6,0 & 9 & Argila & 6 & & 7 & Silte arailoso & 9 & arenosa & 10 & Areia fina & 9 & Areia média & 9 & $\begin{array}{l}\text { Areia } \\
\text { média }\end{array}$ \\
\hline 7,0 & 9 & pouco & 9 & & 9 & silte argiloso & 13 & & 11 & argilosa & 12 & & 11 & argilosa \\
\hline 8,0 & 12 & arenosa & 11 & & 9 & & 14 & & 11 & & 12 & & 14 & \\
\hline 9,0 & 15 & & 10 & & 13 & & 18 & & 15 & & 12 & & 17 & \\
\hline 10,0 & 15 & & 10 & Silte & 11 & & 12 & & 16 & & 14 & & 17 & \\
\hline 11,0 & 13 & & 12 & argiloso & 10 & & 11 & & 11 & & 10 & Areia fina & 13 & \\
\hline 12,0 & 9 & & 14 & & 13 & & 13 & & 14 & & 13 & argilosa & 16 & $\begin{array}{l}\text { Areia } \\
\text { média }\end{array}$ \\
\hline 13,0 & 12 & $\begin{array}{c}\text { Areia fina } \\
\text { argilosa }\end{array}$ & 16 & & 16 & Areia fina siltosa & 14 & $\begin{array}{c}\text { Areia fina } \\
\text { arqilosa }\end{array}$ & 15 & $\begin{array}{c}\text { Areia média } \\
\text { argilosa }\end{array}$ & 14 & & 18 & $\begin{array}{l}\text { média } \\
\text { argilosa }\end{array}$ \\
\hline 14,0 & 12 & & 16 & & 19 & & 14 & & 14 & & 16 & & 20 & \\
\hline 15,0 & 15 & & 20 & & 23 & & 14 & & 19 & & 20 & & 12 & \\
\hline 16,0 & 14 & & 22 & & 20 & & 18 & & 23 & & 24 & & 20 & \\
\hline 17,0 & 18 & & - & & - & & 23 & & - & & - & & - & \\
\hline
\end{tabular}


Tabela 9 - Resultados das sondagens SPT para as torres 221/2 até 246/1

\begin{tabular}{|c|c|c|c|c|c|c|c|c|c|c|c|c|c|c|}
\hline \multirow{2}{*}{$\begin{array}{c}\text { Torre } \\
\text { Prof. (m) }\end{array}$} & \multicolumn{2}{|c|}{$222 / 1$} & \multicolumn{2}{|r|}{$223 / 1$} & \multicolumn{2}{|r|}{$226 / 1$} & \multicolumn{2}{|r|}{$226 / 2$} & \multicolumn{2}{|r|}{$245 / 1$} & \multicolumn{2}{|r|}{$245 / 2$} & \multicolumn{2}{|r|}{$246 / 1$} \\
\hline & $\mathbf{N}_{\text {SPT }}$ & Solo & $\mathrm{N}_{\text {SPT }}$ & Solo & $\mathbf{N}_{\text {SPT }}$ & Solo & $\mathbf{N}_{\text {SPT }}$ & Solo & $\mathbf{N}_{\text {SPT }}$ & Solo & $\mathrm{N}_{\text {SPT }}$ & Solo & $\mathrm{N}_{\text {SPT }}$ & Solo \\
\hline 1,0 & 0 & \multirow{8}{*}{$\begin{array}{c}\text { Areia } \\
\text { fina } \\
\text { pouco } \\
\text { argilosa }\end{array}$} & 0 & Areia fina & 0 & $\begin{array}{c}\text { Areia fina } \\
\text { pouco } \\
\text { argilosa }\end{array}$ & 0 & $\begin{array}{l}\text { Areia fina } \\
\text { pouco } \\
\text { argilosa } \\
\end{array}$ & 0 & $\begin{array}{c}\text { Areia fina } \\
\text { pouco } \\
\text { argilosa } \\
\end{array}$ & 0 & $\begin{array}{c}\text { Areia fina } \\
\text { pouco } \\
\text { argilosa } \\
\end{array}$ & 0 & $\begin{array}{c}\text { Areia fina } \\
\text { pouco } \\
\text { argilosa }\end{array}$ \\
\hline 2,0 & 3 & & 2 & $\begin{array}{c}\text { Areia fina } \\
\text { pouco } \\
\text { argilosa } \\
\end{array}$ & 3 & \multirow[t]{2}{*}{$\begin{array}{l}\text { Areia fina } \\
\text { argilosa }\end{array}$} & 6 & \multirow[t]{2}{*}{ Areia fina } & \multirow[t]{2}{*}{2} & \multirow{6}{*}{$\begin{array}{l}\text { Areia fina } \\
\text { argilosa }\end{array}$} & 2 & \multirow{4}{*}{$\begin{array}{l}\text { Areia fina } \\
\text { argilosa }\end{array}$} & 3 & \multirow{4}{*}{$\begin{array}{c}\text { Areia fina } \\
\text { argilosa }\end{array}$} \\
\hline 3,0 & 4 & & 3 & \multirow{4}{*}{$\begin{array}{l}\text { Areia fina } \\
\text { argilosa }\end{array}$} & 4 & & \multirow{3}{*}{$\begin{array}{l}8 \\
9 \\
9\end{array}$} & & & & \multirow{3}{*}{$\begin{array}{l}3 \\
4 \\
5\end{array}$} & & \multirow{3}{*}{$\begin{array}{l}3 \\
3 \\
4\end{array}$} & \\
\hline 4,0 & 6 & & 4 & & 5 & \multirow{5}{*}{$\begin{array}{l}\text { Areia fina } \\
\text { argilosa }\end{array}$} & & \multirow{2}{*}{$\begin{array}{c}\text { Areia fina } \\
\text { argilosa }\end{array}$} & 3 & & & & & \\
\hline 5,0 & 4 & & 6 & & 7 & & & & 4 & & & & & \\
\hline 6,0 & 7 & & 8 & & 8 & & 24 & $\begin{array}{c}\text { Areia fina } \\
\text { pouco } \\
\text { argilosa } \\
\end{array}$ & 5 & & 7 & \multirow{6}{*}{$\begin{array}{l}\text { Areia média } \\
\text { argilosa }\end{array}$} & 3 & \\
\hline 7,0 & 6 & & 7 & \multirow{3}{*}{$\begin{array}{l}\text { Areia média } \\
\text { argilosa }\end{array}$} & 9 & & 6 & \multirow{12}{*}{$\begin{array}{l}\text { Areia média } \\
\text { argilosa }\end{array}$} & 5 & & 8 & & 5 & $\begin{array}{c}\text { Areia fina } \\
\text { pouco }\end{array}$ \\
\hline 8,0 & 9 & & 12 & & 9 & & 7 & & 5 & \multirow{4}{*}{$\begin{array}{l}\text { Areia fina } \\
\text { argilosa }\end{array}$} & 11 & & 6 & argilosa \\
\hline 9,0 & 12 & \multirow{3}{*}{$\begin{array}{c}\text { Areia } \\
\text { média } \\
\text { argilosa }\end{array}$} & 13 & & 12 & \multirow{8}{*}{$\begin{array}{l}\text { Areia média } \\
\text { argilosa }\end{array}$} & 6 & & 12 & & 12 & & 4 & \\
\hline 10,0 & 14 & & 11 & \multirow{7}{*}{$\begin{array}{c}\text { Areia média } \\
\text { pouco } \\
\text { argilosa }\end{array}$} & 14 & & 7 & & 12 & & 12 & & 5 & \\
\hline 11,0 & 17 & & 12 & & 14 & & 6 & & 11 & & 15 & & 6 & \\
\hline 12,0 & 10 & \multirow{6}{*}{$\begin{array}{c}\text { Areia } \\
\text { média } \\
\text { argilosa }\end{array}$} & 15 & & 16 & & 7 & & 13 & \multirow{6}{*}{$\begin{array}{c}\text { Areia média } \\
\text { pouco } \\
\text { argilosa }\end{array}$} & 15 & & 5 & \\
\hline 13,0 & 13 & & 16 & & 18 & & 10 & & 15 & & 14 & & 10 & \\
\hline 14,0 & 14 & & 19 & & 19 & & 15 & & 15 & & 15 & $\begin{array}{c}\text { Areia fina } \\
\text { arailosa }\end{array}$ & 12 & Areia fina \\
\hline 15,0 & 19 & & 17 & & 23 & & 14 & & 16 & & 17 & & 13 & argilosa \\
\hline 16,0 & 20 & & 18 & & 24 & & 14 & & 16 & & 22 & & 15 & \\
\hline 17,0 & 21 & & - & & - & & 16 & & 19 & & - & & 15 & \\
\hline 18,0 & - & & - & & - & & 18 & & - & & - & & 16 & \\
\hline
\end{tabular}




\section{APÊNDICE B - Síntese da base de dados}

Tabela 10 - Síntese das principais informações disponíveis na base de dados

\begin{tabular}{|c|c|c|c|c|c|c|c|c|c|c|c|c|c|c|c|c|c|c|c|c|c|c|c|c|c|c|c|c|c|}
\hline Estaca & Torre & $\begin{array}{c}\text { No. } \\
\text { hélices }\end{array}$ & 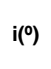 & $L(m)$ & $\begin{array}{c}\mathrm{T} \\
(\mathrm{kN} \cdot \mathrm{m})\end{array}$ & Estaca & Torre & $\begin{array}{c}\text { No. } \\
\text { hélices }\end{array}$ & $i\left({ }^{\circ}\right)$ & $L(m)$ & $\begin{array}{c}\mathrm{T} \\
(\mathbf{k N} \cdot \mathbf{m})\end{array}$ & Estaca & Torre & $\begin{array}{c}\text { No. } \\
\text { hélices }\end{array}$ & 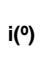 & $\mathrm{L}(\mathrm{m})$ & $\begin{array}{c}\top \\
(\mathbf{k N} \cdot \mathbf{m})\end{array}$ & Estaca & Torre & $\begin{array}{c}\text { No. } \\
\text { hélices }\end{array}$ & $i(\stackrel{0}{)})$ & $\mathrm{L}(\mathrm{m})$ & $\begin{array}{c}\mathrm{T} \\
(\mathbf{k N} \cdot \mathbf{m})\end{array}$ & Estaca & Torre & $\begin{array}{c}\text { No. } \\
\text { hélices }\end{array}$ & 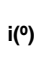 & $\mathrm{L}(\mathrm{m})$ & $\begin{array}{c}\mathrm{T} \\
(\mathrm{kN} \cdot \mathrm{m})\end{array}$ \\
\hline 1 & $36 / 1$ & 4 & 5 & 8.35 & 16.13 & 155 & $137 / 2$ & 6 & 20 & 8.00 & 14.64 & 309 & $200 / 1$ & 6 & 5 & 13.26 & 15.59 & 463 & $205 / 2$ & 6 & 20 & 13.90 & 15.05 & 617 & $226 / 1$ & 6 & 18 & 13.18 & 15.46 \\
\hline 2 & $36 / 1$ & 6 & 23 & 8.75 & 16.13 & 156 & $137 / 2$ & 6 & 20 & 8.00 & 14.51 & 310 & $200 / 1$ & 6 & 18 & 13.73 & 15.46 & 464 & $219 / 1$ & 6 & 5 & 9.00 & 15.59 & 618 & $226 / 1$ & 6 & 0 & 12.65 & 16.27 \\
\hline 3 & $36 / 1$ & 6 & 23 & 8.75 & 15.86 & 157 & $137 / 2$ & 6 & 20 & 10.00 & 14.64 & 311 & $200 / 1$ & 6 & 18 & 13.36 & 16.00 & 465 & $219 / 1$ & 6 & 23 & 8.00 & 15.19 & 619 & $226 / 1$ & 6 & 5 & 13.36 & 15.46 \\
\hline 4 & $36 / 1$ & 4 & 5 & 8.25 & 16.13 & 158 & $137 / 2$ & 6 & 20 & 8.00 & 14.64 & 312 & $200 / 1$ & 6 & 0 & 15.17 & 15.32 & 466 & $219 / 1$ & 6 & 23 & 8.00 & 15.46 & 620 & $226 / 1$ & 6 & 23 & 15.89 & 15.19 \\
\hline 5 & $36 / 1$ & 6 & 5 & 8.85 & 15.86 & 159 & $137 / 2$ & 6 & 20 & 17.00 & 14.64 & 313 & $200 / 1$ & 6 & 5 & 12.95 & 16.13 & 467 & $219 / 1$ & 6 & 5 & 9.00 & 16.41 & 621 & $226 / 1$ & 6 & 23 & 15.22 & 15.59 \\
\hline 6 & $36 / 1$ & 6 & 5 & 8.75 & 15.86 & 160 & $137 / 2$ & 6 & 20 & 8.00 & 14.51 & 314 & $200 / 1$ & 6 & 23 & 15.45 & 16.13 & 468 & $219 / 1$ & 6 & 18 & 8.00 & 15.05 & 622 & $226 / 1$ & 6 & 5 & 13.27 & 16.27 \\
\hline 7 & $36 / 1$ & 4 & 20 & 8.05 & 15.46 & 161 & $137 / 2$ & 6 & 20 & 8.00 & 14.64 & 315 & $200 / 1$ & 6 & 23 & 13.39 & 15.46 & 469 & $219 / 1$ & 6 & 18 & 8.00 & 15.32 & 623 & $226 / 1$ & 6 & 18 & 11.03 & 14.78 \\
\hline 8 & $36 / 1$ & 4 & 18 & 8.15 & 15.59 & 162 & $137 / 2$ & 6 & 20 & 8.00 & 14.78 & 316 & $200 / 1$ & 6 & 5 & 15.81 & 15.19 & 470 & $219 / 1$ & 6 & 0 & 8.00 & 16.54 & 624 & $226 / 1$ & 6 & 18 & 13.08 & 14.91 \\
\hline 9 & $36 / 1$ & 4 & 20 & 8.15 & 15.73 & 163 & $137 / 2$ & 6 & 20 & 9.35 & 15.59 & 317 & $200 / 1$ & 6 & 18 & 15.72 & 15.86 & 471 & $219 / 1$ & 6 & 5 & 8.26 & 15.32 & 625 & $226 / 1$ & 6 & 0 & 12.64 & 16.27 \\
\hline 10 & $36 / 1$ & 6 & 5 & 8.95 & 15.46 & 164 & $137 / 2$ & 6 & 20 & 15.95 & 15.19 & 318 & $200 / 1$ & 6 & 18 & 13.32 & 15.73 & 472 & $219 / 1$ & 6 & 23 & 8.26 & 14.24 & 626 & $226 / 2$ & 4 & 5 & 7.65 & 15.46 \\
\hline 11 & $36 / 1$ & 6 & 23 & 8.85 & 15.59 & 165 & $137 / 2$ & 6 & 20 & 9.05 & 16.00 & 319 & $200 / 1$ & 6 & 0 & 15.13 & 16.00 & 473 & $219 / 1$ & 6 & 23 & 8.51 & 15.32 & 627 & $226 / 2$ & 4 & 5 & 7.72 & 15.73 \\
\hline 12 & $36 / 1$ & 6 & 23 & 8.85 & 16.13 & 166 & $137 / 2$ & 6 & 20 & 11.45 & 15.86 & 320 & $201 / 2$ & 6 & 5 & 15.98 & 15.86 & 474 & $219 / 1$ & 6 & 5 & 8.26 & 15.46 & 628 & $226 / 2$ & 4 & 5 & 7.85 & 14.78 \\
\hline 13 & $36 / 1$ & 6 & 5 & 8.75 & 15.86 & 167 & $137 / 2$ & 6 & 20 & 8.75 & 16.13 & 321 & $201 / 2$ & 6 & 23 & 18.28 & 16.13 & 475 & $219 / 1$ & 6 & 18 & 8.26 & 15.73 & 629 & $226 / 2$ & 4 & 5 & 8.15 & 15.86 \\
\hline 14 & $36 / 1$ & 6 & 5 & 8.95 & 15.73 & 168 & $137 / 2$ & 6 & 20 & 9.35 & 15.73 & 322 & 201/2 & 6 & 23 & 18.00 & 13.56 & 476 & $219 / 1$ & 6 & 18 & 8.26 & 15.73 & 630 & $226 / 2$ & 4 & 5 & 8.05 & 15.32 \\
\hline 15 & $36 / 1$ & 4 & 5 & 10.00 & 15.05 & 169 & $137 / 2$ & 6 & 20 & 8.85 & 16.13 & 323 & $201 / 2$ & 6 & 5 & 17.00 & 14.24 & 477 & $219 / 1$ & 6 & 0 & 8.26 & 16.00 & 631 & $226 / 2$ & 4 & 5 & 8.05 & 15.73 \\
\hline 16 & $36 / 1$ & 4 & 20 & 8.15 & 16.13 & 170 & $137 / 2$ & 6 & 20 & 8.95 & 15.46 & 324 & $201 / 2$ & 6 & 5 & 14.54 & 15.73 & 478 & $219 / 1$ & 6 & 5 & 8.00 & 15.32 & 632 & $226 / 2$ & 4 & 5 & 7.85 & 13.15 \\
\hline 17 & $36 / 1$ & 4 & 18 & 8.25 & 15.59 & 171 & $137 / 2$ & 6 & 20 & 8.80 & 16.27 & 325 & $201 / 2$ & 6 & 5 & 15.53 & 13.96 & 479 & $219 / 1$ & 6 & 23 & 10.00 & 14.90 & 633 & $226 / 2$ & 4 & 5 & 8.05 & 15.59 \\
\hline 18 & $36 / 1$ & 6 & 20 & 8.75 & 16.13 & 172 & $177 / 1$ & 6 & 5 & 15.82 & 14.64 & 326 & 201/2 & 6 & 20 & 17.83 & 15.59 & 480 & $219 / 1$ & 6 & 23 & 10.00 & 15.19 & 634 & $226 / 2$ & 4 & 5 & 8.00 & 15.46 \\
\hline 19 & $36 / 1$ & 6 & 5 & 9.00 & 16.00 & 173 & $177 / 1$ & 6 & 23 & 18.00 & 14.78 & 327 & 201/2 & 6 & 18 & 17.39 & 14.64 & 481 & $219 / 1$ & 6 & 5 & 8.00 & 15.73 & 635 & $226 / 2$ & 4 & 5 & 8.15 & 16.13 \\
\hline 20 & $36 / 1$ & 6 & 23 & 9.00 & 16.81 & 174 & $177 / 1$ & 6 & 23 & 17.65 & 16.00 & 328 & $201 / 2$ & 6 & 20 & 17.39 & 15.73 & 482 & $219 / 1$ & 6 & 18 & 8.00 & 15.32 & 636 & $226 / 2$ & 4 & 5 & 8.05 & 15.19 \\
\hline 21 & $36 / 1$ & 6 & 23 & 9.00 & 16.54 & 175 & $177 / 1$ & 6 & 5 & 17.93 & 15.73 & 329 & 201/2 & 6 & 5 & 16.00 & 16.68 & 483 & $219 / 1$ & 6 & 18 & 9.00 & 14.78 & 637 & $226 / 2$ & 4 & 5 & 8.15 & 15.73 \\
\hline 22 & $36 / 1$ & 6 & 5 & 9.00 & 16.81 & 176 & $177 / 1$ & 6 & 18 & 16.01 & 15.32 & 330 & $201 / 2$ & 6 & 23 & 16.00 & 15.46 & 484 & $219 / 1$ & 6 & 0 & 8.00 & 15.59 & 638 & $226 / 2$ & 4 & 5 & 8.15 & 15.46 \\
\hline 23 & $36 / 1$ & 6 & 5 & 9.00 & 16.13 & 177 & $177 / 1$ & 6 & 18 & 16.58 & 16.27 & 331 & $201 / 2$ & 6 & 23 & 16.00 & 14.64 & 485 & $219 / 1$ & 6 & 5 & 8.26 & 15.59 & 639 & $226 / 2$ & 4 & 5 & 8.05 & 15.46 \\
\hline 24 & $36 / 1$ & 6 & 5 & 9.00 & 16.00 & 178 & $177 / 1$ & 6 & 0 & 15.48 & 14.78 & 332 & $201 / 2$ & 6 & 5 & 16.00 & 16.54 & 486 & $219 / 1$ & 6 & 23 & 8.78 & 15.19 & 640 & $226 / 2$ & 4 & 5 & 8.05 & 15.32 \\
\hline 25 & $36 / 1$ & 6 & 20 & 9.00 & 16.68 & 179 & $177 / 1$ & 6 & 5 & 14.00 & 16.27 & 333 & $201 / 2$ & 6 & 5 & 16.00 & 16.00 & 487 & $219 / 1$ & 6 & 23 & 8.72 & 15.32 & 641 & $226 / 2$ & 4 & 5 & 8.35 & 15.46 \\
\hline 26 & $36 / 1$ & 6 & 18 & 9.00 & 16.81 & 180 & $177 / 1$ & 6 & 23 & 14.00 & 16.13 & 334 & $201 / 2$ & 6 & 5 & 16.00 & 16.41 & 488 & $219 / 1$ & 6 & 5 & 8.26 & 15.46 & 642 & $226 / 2$ & 4 & 5 & 7.95 & 15.86 \\
\hline 27 & $36 / 1$ & 6 & 20 & 9.00 & 16.68 & 181 & $177 / 1$ & 6 & 23 & 17.00 & 16.27 & 335 & $201 / 2$ & 6 & 20 & 16.00 & 14.64 & 489 & $219 / 1$ & 6 & 18 & 8.76 & 15.46 & 643 & $226 / 2$ & 4 & 5 & 8.40 & 16.27 \\
\hline 28 & $36 / 1$ & 6 & 5 & 8.00 & 15.73 & 182 & $177 / 1$ & 6 & 5 & 13.00 & 16.00 & 336 & 201/2 & 6 & 18 & 16.00 & 15.19 & 490 & $219 / 1$ & 6 & 18 & 8.85 & 15.59 & 644 & $226 / 2$ & 4 & 5 & 7.75 & 15.05 \\
\hline 29 & $36 / 1$ & 6 & 23 & 8.00 & 15.19 & 183 & $177 / 1$ & 6 & 18 & 15.00 & 15.86 & 337 & 201/2 & 6 & 20 & 16.00 & 14.10 & 491 & $219 / 1$ & 6 & 0 & 8.26 & 16.13 & 645 & $226 / 2$ & 4 & 5 & 7.75 & 15.46 \\
\hline 30 & $36 / 1$ & 6 & 23 & 8.00 & 16.68 & 184 & $177 / 1$ & 6 & 18 & 15.00 & 16.00 & 338 & 201/2 & 6 & 5 & 16.00 & 15.46 & 492 & 220/1 & 6 & 5 & 8.26 & 15.46 & 646 & $226 / 2$ & 4 & 5 & 7.95 & 16.13 \\
\hline
\end{tabular}




\begin{tabular}{|c|c|c|c|c|c|c|c|c|c|c|c|c|c|c|c|c|c|c|c|c|c|c|c|c|c|c|c|c|c|}
\hline Estaca & Torre & $\begin{array}{c}\text { No. } \\
\text { hélices }\end{array}$ & 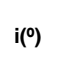 & $L(m)$ & $\left(\begin{array}{c}\top \\
(\mathbf{N} \cdot \mathbf{m})\end{array}\right.$ & Estaca & Torre & $\begin{array}{l}\text { No. } \\
\text { hélices }\end{array}$ & 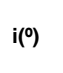 & $\mathrm{L}(\mathrm{m})$ & $\begin{array}{c}\mathrm{T} \\
(\mathrm{kN} \cdot \mathrm{m})\end{array}$ & Estaca & Torre & $\begin{array}{c}\text { No. } \\
\text { hélices }\end{array}$ & $i(-\circ)$ & $L(m)$ & $\begin{array}{c}\mathrm{T} \\
(\mathrm{kN} \cdot \mathrm{m})\end{array}$ & Estaca & Torre & $\begin{array}{c}\text { No. } \\
\text { hélices }\end{array}$ & 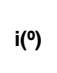 & $L(m)$ & ${ }_{(\mathrm{kN} \cdot \mathrm{m})}^{\mathrm{T}}$ & Estaca & Torre & $\begin{array}{c}\text { No. } \\
\text { hélices }\end{array}$ & $i(\stackrel{\circ}{)}$ & $L(m)$ & ${ }_{(\mathrm{kN} \cdot \mathrm{m})}^{\mathrm{T}}$ \\
\hline 31 & $36 / 1$ & 6 & 5 & 8.00 & 16.81 & 185 & $177 / 1$ & 6 & 0 & 17.00 & 15.73 & 339 & $201 / 2$ & 6 & 23 & 16.00 & 16.00 & 493 & $220 / 1$ & 6 & 23 & 8.26 & 16.13 & 647 & $226 / 2$ & 4 & 5 & 7.95 & 14.51 \\
\hline 32 & $36 / 1$ & 6 & 5 & 8.00 & 16.54 & 186 & $177 / 1$ & 6 & 5 & 17.00 & 16.13 & 340 & $201 / 2$ & 6 & 23 & 16.00 & 16.41 & 494 & $220 / 1$ & 6 & 23 & 8.26 & 15.86 & 648 & $226 / 2$ & 4 & 5 & 7.95 & 15.73 \\
\hline 33 & $36 / 1$ & 6 & 5 & 8.00 & 16.00 & 187 & $177 / 1$ & 6 & 23 & 15.00 & 16.27 & 341 & $201 / 2$ & 6 & 5 & 16.00 & 16.00 & 495 & $220 / 1$ & 6 & 5 & 8.26 & 16.00 & 649 & $226 / 2$ & 4 & 5 & 7.98 & 15.86 \\
\hline 34 & $36 / 1$ & 6 & 20 & 8.00 & 16.13 & 188 & $177 / 1$ & 6 & 23 & 15.00 & 16.13 & 342 & $201 / 2$ & 6 & 5 & 15.45 & 15.05 & 496 & $220 / 1$ & 6 & 18 & 8.26 & 15.73 & 650 & $226 / 2$ & 4 & 5 & 7.70 & 15.19 \\
\hline 35 & $36 / 1$ & 6 & 18 & 8.00 & 16.68 & 189 & $177 / 1$ & 6 & 5 & 15.00 & 16.00 & 343 & $201 / 2$ & 6 & 5 & 16.00 & 14.78 & 497 & $220 / 1$ & 6 & 18 & 8.26 & 15.46 & 651 & $226 / 2$ & 4 & 5 & 7.65 & 15.73 \\
\hline 36 & $36 / 1$ & 6 & 20 & 8.00 & 15.73 & 190 & $177 / 1$ & 6 & 18 & 15.00 & 15.86 & 344 & $201 / 2$ & 6 & 20 & 16.00 & 15.73 & 498 & $220 / 1$ & 6 & 0 & 8.26 & 15.86 & 652 & $226 / 2$ & 4 & 5 & 7.75 & 15.46 \\
\hline 37 & $47 / 2$ & 6 & 5 & 13.80 & 15.59 & 191 & $177 / 1$ & 6 & 18 & 17.00 & 16.27 & 345 & $201 / 2$ & 6 & 18 & 16.00 & 15.32 & 499 & $220 / 1$ & 6 & 5 & 8.00 & 16.13 & 653 & $226 / 2$ & 4 & 5 & 7.95 & 14.51 \\
\hline 38 & $47 / 2$ & 6 & 23 & 16.80 & 15.46 & 192 & $177 / 1$ & 6 & 0 & 15.00 & 16.13 & 346 & $201 / 2$ & 6 & 20 & 16.00 & 15.19 & 500 & $220 / 1$ & 6 & 23 & 8.00 & 15.19 & 654 & $226 / 2$ & 4 & 5 & 7.95 & 15.19 \\
\hline 39 & $47 / 2$ & 6 & 23 & 18.04 & 15.05 & 193 & $177 / 1$ & 6 & 5 & 15.82 & 15.46 & 347 & $201 / 2$ & 6 & 5 & 17.00 & 16.00 & 501 & $220 / 1$ & 6 & 23 & 8.00 & 15.19 & 655 & $226 / 2$ & 4 & 5 & 12.15 & 15.46 \\
\hline 40 & $47 / 2$ & 6 & 5 & 15.52 & 15.86 & 194 & $177 / 1$ & 6 & 23 & 19.00 & 16.27 & 348 & $201 / 2$ & 6 & 23 & 18.00 & 14.51 & 502 & $220 / 1$ & 6 & 5 & 8.00 & 15.19 & 656 & $226 / 2$ & 4 & 5 & 8.05 & 14.78 \\
\hline 41 & $47 / 2$ & 6 & 5 & 14.14 & 15.59 & 195 & $177 / 1$ & 6 & 23 & 15.98 & 15.32 & 349 & $201 / 2$ & 6 & 23 & 18.00 & 15.32 & 503 & $220 / 1$ & 6 & 18 & 8.00 & 14.91 & 657 & $226 / 2$ & 4 & 5 & 8.05 & 15.59 \\
\hline 42 & $47 / 2$ & 6 & 5 & 14.02 & 15.46 & 196 & $177 / 1$ & 6 & 5 & 15.80 & 14.91 & 350 & $201 / 2$ & 6 & 5 & 17.00 & 15.46 & 504 & $220 / 1$ & 6 & 18 & 8.00 & 15.05 & 658 & $226 / 2$ & 4 & 5 & 9.95 & 15.73 \\
\hline 43 & $47 / 2$ & 6 & 20 & 13.84 & 15.73 & 197 & $177 / 1$ & 6 & 18 & 16.97 & 16.00 & 351 & $201 / 2$ & 6 & 5 & 17.00 & 14.51 & 505 & $220 / 1$ & 6 & 0 & 8.00 & 15.32 & 659 & $226 / 2$ & 4 & 5 & 8.35 & 15.86 \\
\hline 44 & $47 / 2$ & 6 & 18 & 13.83 & 15.86 & 198 & $177 / 1$ & 6 & 18 & 15.50 & 15.86 & 352 & $201 / 2$ & 6 & 5 & 15.86 & 15.46 & 506 & $220 / 1$ & 6 & 5 & 8.00 & 15.19 & 660 & $226 / 2$ & 4 & 5 & 8.05 & 15.46 \\
\hline 45 & $47 / 2$ & 6 & 20 & 15.29 & 15.46 & 199 & $177 / 1$ & 6 & 0 & 16.05 & 16.00 & 353 & $201 / 2$ & 6 & 20 & 18.00 & 16.54 & 507 & $220 / 1$ & 6 & 23 & 8.00 & 15.05 & 661 & $226 / 2$ & 4 & 5 & 8.05 & 15.05 \\
\hline 46 & $47 / 2$ & 6 & 5 & 14.00 & 15.32 & 200 & $184 / 2$ & 6 & 5 & 17.00 & 16.13 & 354 & $201 / 2$ & 6 & 18 & 17.00 & 15.59 & 508 & $220 / 1$ & 6 & 23 & 8.00 & 15.19 & 662 & $245 / 1$ & 6 & 5 & 12.00 & 16.13 \\
\hline 47 & $47 / 2$ & 6 & 23 & 15.00 & 15.73 & 201 & $184 / 2$ & 6 & 23 & 17.00 & 16.00 & 355 & $201 / 2$ & 6 & 20 & 18.00 & 16.27 & 509 & $220 / 1$ & 6 & 5 & 8.00 & 15.32 & 663 & $245 / 1$ & 6 & 23 & 13.00 & 16.27 \\
\hline 48 & $47 / 2$ & 6 & 23 & 15.00 & 16.54 & 202 & $184 / 2$ & 6 & 23 & 17.00 & 16.27 & 356 & $202 / 1$ & 6 & 5 & 15.77 & 15.73 & 510 & $220 / 1$ & 6 & 18 & 8.00 & 15.19 & 664 & $245 / 1$ & 6 & 23 & 12.00 & 16.13 \\
\hline 49 & $47 / 2$ & 6 & 5 & 15.00 & 17.49 & 203 & $184 / 2$ & 6 & 5 & 17.00 & 16.27 & 357 & $202 / 1$ & 6 & 23 & 17.00 & 14.78 & 511 & $220 / 1$ & 6 & 18 & 8.00 & 15.32 & 665 & $245 / 1$ & 6 & 5 & 13.00 & 16.27 \\
\hline 50 & $47 / 2$ & 6 & 5 & 15.00 & 17.08 & 204 & $184 / 2$ & 6 & 18 & 13.00 & 16.13 & 358 & $202 / 1$ & 6 & 23 & 16.79 & 15.86 & 512 & $220 / 1$ & 6 & 0 & 8.00 & 15.46 & 666 & $245 / 1$ & 6 & 5 & 13.00 & 15.73 \\
\hline 51 & $47 / 2$ & 6 & 5 & 15.00 & 16.54 & 205 & $184 / 2$ & 6 & 18 & 10.00 & 16.27 & 359 & $202 / 1$ & 6 & 5 & 15.47 & 16.13 & 513 & $220 / 1$ & 6 & 5 & 8.00 & 15.86 & 667 & $245 / 1$ & 6 & 5 & 13.00 & 15.86 \\
\hline 52 & $47 / 2$ & 6 & 20 & 15.00 & 15.73 & 206 & $184 / 2$ & 6 & 0 & 10.00 & 16.13 & 360 & $202 / 1$ & 6 & 5 & 16.00 & 15.46 & 514 & $220 / 1$ & 6 & 23 & 8.26 & 16.00 & 668 & $245 / 1$ & 6 & 20 & 13.00 & 16.27 \\
\hline 53 & $47 / 2$ & 6 & 18 & 15.00 & 16.54 & 207 & $184 / 2$ & 6 & 5 & 15.27 & 15.05 & 361 & $202 / 1$ & 6 & 5 & 15.25 & 15.46 & 515 & $220 / 1$ & 6 & 23 & 8.26 & 15.73 & 669 & $245 / 1$ & 6 & 18 & 11.00 & 15.86 \\
\hline 54 & $47 / 2$ & 6 & 20 & 15.00 & 16.81 & 208 & $184 / 2$ & 6 & 23 & 17.48 & 15.86 & 362 & $202 / 1$ & 6 & 20 & 16.72 & 15.59 & 516 & $220 / 1$ & 6 & 5 & 8.00 & 15.19 & 670 & $245 / 1$ & 6 & 20 & 11.00 & 16.00 \\
\hline 55 & $47 / 2$ & 6 & 5 & 13.00 & 15.73 & 209 & $184 / 2$ & 6 & 23 & 15.59 & 16.27 & 363 & $202 / 1$ & 6 & 18 & 16.49 & 15.32 & 517 & $220 / 1$ & 6 & 18 & 8.00 & 14.78 & 671 & $245 / 1$ & 6 & 5 & 13.00 & 16.27 \\
\hline 56 & $47 / 2$ & 6 & 23 & 14.00 & 16.81 & 210 & $184 / 2$ & 6 & 5 & 14.52 & 15.59 & 364 & $202 / 1$ & 6 & 20 & 15.97 & 14.91 & 518 & $220 / 1$ & 6 & 18 & 8.26 & 15.73 & 672 & $245 / 1$ & 6 & 23 & 13.00 & 16.81 \\
\hline 57 & $47 / 2$ & 6 & 23 & 15.00 & 16.68 & 211 & $184 / 2$ & 6 & 18 & 17.25 & 15.86 & 365 & $202 / 1$ & 6 & 5 & 16.00 & 13.29 & 519 & $220 / 1$ & 6 & 0 & 8.00 & 16.27 & 673 & $245 / 1$ & 6 & 23 & 13.00 & 16.41 \\
\hline 58 & $47 / 2$ & 6 & 5 & 15.00 & 16.81 & 212 & $184 / 2$ & 6 & 18 & 17.42 & 16.13 & 366 & $202 / 1$ & 6 & 23 & 16.00 & 15.05 & 520 & $221 / 1$ & 6 & 5 & 9.00 & 15.46 & 674 & $245 / 1$ & 6 & 5 & 13.00 & 16.68 \\
\hline 59 & $47 / 2$ & 6 & 5 & 15.00 & 16.41 & 213 & $184 / 2$ & 6 & 0 & 14.98 & 15.59 & 367 & $202 / 1$ & 6 & 23 & 16.00 & 15.05 & 521 & $221 / 1$ & 6 & 23 & 9.00 & 15.05 & 675 & $245 / 1$ & 6 & 5 & 13.00 & 16.81 \\
\hline 60 & $47 / 2$ & 6 & 5 & 15.00 & 16.68 & 214 & $184 / 2$ & 6 & 5 & 17.00 & 14.64 & 368 & $202 / 1$ & 6 & 5 & 16.00 & 14.64 & 522 & $221 / 1$ & 6 & 23 & 9.00 & 15.46 & 676 & $245 / 1$ & 6 & 5 & 13.00 & 16.68 \\
\hline 61 & $47 / 2$ & 4 & 20 & 13.00 & 16.00 & 215 & $184 / 2$ & 6 & 23 & 17.24 & 16.27 & 369 & $202 / 1$ & 6 & 5 & 13.00 & 14.78 & 523 & $221 / 1$ & 6 & 5 & 9.00 & 15.32 & 677 & $245 / 1$ & 6 & 20 & 13.00 & 16.54 \\
\hline 62 & $47 / 2$ & 6 & 18 & 13.00 & 16.54 & 216 & $184 / 2$ & 6 & 23 & 18.18 & 16.27 & 370 & $202 / 1$ & 6 & 5 & 16.00 & 15.46 & 524 & $221 / 1$ & 6 & 18 & 9.00 & 15.59 & 678 & $245 / 1$ & 6 & 18 & 13.00 & 16.41 \\
\hline 63 & $47 / 2$ & 6 & 20 & 13.00 & 15.73 & 217 & $184 / 2$ & 6 & 5 & 16.09 & 13.96 & 371 & $202 / 1$ & 6 & 20 & 15.00 & 14.51 & 525 & $221 / 1$ & 6 & 18 & 9.00 & 15.05 & 679 & $245 / 1$ & 6 & 20 & 13.00 & 16.13 \\
\hline 64 & $47 / 2$ & 6 & 5 & 13.00 & 16.00 & 218 & $184 / 2$ & 6 & 18 & 17.42 & 16.13 & 372 & $202 / 1$ & 6 & 18 & 16.00 & 15.73 & 526 & $221 / 1$ & 4 & 0 & 9.00 & 15.19 & 680 & $245 / 1$ & 6 & 5 & 11.00 & 15.86 \\
\hline 65 & $47 / 2$ & 6 & 23 & 17.18 & 16.00 & 219 & $184 / 2$ & 6 & 18 & 17.00 & 13.56 & 373 & $202 / 1$ & 6 & 20 & 16.00 & 15.19 & 527 & $221 / 1$ & 6 & 5 & 8.75 & 16.00 & 681 & $245 / 1$ & 6 & 23 & 14.00 & 16.27 \\
\hline 66 & $47 / 2$ & 6 & 23 & 13.53 & 16.00 & 220 & $184 / 2$ & 6 & 0 & 15.76 & 15.32 & 374 & $202 / 1$ & 6 & 5 & 15.00 & 15.32 & 528 & $221 / 1$ & 6 & 23 & 8.26 & 15.59 & 682 & $245 / 1$ & 6 & 23 & 11.00 & 15.86 \\
\hline
\end{tabular}

(continuação) 


\begin{tabular}{|c|c|c|c|c|c|c|c|c|c|c|c|c|c|c|c|c|c|c|c|c|c|c|c|c|c|c|c|c|c|}
\hline Estaca & Torre & $\begin{array}{c}\text { No. } \\
\text { hélices }\end{array}$ & $i\left({ }^{\circ}\right)$ & $L(m)$ & $\begin{array}{c}\mathrm{T} \\
(\mathrm{kN} \cdot \mathrm{m})\end{array}$ & Estaca & Torre & $\begin{array}{c}\text { No. } \\
\text { hélices }\end{array}$ & $i\left({ }^{\circ}\right)$ & $L(m)$ & $\begin{array}{c}\mathrm{T} \\
(\mathbf{k N} \cdot \mathrm{m})\end{array}$ & Estaca & Torre & $\begin{array}{c}\text { No. } \\
\text { hélices }\end{array}$ & $i(\stackrel{\circ}{ })$ & $L(m)$ & $\begin{array}{c}\mathrm{T} \\
(\mathrm{kN} \cdot \mathrm{m})\end{array}$ & Estaca & Torre & $\begin{array}{c}\text { No. } \\
\text { hélices }\end{array}$ & $i(\stackrel{\circ}{)}$ & $L(m)$ & $\begin{array}{c}\mathrm{T} \\
(\mathrm{kN} \cdot \mathrm{m})\end{array}$ & Estaca & Torre & $\begin{array}{c}\text { No. } \\
\text { hélices }\end{array}$ & $i(\stackrel{\circ}{ })$ & $L(m)$ & $\stackrel{\mathrm{T}}{(\mathrm{kN} \cdot \mathrm{m})}$ \\
\hline 67 & $47 / 2$ & 6 & 5 & 17.00 & 15.86 & 221 & $184 / 2$ & 6 & 5 & 13.00 & 16.27 & 375 & $202 / 1$ & 6 & 23 & 16.00 & 13.83 & 529 & $221 / 1$ & 6 & 23 & 8.79 & 15.05 & 683 & $245 / 1$ & 6 & 5 & 15.00 & 16.13 \\
\hline 68 & $47 / 2$ & 6 & 5 & 18.78 & 16.27 & 222 & $184 / 2$ & 6 & 23 & 13.00 & 16.13 & 376 & $202 / 1$ & 6 & 23 & 16.00 & 13.96 & 530 & $221 / 1$ & 6 & 5 & 8.76 & 16.27 & 684 & $245 / 1$ & 6 & 5 & 14.00 & 16.27 \\
\hline 69 & $47 / 2$ & 6 & 20 & 13.00 & 16.27 & 223 & $184 / 2$ & 6 & 23 & 13.00 & 16.27 & 377 & $202 / 1$ & 6 & 5 & 16.00 & 15.59 & 531 & $221 / 1$ & 6 & 18 & 8.46 & 16.27 & 685 & $245 / 1$ & 6 & 5 & 14.00 & 16.13 \\
\hline 70 & $47 / 2$ & 6 & 18 & 13.00 & 16.54 & 224 & $184 / 2$ & 6 & 5 & 13.00 & 16.13 & 378 & $202 / 1$ & 6 & 5 & 16.00 & 13.83 & 532 & $221 / 1$ & 6 & 18 & 8.39 & 16.13 & 686 & $245 / 1$ & 6 & 20 & 13.00 & 15.73 \\
\hline 71 & $47 / 2$ & 6 & 20 & 13.00 & 16.27 & 225 & $184 / 2$ & 6 & 18 & 11.00 & 16.13 & 379 & $202 / 1$ & 6 & 5 & 16.00 & 14.24 & 533 & $221 / 1$ & 6 & 0 & 8.76 & 16.00 & 687 & $245 / 1$ & 6 & 18 & 13.00 & 16.27 \\
\hline 72 & $114 / 1$ & 6 & 5 & 15.00 & 16.00 & 226 & $184 / 2$ & 6 & 18 & 15.00 & 15.86 & 380 & $202 / 1$ & 6 & 20 & 16.00 & 15.73 & 534 & $221 / 1$ & 6 & 5 & 8.47 & 15.46 & 688 & $245 / 1$ & 6 & 20 & 11.00 & 16.00 \\
\hline 73 & $114 / 1$ & 6 & 23 & 9.00 & 15.86 & 227 & $184 / 2$ & 6 & 0 & 14.00 & 16.13 & 381 & $202 / 1$ & 6 & 18 & 16.00 & 13.56 & 535 & $221 / 1$ & 6 & 23 & 8.21 & 16.13 & 689 & $245 / 1$ & 6 & 5 & 13.00 & 16.81 \\
\hline 74 & $114 / 1$ & 6 & 23 & 9.00 & 16.13 & 228 & $191 / 1$ & 6 & 5 & 17.93 & 15.86 & 382 & $202 / 1$ & 6 & 20 & 15.00 & 14.91 & 536 & $221 / 1$ & 6 & 23 & 8.26 & 15.32 & 690 & $245 / 1$ & 6 & 23 & 13.00 & 16.54 \\
\hline 75 & $114 / 1$ & 6 & 5 & 9.00 & 15.86 & 229 & $191 / 1$ & 6 & 23 & 19.85 & 16.00 & 383 & $202 / 1$ & 6 & 5 & 13.04 & 15.19 & 537 & $221 / 1$ & 6 & 5 & 8.26 & 15.46 & 691 & $245 / 1$ & 6 & 23 & 13.00 & 16.41 \\
\hline 76 & $114 / 1$ & 6 & 18 & 9.00 & 15.73 & 230 & $191 / 1$ & 6 & 23 & 18.14 & 15.46 & 384 & $202 / 1$ & 6 & 23 & 15.12 & 15.59 & 538 & $221 / 1$ & 6 & 18 & 8.21 & 16.27 & 692 & $245 / 1$ & 6 & 5 & 13.00 & 16.68 \\
\hline 77 & $114 / 1$ & 6 & 18 & 9.00 & 16.00 & 231 & $191 / 1$ & 6 & 5 & 15.66 & 15.19 & 385 & $202 / 1$ & 6 & 23 & 15.40 & 16.13 & 539 & $221 / 1$ & 6 & 18 & 8.21 & 14.37 & 693 & $245 / 1$ & 6 & 5 & 13.00 & 16.95 \\
\hline 78 & $114 / 1$ & 6 & 0 & 11.00 & 15.73 & 232 & $191 / 1$ & 6 & 5 & 15.22 & 15.32 & 386 & $202 / 1$ & 6 & 5 & 12.83 & 15.46 & 540 & $221 / 1$ & 6 & 0 & 8.22 & 14.78 & 694 & $245 / 1$ & 6 & 5 & 13.00 & 16.81 \\
\hline 79 & $114 / 1$ & 6 & 5 & 9.00 & 15.86 & 233 & $191 / 1$ & 6 & 5 & 16.71 & 15.73 & 387 & $202 / 1$ & 6 & 5 & 12.25 & 15.32 & 541 & $221 / 1$ & 6 & 5 & 9.00 & 14.78 & 695 & $245 / 1$ & 6 & 20 & 13.00 & 16.54 \\
\hline 80 & $114 / 1$ & 6 & 23 & 9.00 & 15.73 & 234 & $191 / 1$ & 6 & 20 & 15.40 & 15.73 & 388 & $202 / 1$ & 6 & 5 & 16.00 & 15.46 & 542 & $221 / 1$ & 6 & 23 & 9.00 & 15.19 & 696 & $245 / 1$ & 6 & 18 & 13.00 & 17.08 \\
\hline 81 & $114 / 1$ & 6 & 23 & 15.00 & 16.00 & 235 & $191 / 1$ & 6 & 18 & 17.65 & 16.00 & 389 & $202 / 1$ & 6 & 20 & 15.59 & 15.46 & 543 & $221 / 1$ & 6 & 23 & 9.00 & 15.32 & 697 & $245 / 1$ & 6 & 20 & 13.00 & 16.81 \\
\hline 82 & $114 / 1$ & 6 & 5 & 16.00 & 15.86 & 236 & $191 / 1$ & 6 & 20 & 15.67 & 15.59 & 390 & $202 / 1$ & 6 & 18 & 15.21 & 15.86 & 544 & $221 / 1$ & 6 & 5 & 9.00 & 15.46 & 698 & $245 / 2$ & 6 & 5 & 11.00 & 15.86 \\
\hline 83 & $114 / 1$ & 6 & 18 & 18.00 & 16.13 & 237 & $191 / 1$ & 6 & 5 & 16.00 & 15.86 & 391 & $202 / 1$ & 6 & 20 & 15.85 & 15.73 & 545 & $221 / 1$ & 6 & 18 & 9.00 & 15.73 & 699 & $245 / 2$ & 6 & 23 & 11.00 & 16.27 \\
\hline 84 & $114 / 1$ & 6 & 18 & 20.00 & 16.00 & 238 & $191 / 1$ & 6 & 23 & 18.00 & 14.91 & 392 & $204 / 2$ & 6 & 5 & 15.26 & 16.13 & 546 & $221 / 1$ & 6 & 18 & 9.00 & 15.05 & 700 & $245 / 2$ & 6 & 23 & 9.00 & 16.13 \\
\hline 85 & $114 / 1$ & 6 & 0 & 8.00 & 15.73 & 239 & $191 / 1$ & 6 & 23 & 18.01 & 16.27 & 393 & $204 / 2$ & 6 & 23 & 15.65 & 15.86 & 547 & $221 / 1$ & 6 & 0 & 9.00 & 15.46 & 701 & $245 / 2$ & 6 & 5 & 13.00 & 16.27 \\
\hline 86 & $114 / 1$ & 6 & 5 & 18.00 & 15.32 & 240 & $191 / 1$ & 6 & 5 & 15.00 & 14.10 & 394 & $204 / 2$ & 6 & 23 & 15.49 & 16.13 & 548 & $222 / 1$ & 4 & 23 & 7.00 & 16.27 & 702 & $245 / 2$ & 6 & 5 & 13.00 & 16.13 \\
\hline 87 & $114 / 1$ & 6 & 23 & 17.00 & 15.73 & 241 & $191 / 1$ & 6 & 5 & 18.00 & 16.00 & 395 & $204 / 2$ & 6 & 5 & 15.68 & 15.19 & 549 & $222 / 1$ & 6 & 5 & 8.00 & 16.00 & 703 & $245 / 2$ & 6 & 5 & 11.00 & 16.27 \\
\hline 88 & $114 / 1$ & 6 & 23 & 19.00 & 16.13 & 242 & $191 / 1$ & 6 & 5 & 17.00 & 16.27 & 396 & $204 / 2$ & 6 & 5 & 16.00 & 14.10 & 550 & $222 / 1$ & 6 & 23 & 8.00 & 16.27 & 704 & $245 / 2$ & 6 & 20 & 9.00 & 15.73 \\
\hline 89 & $114 / 1$ & 6 & 5 & 18.00 & 15.19 & 243 & $191 / 1$ & 6 & 20 & 18.00 & 15.86 & 397 & $204 / 2$ & 6 & 5 & 15.63 & 15.86 & 551 & $222 / 1$ & 6 & 23 & 8.00 & 16.27 & 705 & $245 / 2$ & 6 & 18 & 11.00 & 16.27 \\
\hline 90 & $114 / 1$ & 6 & 18 & 17.00 & 15.32 & 244 & $191 / 1$ & 6 & 18 & 18.00 & 15.73 & 398 & $204 / 2$ & 6 & 20 & 16.57 & 15.46 & 552 & $222 / 1$ & 6 & 5 & 8.00 & 16.27 & 706 & $245 / 2$ & 6 & 20 & 11.00 & 16.68 \\
\hline 91 & $114 / 1$ & 6 & 18 & 19.00 & 16.00 & 245 & $191 / 1$ & 6 & 20 & 18.00 & 14.10 & 399 & $204 / 2$ & 6 & 18 & 15.28 & 14.91 & 553 & $222 / 1$ & 6 & 18 & 8.00 & 16.27 & 707 & $245 / 2$ & 6 & 5 & 11.00 & 16.54 \\
\hline 92 & $114 / 1$ & 6 & 0 & 19.99 & 16.00 & 246 & $191 / 1$ & 6 & 5 & 16.00 & 14.24 & 400 & $204 / 2$ & 6 & 20 & 15.00 & 15.32 & 554 & $222 / 1$ & 6 & 18 & 8.00 & 16.27 & 708 & $245 / 2$ & 6 & 23 & 11.00 & 16.81 \\
\hline 93 & $114 / 1$ & 6 & 5 & 9.00 & 15.59 & 247 & $191 / 1$ & 6 & 23 & 15.00 & 13.56 & 401 & $204 / 2$ & 6 & 5 & 15.00 & 14.78 & 555 & $222 / 1$ & 6 & 0 & 8.00 & 16.27 & 709 & $245 / 2$ & 6 & 23 & 10.95 & 16.68 \\
\hline 94 & $114 / 1$ & 6 & 23 & 20.00 & 16.00 & 248 & $191 / 1$ & 6 & 23 & 17.00 & 14.24 & 402 & $204 / 2$ & 6 & 23 & 17.00 & 13.56 & 556 & $222 / 1$ & 6 & 5 & 8.00 & 16.27 & 710 & $245 / 2$ & 6 & 5 & 11.00 & 16.54 \\
\hline 95 & $114 / 1$ & 6 & 23 & 19.00 & 16.27 & 249 & $191 / 1$ & 6 & 5 & 15.00 & 13.56 & 403 & $204 / 2$ & 6 & 23 & 16.00 & 15.46 & 557 & $222 / 1$ & 6 & 23 & 8.00 & 16.00 & 711 & $245 / 2$ & 6 & 5 & 11.00 & 16.95 \\
\hline 96 & $114 / 1$ & 6 & 5 & 16.92 & 14.78 & 250 & $191 / 1$ & 6 & 5 & 17.00 & 14.10 & 404 & $204 / 2$ & 6 & 5 & 13.00 & 15.19 & 558 & $222 / 1$ & 6 & 23 & 8.00 & 16.13 & 712 & $245 / 2$ & 6 & 5 & 10.95 & 16.68 \\
\hline 97 & $114 / 1$ & 6 & 18 & 18.00 & 14.51 & 251 & $191 / 1$ & 6 & 5 & 17.00 & 13.83 & 405 & $204 / 2$ & 6 & 5 & 13.00 & 14.91 & 559 & $222 / 1$ & 6 & 5 & 8.00 & 16.27 & 713 & $245 / 2$ & 6 & 20 & 11.00 & 16.81 \\
\hline 98 & $114 / 1$ & 6 & 18 & 23.00 & 13.15 & 252 & $191 / 1$ & 6 & 20 & 17.00 & 13.96 & 406 & $204 / 2$ & 6 & 5 & 13.00 & 15.05 & 560 & $222 / 1$ & 6 & 18 & 8.00 & 16.00 & 714 & $245 / 2$ & 6 & 18 & 11.00 & 16.54 \\
\hline 99 & $114 / 1$ & 6 & 0 & 17.00 & 16.27 & 253 & $191 / 1$ & 6 & 18 & 16.00 & 14.24 & 407 & $204 / 2$ & 6 & 20 & 16.00 & 15.46 & 561 & $222 / 1$ & 6 & 18 & 10.00 & 16.27 & 715 & $245 / 2$ & 6 & 20 & 11.00 & 16.54 \\
\hline 100 & $114 / 2$ & 6 & 5 & 17.98 & 16.00 & 254 & $191 / 1$ & 6 & 20 & 17.00 & 14.37 & 408 & $204 / 2$ & 6 & 18 & 16.00 & 14.78 & 562 & $222 / 1$ & 6 & 0 & 9.00 & 16.27 & 716 & $245 / 2$ & 6 & 5 & 11.00 & 16.00 \\
\hline 101 & $114 / 2$ & 6 & 23 & 21.00 & 16.00 & 255 & $191 / 1$ & 6 & 5 & 17.00 & 15.32 & 409 & $204 / 2$ & 6 & 20 & 17.00 & 15.32 & 563 & $222 / 1$ & 6 & 5 & 8.00 & 16.27 & 717 & $245 / 2$ & 6 & 23 & 10.95 & 16.68 \\
\hline 102 & $114 / 2$ & 6 & 23 & 18.00 & 15.86 & 256 & $191 / 1$ & 6 & 23 & 17.00 & 14.78 & 410 & $204 / 2$ & 6 & 5 & 16.00 & 13.56 & 564 & $222 / 1$ & 6 & 23 & 8.00 & 16.00 & 718 & $245 / 2$ & 6 & 23 & 11.00 & 16.81 \\
\hline
\end{tabular}




\begin{tabular}{|c|c|c|c|c|c|c|c|c|c|c|c|c|c|c|c|c|c|c|c|c|c|c|c|c|c|c|c|c|c|}
\hline Estaca & Torre & $\begin{array}{c}\text { No. } \\
\text { hélices }\end{array}$ & i( $(\circ)$ & $\mathrm{L}(\mathrm{m})$ & 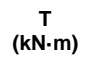 & Estaca & Torre & $\begin{array}{c}\text { No. } \\
\text { hélices }\end{array}$ & i( $(\stackrel{9}{)}$ & $\mathrm{L}(\mathrm{m})$ & $\begin{array}{c}\mathrm{T} \\
(\mathrm{kN} \cdot \mathrm{m})\end{array}$ & Estaca & Torre & $\begin{array}{c}\text { No. } \\
\text { hélices }\end{array}$ & $i\left({ }^{\circ}\right)$ & $\mathrm{L}(\mathrm{m})$ & $\begin{array}{c}\mathrm{\top} \\
(\mathrm{kN} \cdot \mathrm{m})\end{array}$ & Estaca & Torre & $\begin{array}{c}\text { No. } \\
\text { hélices }\end{array}$ & 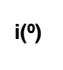 & $\mathrm{L}(\mathrm{m})$ & $\stackrel{\mathrm{T}}{\mathrm{T}}$ & Estaca & Torre & $\begin{array}{c}\text { No. } \\
\text { hélices }\end{array}$ & i(皁) & $L(m)$ & $\begin{array}{c}\mathrm{T} \\
(\mathrm{kN} \cdot \mathrm{m})\end{array}$ \\
\hline 103 & $114 / 2$ & 6 & 5 & 14.00 & 16.13 & 257 & $191 / 1$ & 6 & 23 & 18.00 & 15.32 & 411 & $204 / 2$ & 6 & 23 & 16.00 & 13.83 & 565 & $222 / 1$ & 6 & 23 & 8.00 & 15.59 & 719 & $245 / 2$ & 6 & 5 & 11.00 & 16.54 \\
\hline 104 & $114 / 2$ & 6 & 5 & 20.00 & 6.00 & 258 & $191 / 1$ & 6 & 5 & 15.00 & 14.78 & 412 & 204/2 & 6 & 23 & 16.00 & 14.78 & 566 & 222/1 & 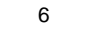 & 5 & 8.00 & 16.27 & 720 & 245/2 & 6 & 5 & 11.00 & 16.41 \\
\hline 105 & $114 / 2$ & 6 & 5 & 19.00 & 16.00 & 259 & $191 / 1$ & 6 & 5 & 14.00 & 15.32 & 413 & 204/2 & 6 & 5 & 15.00 & 15.05 & 567 & $222 / 1$ & 0 & 18 & 8.00 & 15.86 & 721 & $245 / 2$ & 6 & 5 & 10.95 & 17.22 \\
\hline 106 & $114 / 2$ & 6 & 20 & 19.00 & 16.13 & 260 & $191 / 1$ & 6 & 5 & 15.00 & 14.78 & 414 & $204 / 2$ & 6 & 5 & 16.00 & 13.83 & 568 & $222 / 1$ & 6 & 18 & 8.00 & 15.32 & 722 & $245 / 2$ & 6 & 20 & 11.00 & 16.00 \\
\hline 107 & $114 / 2$ & 6 & 18 & 19.00 & 16.00 & 261 & $191 / 1$ & 6 & 20 & 17.00 & 15.05 & 415 & $204 / 2$ & 6 & 5 & 15.00 & 14.78 & 569 & $222 / 1$ & 6 & 0 & 8.00 & 15.73 & 723 & $245 / 2$ & 6 & 18 & 11.00 & 16.13 \\
\hline 108 & $114 / 2$ & 6 & 20 & 16.00 & 16.13 & 262 & $191 / 1$ & 6 & 18 & 18.00 & 14.91 & 416 & $204 / 2$ & 6 & 20 & 17.00 & 15.05 & 570 & $223 / 1$ & 4 & 5 & 8.00 & 16.13 & 724 & $245 / 2$ & 6 & 20 & 11.00 & 16.68 \\
\hline 109 & $114 / 2$ & 6 & 5 & 21.00 & 16.00 & 263 & $191 / 1$ & 6 & 20 & 17.00 & 15.19 & 417 & $204 / 2$ & 6 & 18 & 16.00 & 13.69 & 571 & $223 / 1$ & 6 & 23 & 8.00 & 16.27 & 725 & $245 / 2$ & 6 & 5 & 9.00 & 16.27 \\
\hline 110 & $114 / 2$ & 6 & 23 & 19.00 & 15.73 & 264 & 199/2 & 6 & 5 & 16.36 & 16.00 & 418 & $204 / 2$ & 6 & 20 & 15.00 & 15.32 & 572 & $223 / 1$ & 4 & 23 & 8.00 & 16.27 & 726 & $245 / 2$ & 6 & 23 & 9.00 & 15.86 \\
\hline 111 & $114 / 2$ & 6 & 23 & 15.00 & 16.00 & 265 & 199/2 & 6 & 23 & 16.13 & 14.64 & 419 & $204 / 2$ & 6 & 5 & 14.93 & 15.59 & 573 & $223 / 1$ & 4 & 5 & 8.00 & 16.00 & 727 & $245 / 2$ & 6 & 23 & 9.00 & 16.00 \\
\hline 112 & $114 / 2$ & 6 & 5 & 16.00 & 16.13 & 266 & 199/2 & 6 & 23 & 18.66 & 16.00 & 420 & 204/2 & 6 & 23 & 15.56 & 15.46 & 574 & $223 / 1$ & 4 & 18 & 8.00 & 16.13 & 728 & $245 / 2$ & 6 & 5 & 10.00 & 16.27 \\
\hline 113 & $114 / 2$ & 6 & 5 & 17.00 & 16.13 & 267 & $199 / 2$ & 6 & 5 & 16.13 & 14.64 & 421 & $204 / 2$ & 6 & 23 & 15.53 & 16.00 & 575 & $223 / 1$ & 4 & 18 & 8.00 & 16.27 & 729 & $245 / 2$ & 6 & 5 & 9.00 & 15.86 \\
\hline 114 & $114 / 2$ & 6 & 5 & 21.85 & 15.86 & 268 & $199 / 2$ & 6 & 18 & 13.05 & 14.24 & 422 & $204 / 2$ & 6 & 5 & 16.00 & 14.51 & 576 & $223 / 1$ & 4 & 0 & 8.00 & 16.00 & 730 & $245 / 2$ & 6 & 5 & 9.00 & 16.13 \\
\hline 115 & $114 / 2$ & 6 & 20 & 16.00 & 16.00 & 269 & $199 / 2$ & 6 & 18 & 17.25 & 16.13 & 423 & $204 / 2$ & 6 & 5 & 15.43 & 15.32 & 577 & $223 / 1$ & 6 & 5 & 9.00 & 16.00 & 731 & $245 / 2$ & 6 & 20 & 9.00 & 16.27 \\
\hline 116 & $114 / 2$ & 6 & 18 & 21.00 & 16.54 & 270 & 199/2 & 6 & 0 & 14.49 & 16.00 & 424 & $204 / 2$ & 6 & 5 & 15.69 & 15.46 & 578 & $223 / 1$ & 6 & 23 & 8.00 & 16.13 & 732 & $245 / 2$ & 6 & 18 & 9.00 & 16.27 \\
\hline 117 & $114 / 2$ & 6 & 20 & 17.00 & 15.73 & 271 & 199/2 & 6 & 5 & 18.00 & 16.13 & 425 & $204 / 2$ & 6 & 20 & 15.06 & 14.64 & 579 & $223 / 1$ & 6 & 23 & 8.00 & 16.00 & 733 & $245 / 2$ & 6 & 20 & 9.00 & 16.13 \\
\hline 118 & $114 / 2$ & 6 & 5 & 18.00 & 15.46 & 272 & 199/2 & 6 & 23 & 18.00 & 15.32 & 426 & $204 / 2$ & 6 & 20 & 15.00 & 15.86 & 580 & $223 / 1$ & 4 & 5 & 8.00 & 16.27 & 734 & $246 / 1$ & 6 & 5 & 9.00 & 16.27 \\
\hline 119 & $114 / 2$ & 6 & 23 & 16.00 & 16.00 & 273 & $199 / 2$ & 6 & 23 & 16.00 & 14.37 & 427 & $204 / 2$ & 6 & 18 & 16.00 & 14.64 & 581 & $223 / 1$ & 4 & 18 & 7.00 & 16.13 & 735 & $246 / 1$ & 6 & 23 & 13.00 & 16.13 \\
\hline 120 & $114 / 2$ & 6 & 23 & 20.00 & 15.73 & 274 & 199/2 & 6 & 5 & 18.00 & 14.64 & 428 & $205 / 2$ & 6 & 5 & 9.00 & 15.73 & 582 & $223 / 1$ & 4 & 18 & 8.00 & 16.27 & 736 & $246 / 1$ & 6 & 23 & 9.00 & 15.46 \\
\hline 121 & $114 / 2$ & 6 & 5 & 18.00 & 16.27 & 275 & 199/2 & 6 & 18 & 18.00 & 15.46 & 429 & $205 / 2$ & 6 & 23 & 13.00 & 16.00 & 583 & $223 / 1$ & 4 & 0 & 7.00 & 16.00 & 737 & $246 / 1$ & 6 & 5 & 10.00 & 16.27 \\
\hline 122 & $114 / 2$ & 6 & 5 & 18.00 & 15.19 & 276 & $199 / 2$ & 6 & 18 & 18.00 & 15.19 & 430 & $205 / 2$ & 6 & 23 & 11.00 & 16.13 & 584 & $223 / 1$ & 4 & 5 & 8.00 & 16.00 & 738 & $246 / 1$ & 6 & 5 & 11.00 & 16.13 \\
\hline 123 & $114 / 2$ & 6 & 5 & 20.00 & 15.46 & 277 & 199/2 & 6 & 0 & 16.00 & 13.69 & 431 & 205/2 & 6 & 5 & 13.00 & 15.73 & 585 & $223 / 1$ & 6 & 23 & 8.00 & 16.27 & 739 & $246 / 1$ & 6 & 5 & 9.00 & 16.27 \\
\hline 124 & $114 / 2$ & 6 & 20 & 22.00 & 16.00 & 278 & 199/2 & 6 & 5 & 16.25 & 15.32 & 432 & 205/2 & 6 & 5 & 10.00 & 15.86 & 586 & $223 / 1$ & 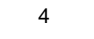 & 23 & 7.00 & 16.13 & 740 & $246 / 1$ & 6 & 20 & 14.00 & 16.13 \\
\hline 125 & $114 / 2$ & 6 & 18 & 22.00 & 15.86 & 279 & 199/2 & 6 & 23 & 18.00 & 15.73 & 433 & $205 / 2$ & 6 & 5 & 10.00 & 15.86 & 587 & $223 / 1$ & 4 & 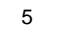 & 8.00 & 16.27 & 741 & $246 / 1$ & 6 & 18 & 12.00 & 15.73 \\
\hline 126 & $114 / 2$ & 6 & 20 & 18.00 & 15.59 & 280 & 199/2 & 6 & 23 & 18.00 & 14.64 & 434 & $205 / 2$ & 6 & 20 & 15.00 & 15.73 & 588 & $223 / 1$ & 4 & 18 & 7.00 & 15.73 & 742 & $246 / 1$ & 6 & 20 & 10.73 & 16.81 \\
\hline 127 & $114 / 2$ & 6 & 5 & 16.00 & 16.54 & 281 & $199 / 2$ & 6 & 5 & 18.00 & 15.73 & 435 & $205 / 2$ & 6 & 18 & 9.00 & 16.13 & 589 & $223 / 1$ & 4 & 18 & 7.00 & 16.27 & 743 & $246 / 1$ & 6 & 5 & 11.00 & 16.54 \\
\hline 128 & $114 / 2$ & 6 & 23 & 16.00 & 15.59 & 282 & 199/2 & 6 & 18 & 18.00 & 14.78 & 436 & $205 / 2$ & 6 & 20 & 13.69 & 14.24 & 590 & $223 / 1$ & 6 & 0 & 12.00 & 16.00 & 744 & $246 / 1$ & 6 & 23 & 11.00 & 16.00 \\
\hline 129 & $114 / 2$ & 6 & 23 & 16.00 & 16.00 & 283 & 199/2 & 6 & 18 & 18.00 & 15.19 & 437 & $205 / 2$ & 6 & 5 & 11.00 & 15.86 & 591 & $223 / 1$ & 6 & 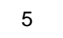 & 8.00 & 16.13 & 745 & $246 / 1$ & 6 & 23 & 11.00 & 16.68 \\
\hline 130 & $114 / 2$ & 6 & 5 & 16.00 & 16.27 & 284 & 199/2 & 6 & 0 & 17.00 & 14.78 & 438 & 205/2 & 6 & 23 & 13.00 & 16.13 & 592 & $223 / 1$ & 6 & 23 & 8.00 & 15.73 & 746 & $246 / 1$ & 6 & 5 & 11.00 & 16.81 \\
\hline 131 & $114 / 2$ & 6 & 5 & 15.00 & 15.46 & 285 & $199 / 2$ & 6 & 5 & 13.22 & 13.83 & 439 & $205 / 2$ & 6 & 23 & 6.78 & 16.00 & 593 & $223 / 1$ & 6 & 23 & 8.00 & 16.00 & 747 & $246 / 1$ & 6 & 5 & 11.00 & 16.54 \\
\hline 132 & $114 / 2$ & 6 & 5 & 16.00 & 15.73 & 286 & $199 / 2$ & 6 & 23 & 17.52 & 15.46 & 440 & $205 / 2$ & 6 & 5 & 8.85 & 16.00 & 594 & $223 / 1$ & 6 & 5 & 8.00 & 15.73 & 748 & $246 / 1$ & 6 & 5 & 11.00 & 16.68 \\
\hline 133 & $114 / 2$ & 6 & 20 & 16.00 & 15.19 & 287 & $199 / 2$ & 6 & 23 & 15.55 & 15.32 & 441 & $205 / 2$ & 6 & 5 & 13.00 & 15.73 & 595 & $223 / 1$ & 6 & 18 & 8.00 & 16.00 & 749 & $246 / 1$ & 6 & 20 & 11.00 & 16.13 \\
\hline 134 & $114 / 2$ & 6 & 18 & 16.00 & 15.05 & 288 & 199/2 & 6 & 5 & 15.66 & 15.86 & 442 & $205 / 2$ & 6 & 5 & 11.00 & 16.00 & 596 & $223 / 1$ & 0 & 18 & 8.00 & 15.86 & 750 & $246 / 1$ & 6 & 18 & 11.00 & 16.00 \\
\hline 135 & $114 / 2$ & 6 & 20 & 15.00 & 15.86 & 289 & $199 / 2$ & 6 & 18 & 15.31 & 14.51 & 443 & $205 / 2$ & 6 & 20 & 9.00 & 15.73 & 597 & $223 / 1$ & 6 & 0 & 8.00 & 15.73 & 751 & $246 / 1$ & 6 & 20 & 11.00 & 16.13 \\
\hline 136 & $137 / 2$ & 6 & 5 & 8.00 & 14.37 & 290 & 199/2 & 6 & 18 & 15.53 & 14.37 & 444 & 205/2 & 6 & 18 & 11.00 & 15.86 & 598 & $226 / 1$ & 6 & 5 & 8.00 & 15.86 & 752 & $246 / 1$ & 6 & 5 & 11.00 & 16.54 \\
\hline 137 & $137 / 2$ & 6 & 23 & 9.00 & 14.51 & 291 & $199 / 2$ & 6 & 0 & 15.55 & 16.13 & 445 & $205 / 2$ & 6 & 20 & 9.00 & 16.13 & 599 & $226 / 1$ & 6 & 23 & 11.00 & 16.00 & 753 & $246 / 1$ & 6 & 23 & 11.00 & 15.73 \\
\hline 138 & 137/2 & 6 & 23 & 18.00 & 14.78 & 292 & $200 / 1$ & 6 & 5 & 13.36 & 14.91 & 446 & 205/2 & 6 & 5 & 8.82 & 14.37 & 600 & $226 / 1$ & 6 & 23 & 11.00 & 16.13 & 754 & $246 / 1$ & 6 & 23 & 11.00 & 17.49 \\
\hline
\end{tabular}

(continuação) 


\begin{tabular}{|c|c|c|c|c|c|c|c|c|c|c|c|c|c|c|c|c|c|c|c|c|c|c|c|c|c|c|c|c|c|}
\hline Estaca & Torre & $\begin{array}{c}\text { No. } \\
\text { hélices }\end{array}$ & $i\left({ }^{\circ}\right)$ & $L(m)$ & $\stackrel{\mathrm{T}}{\mathrm{T} \cdot \mathrm{k} \cdot \mathrm{m})}$ & Estaca & Torre & $\begin{array}{c}\text { No. } \\
\text { hélices }\end{array}$ & $i\left({ }^{\circ}\right)$ & $L(m)$ & $\begin{array}{c}\mathrm{T} \\
(\mathrm{kN} \cdot \mathrm{m})\end{array}$ & Estaca & Torre & $\begin{array}{c}\text { No. } \\
\text { hélices }\end{array}$ & $i(\stackrel{\circ}{)}$ & $L(m)$ & $\begin{array}{c}\mathrm{T} \\
(\mathbf{k N} \cdot \mathbf{m})\end{array}$ & Estaca & Torre & $\begin{array}{c}\text { No. } \\
\text { hélices }\end{array}$ & $i\left({ }^{\circ}\right)$ & $L(m)$ & $\begin{array}{c}\mathrm{T} \\
(\mathbf{k N} \cdot \mathbf{m})\end{array}$ & Estaca & Torre & $\begin{array}{c}\text { No. } \\
\text { hélices }\end{array}$ & $i\left({ }^{\circ}\right)$ & $L(m)$ & 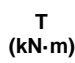 \\
\hline 139 & $137 / 2$ & 6 & 5 & 8.00 & 14.64 & 293 & $200 / 1$ & 6 & 23 & 15.64 & 15.59 & 447 & $205 / 2$ & 6 & 23 & 13.38 & 15.73 & 601 & $226 / 1$ & 6 & 5 & 8.00 & 15.73 & 755 & $246 / 1$ & 6 & 5 & 11.00 & 16.68 \\
\hline 140 & $137 / 2$ & 6 & 5 & 15.00 & 14.51 & 294 & $200 / 1$ & 6 & 23 & 15.78 & 15.46 & 448 & $205 / 2$ & 6 & 23 & 8.92 & 15.46 & 602 & $226 / 1$ & 6 & 18 & 11.00 & 16.00 & 756 & $246 / 1$ & 6 & 5 & 11.00 & 16.00 \\
\hline 141 & $137 / 2$ & 6 & 5 & 8.00 & 14.24 & 295 & $200 / 1$ & 6 & 5 & 15.09 & 15.32 & 449 & $205 / 2$ & 6 & 5 & 14.56 & 16.00 & 603 & $226 / 1$ & 6 & 18 & 12.00 & 15.86 & 757 & $246 / 1$ & 6 & 5 & 11.00 & 16.13 \\
\hline 142 & $137 / 2$ & 6 & 20 & 8.00 & 14.51 & 296 & $200 / 1$ & 6 & 18 & 14.41 & 14.78 & 450 & $205 / 2$ & 6 & 5 & 14.04 & 16.00 & 604 & $226 / 1$ & 6 & 0 & 8.00 & 16.13 & 758 & $246 / 1$ & 6 & 20 & 11.00 & 16.54 \\
\hline 143 & $137 / 2$ & 6 & 18 & 8.00 & 14.37 & 297 & $200 / 1$ & 6 & 18 & 13.56 & 15.19 & 451 & $205 / 2$ & 6 & 5 & 14.84 & 16.13 & 605 & $226 / 1$ & 6 & 5 & 13.00 & 16.13 & 759 & $246 / 1$ & 6 & 18 & 11.00 & 16.00 \\
\hline 144 & $137 / 2$ & 6 & 20 & 8.00 & 14.78 & 298 & $200 / 1$ & 6 & 0 & 13.36 & 15.32 & 452 & $205 / 2$ & 6 & 20 & 15.37 & 16.27 & 606 & $226 / 1$ & 6 & 23 & 10.99 & 15.86 & 760 & $246 / 1$ & 6 & 20 & 11.00 & 16.81 \\
\hline 145 & $137 / 2$ & 6 & 20 & 10.00 & 15.32 & 299 & $200 / 1$ & 6 & 5 & 16.00 & 15.46 & 453 & $205 / 2$ & 6 & 18 & 13.92 & 15.59 & 607 & $226 / 1$ & 6 & 23 & 11.00 & 15.73 & 761 & $246 / 1$ & 6 & 5 & 9.00 & 17.49 \\
\hline 146 & $137 / 2$ & 6 & 20 & 15.00 & 14.91 & 300 & $200 / 1$ & 6 & 23 & 15.00 & 15.05 & 454 & $205 / 2$ & 6 & 20 & 13.10 & 14.24 & 608 & $226 / 1$ & 6 & 5 & 11.00 & 16.13 & 762 & $246 / 1$ & 6 & 23 & 9.00 & 15.86 \\
\hline 147 & $137 / 2$ & 6 & 20 & 9.00 & 15.86 & 301 & $200 / 1$ & 6 & 23 & 15.00 & 15.05 & 455 & $205 / 2$ & 6 & 5 & 11.22 & 16.13 & 609 & $226 / 1$ & 6 & 18 & 15.00 & 15.86 & 763 & $246 / 1$ & 6 & 23 & 9.00 & 16.00 \\
\hline 148 & $137 / 2$ & 6 & 20 & 8.00 & 16.27 & 302 & $200 / 1$ & 6 & 5 & 14.00 & 15.19 & 456 & $205 / 2$ & 6 & 23 & 16.35 & 14.64 & 610 & $226 / 1$ & 6 & 18 & 12.00 & 16.13 & 764 & $246 / 1$ & 6 & 5 & 9.00 & 16.27 \\
\hline 149 & $137 / 2$ & 6 & 20 & 9.00 & 16.00 & 303 & $200 / 1$ & 6 & 18 & 15.00 & 14.78 & 457 & $205 / 2$ & 6 & 23 & 13.81 & 14.10 & 611 & $226 / 1$ & 6 & 0 & 13.00 & 16.00 & 765 & $246 / 1$ & 6 & 5 & 11.00 & 16.13 \\
\hline 150 & $137 / 2$ & 6 & 20 & 8.00 & 15.73 & 304 & $200 / 1$ & 6 & 18 & 16.00 & 14.91 & 458 & $205 / 2$ & 6 & 5 & 12.69 & 15.59 & 612 & $226 / 1$ & 6 & 5 & 12.81 & 16.27 & 766 & $246 / 1$ & 6 & 5 & 9.00 & 15.73 \\
\hline 151 & $137 / 2$ & 6 & 20 & 9.00 & 15.73 & 305 & $200 / 1$ & 6 & 0 & 15.00 & 14.91 & 459 & $205 / 2$ & 6 & 5 & 14.87 & 14.91 & 613 & $226 / 1$ & 6 & 23 & 14.02 & 14.64 & 767 & $246 / 1$ & 6 & 20 & 11.00 & 16.27 \\
\hline 152 & $137 / 2$ & 6 & 20 & 8.00 & 15.86 & 306 & $200 / 1$ & 6 & 5 & 14.08 & 15.86 & 460 & $205 / 2$ & 6 & 5 & 8.39 & 14.78 & 614 & $226 / 1$ & 6 & 23 & 13.22 & 15.46 & 768 & $246 / 1$ & 6 & 18 & 9.00 & 16.13 \\
\hline 153 & $137 / 2$ & 6 & 20 & 9.00 & 16.13 & 307 & $200 / 1$ & 6 & 23 & 16.00 & 14.78 & 461 & $205 / 2$ & 6 & 20 & 13.89 & 15.46 & 615 & $226 / 1$ & 6 & 5 & 11.03 & 16.00 & 769 & $246 / 1$ & 6 & 20 & 9.00 & 16.27 \\
\hline 154 & $137 / 2$ & 6 & 20 & 8.00 & 14.51 & 308 & $200 / 1$ & 6 & 23 & 15.59 & 15.19 & 462 & $205 / 2$ & 6 & 18 & 9.02 & 15.73 & 616 & $226 / 1$ & 6 & 18 & 14.97 & 14.37 & & & & & & \\
\hline
\end{tabular}

\section{(conclusão)}


APÊNDICE C - Resumo dos resultados das análises de regressão e das correções do erro de modelo

Tabela 11 - Resumo dos resultados das análises de regressão e das correções do erro de modelo para 769 estacas e $\delta_{r}=20^{\circ}$

\begin{tabular}{|c|c|c|c|c|c|c|}
\hline & $X_{s 1}$ & $X_{\mathrm{s} 2}$ & $X_{\mathrm{s} 3}$ & $X_{s 3,2}$ & $X_{s 3,3}$ & $X_{s 4}$ \\
\hline \multicolumn{7}{|c|}{ Estatísticas de regressão } \\
\hline $\mathrm{R}^{2}$ & 0,80 & 0,90 & 0,82 & 0,86 & 0,87 & 0,79 \\
\hline Erro padrão & 7,10 & 5,02 & 6,62 & 5,79 & 5,56 & 7,16 \\
\hline \multicolumn{7}{|c|}{ Coeficientes de regressão } \\
\hline$\alpha_{s}$ & 2,16 & 15,58 & 11,06 & 13,98 & 15,11 & $-0,46$ \\
\hline$\alpha_{h, p}$ & 119,43 & 3,15 & 66,96 & 37,65 & 18,46 & 116,35 \\
\hline$\alpha_{\mathrm{h}, \mathrm{int}}$ & 51,76 & 42,24 & 61,03 & 22,00 & 44,34 & 59,71 \\
\hline$a_{h, \text { sup }}$ & 7,02 & $-7,24$ & 5,26 & 59,30 & - & 23,49 \\
\hline \multicolumn{7}{|c|}{ Correções } \\
\hline 1a correção & $\begin{array}{c}\mathrm{C} 1(\mathrm{~N} 1)=-0,1182 \times(\mathrm{N} 1)+ \\
2,7784\end{array}$ & $\begin{array}{c}\mathrm{C} 1(\mathrm{~L})=-0,1072 \times(\mathrm{L})+ \\
2,5907\end{array}$ & $\begin{array}{c}\mathrm{C} 1(\mathrm{~N} 1)=-0,0893 \times(\mathrm{N} 1)+ \\
2,4049\end{array}$ & $\begin{array}{c}C 1(L)=-0,1047 x(L)+ \\
2,6153\end{array}$ & $\mathrm{C} 1(\mathrm{~L})=-0,114 \times(\mathrm{L})+2,7318$ & $\begin{array}{c}\mathrm{C} 1(\mathrm{~N} 1)=-0,1265 \times(\mathrm{N} 1)+ \\
2,8887\end{array}$ \\
\hline $\begin{array}{l}\mathrm{R}^{2} \\
2^{\underline{a}} \text { correção }\end{array}$ & 0,71 & $\begin{array}{c}0,75 \\
\mathrm{C} 2(\mathrm{~N} 1)=-0,0201 \times(\mathrm{N} 1)+ \\
1,2291\end{array}$ & $\begin{array}{c}0,56 \\
C 2(L)=-0,0412 \times(L)+1,541\end{array}$ & $\begin{array}{c}0,57 \\
\mathrm{C} 2(\mathrm{~N} 1)^{*}=-0,0359 \times(\mathrm{N} 1)+ \\
1,4112\end{array}$ & $\begin{array}{c}0,66 \\
\mathrm{C} 2(\mathrm{~N} 1)=-0,0288 \times(\mathrm{N} 1)+ \\
1,3344\end{array}$ & $\begin{array}{l}0,68 \\
-\end{array}$ \\
\hline $\mathrm{R}^{2}$ & - & 0,39 & 0,28 & 0,54 & 0,45 & - \\
\hline \multicolumn{7}{|c|}{ Estatísticas do erro de modelo antes da primeira correção } \\
\hline Média & 1,419 & 1,253 & 1,380 & 1,292 & 1,291 & 1,449 \\
\hline Desvio padrão & 0,624 & 0,449 & 0,613 & 0,501 & 0,510 & 0,692 \\
\hline $\begin{array}{l}\text { Coeficiente de } \\
\text { variação }\end{array}$ & 0,440 & 0,358 & 0,444 & 0,388 & 0,345 & 0,477 \\
\hline $\begin{array}{l}\mathrm{n} \cap 0 \text { de estacas } \\
\text { (sem outliers) }\end{array}$ & 666 & 759 & 721 & 728 & 746 & 677 \\
\hline \multicolumn{7}{|c|}{ Estatísticas do erro de modelo depois das correções } \\
\hline Média & 1,018 & 1,001 & 1,000 & 1,002 & 1,001 & 1,032 \\
\hline $\begin{array}{l}\text { Desvio padrão } \\
\text { (DP) }\end{array}$ & 0,242 & 0,137 & 0,253 & 0,166 & 0,179 & 0,291 \\
\hline $\begin{array}{l}\text { Coeficiente de } \\
\text { variação }(C V)\end{array}$ & 0,238 & 0,137 & 0,253 & 0,165 & 0,178 & 0,282 \\
\hline $\begin{array}{l}\mathrm{n}{ }^{\circ} \text { de estacas } \\
\text { (sem outliers) }\end{array}$ & 666 & 759 & 721 & 728 & 746 & 677 \\
\hline
\end{tabular}


Tabela 12 - Resumo dos resultados das análises de regressão e das correções do erro de modelo para 769 estacas e $\delta_{r}=29^{\circ}$

\begin{tabular}{|c|c|c|c|c|c|c|}
\hline & $X_{s 1}$ & $X_{s 2}$ & $X_{s 3}$ & $X_{s 3,2}$ & $X_{s 3,3}$ & $X_{s 4}$ \\
\hline \multicolumn{7}{|c|}{ Estatísticas de regressão } \\
\hline $\mathrm{R}^{2}$ & 0,79 & 0,90 & 0,82 & 0,86 & 0,87 & 0,79 \\
\hline Erro padrão & 7,13 & 5,02 & 6,62 & 5,81 & 5,57 & 7,20 \\
\hline \multicolumn{7}{|c|}{ Coeficientes de regressão } \\
\hline$\alpha_{\mathrm{s}}$ & 2,40 & 15,67 & 11,43 & 14,11 & 15,21 & $-0,19$ \\
\hline$\alpha_{\mathrm{h}, \mathrm{p}}$ & 84,07 & 1,75 & 45,57 & 25,50 & 12,19 & 81,70 \\
\hline$\alpha_{\mathrm{h}, \mathrm{int}}$ & 36,11 & 29,75 & 42,88 & 15,46 & 30,86 & 42,35 \\
\hline$a_{h, \text { sup }}$ & 3,43 & $-5,41$ & 3,18 & 41,00 & - & 15,24 \\
\hline \multicolumn{7}{|c|}{ Correções } \\
\hline $1^{\text {a }}$ correção & $\begin{array}{c}\mathrm{C} 1(\mathrm{~N} 1)=-0,1303 \times(\mathrm{N} 1) \\
+2,9514\end{array}$ & $\begin{array}{c}\mathrm{C} 1(\mathrm{~L})=-0,1079 \times(\mathrm{L})+ \\
2,5985\end{array}$ & $\begin{array}{c}\mathrm{C} 1(\mathrm{~N} 1)= \\
2,5006\end{array}$ & $\begin{array}{c}C 1(L)=-0,0926 \times(L)+ \\
2,4602\end{array}$ & $\begin{array}{c}\mathrm{C} 1(\mathrm{~L})=-0,1271 \times(\mathrm{L})+ \\
2,9304\end{array}$ & $\begin{array}{c}\mathrm{C} 1(\mathrm{~N} 1)=-0,1152 \times(\mathrm{N} 1)+ \\
2,7251\end{array}$ \\
\hline $\begin{array}{l}\mathrm{R}^{2} \\
2^{\mathrm{a}} \text { correção }\end{array}$ & $\begin{array}{c}0,72 \\
-\end{array}$ & $\begin{array}{c}0,75 \\
\mathrm{C} 2(\mathrm{~N} 1)=-0,0199 \times(\mathrm{N} 1)+ \\
1,2267\end{array}$ & $\begin{array}{c}0,51 \\
C 2(L)=-0,0373 \times(L)+1,3\end{array}$ & $\begin{array}{c}0,45 \\
\mathrm{C} 2(\mathrm{~N} 1)=-0,0287 \times(\mathrm{N} 1)+ \\
1,3293\end{array}$ & $\mathrm{C} 2(\mathrm{~N} 1)=\begin{array}{l}0,61 \\
-0,0313 \times(\mathrm{N} 1)+ \\
1,358\end{array}$ & $\begin{array}{c}0,69 \\
-\end{array}$ \\
\hline $\mathrm{R}^{2}$ & - & 0,40 & 0,31 & 0,26 & 0,41 & - \\
\hline \multicolumn{7}{|c|}{ Estatísticas do erro de modelo antes da primeira correção } \\
\hline Média & 1,487 & 1,250 & 1,465 & 1,285 & 1,344 & 1,391 \\
\hline $\begin{array}{l}\text { Desvio padrão } \\
\text { (DP) }\end{array}$ & 0,708 & 0,447 & 0,622 & 0,513 & 0,589 & 0,607 \\
\hline $\begin{array}{l}\text { Coeficiente de } \\
\text { variação }(C V)\end{array}$ & 0,476 & 0,358 & 0,424 & 0,400 & 0,439 & 0,437 \\
\hline $\begin{array}{l}\mathrm{n}^{\circ} \text { de estacas } \\
\text { (sem outliers) }\end{array}$ & 689 & 755 & 668 & 735 & 759 & 653 \\
\hline \multicolumn{7}{|c|}{ Estatísticas do erro de modelo depois das correções } \\
\hline Média & 1,032 & 1,001 & 1,192 & 1,000 & 1,002 & 1,019 \\
\hline $\begin{array}{l}\text { Desvio padrão } \\
\text { (DP) }\end{array}$ & 0,288 & 0,134 & 0,219 & 0,243 & 0,197 & 0,242 \\
\hline $\begin{array}{l}\text { Coeficiente de } \\
\text { variação }(\mathrm{CV})\end{array}$ & 0,279 & 0,133 & 0,184 & 0,243 & 0,197 & 0,237 \\
\hline $\begin{array}{l}\mathrm{n}^{\circ} \text { de estacas } \\
\text { (sem outliers) }\end{array}$ & 689 & 755 & 668 & 735 & 759 & 653 \\
\hline
\end{tabular}




\section{APÊNDICE D - Erros de modelo e correções}

Figura 27 - Erro de modelo $X_{s 1}$ e $\delta_{r}=20^{\circ}$

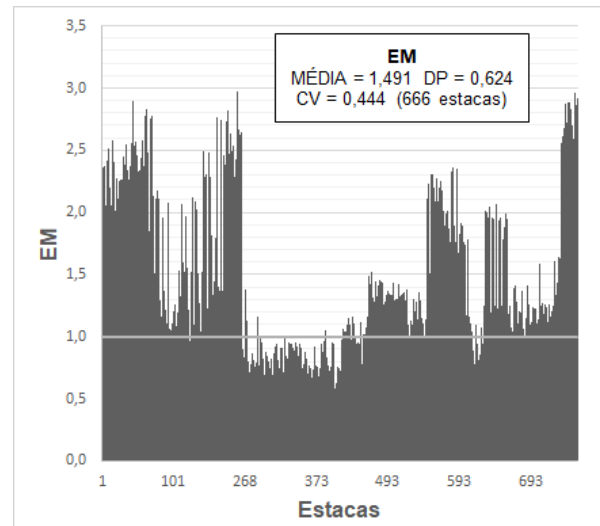

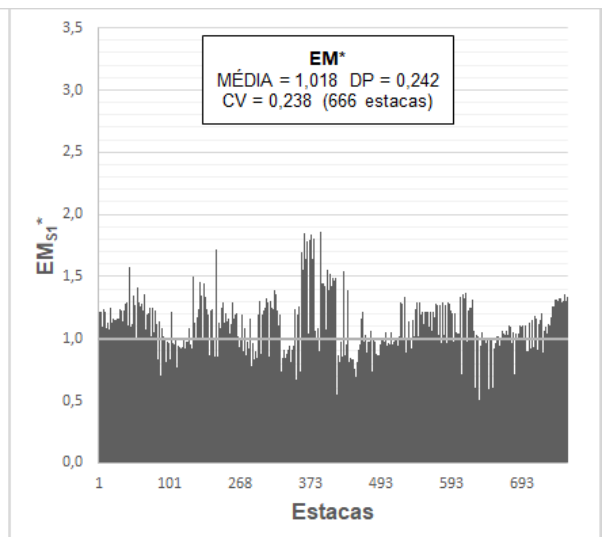

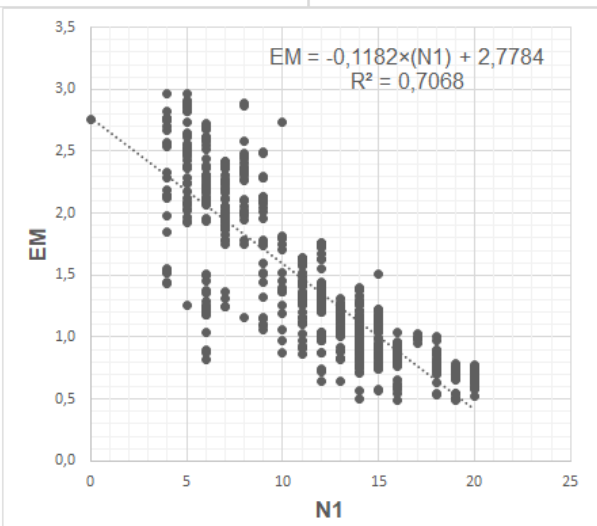

Fonte: do autor.

Figura 28 - Erro de modelo $X_{s 2}$ e $\delta_{r}=20^{\circ}$
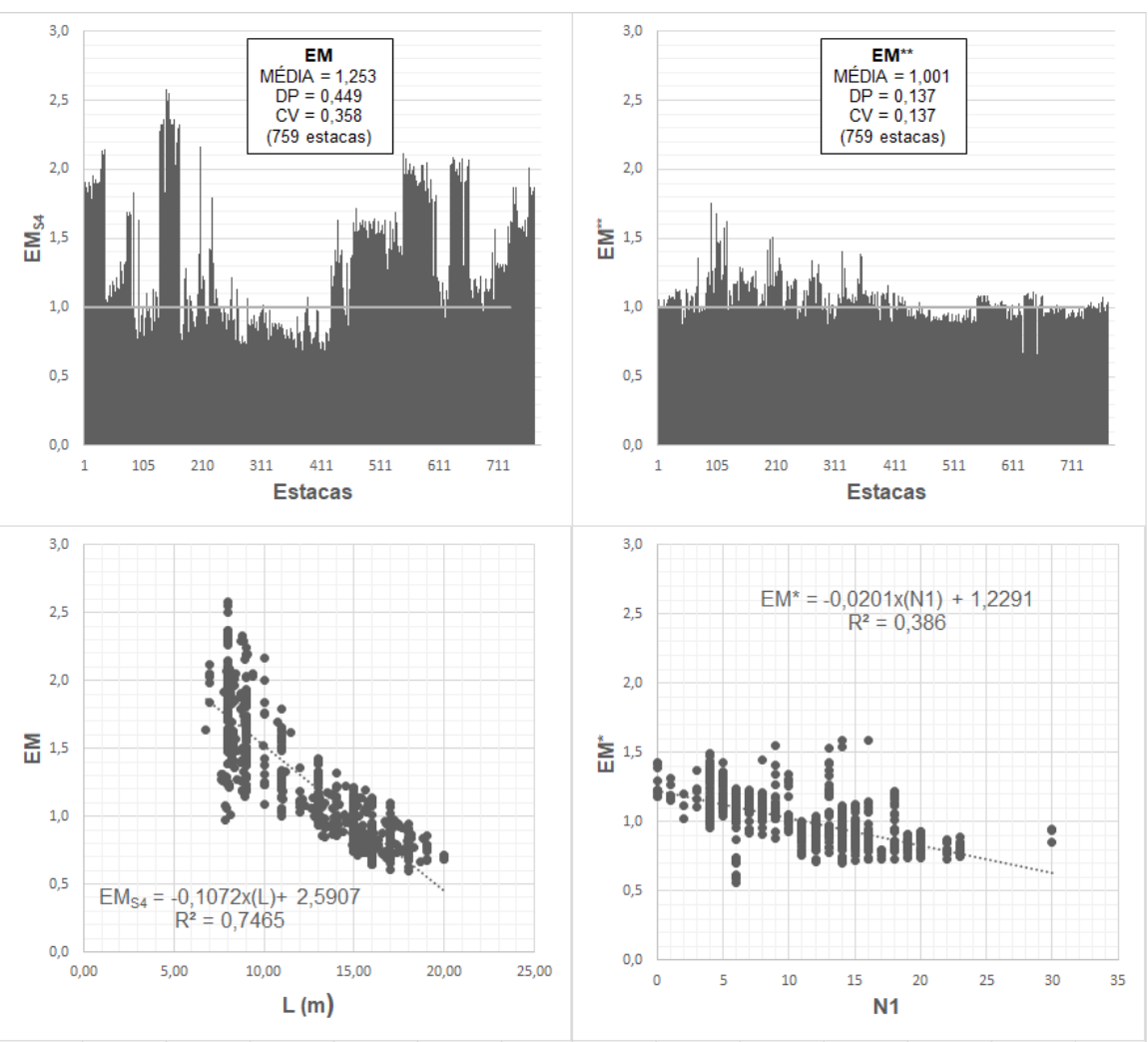

Fonte: do autor. 
Figura 29 - Erro de modelo $X_{s 3}$ e $\delta_{r}=20^{\circ}$
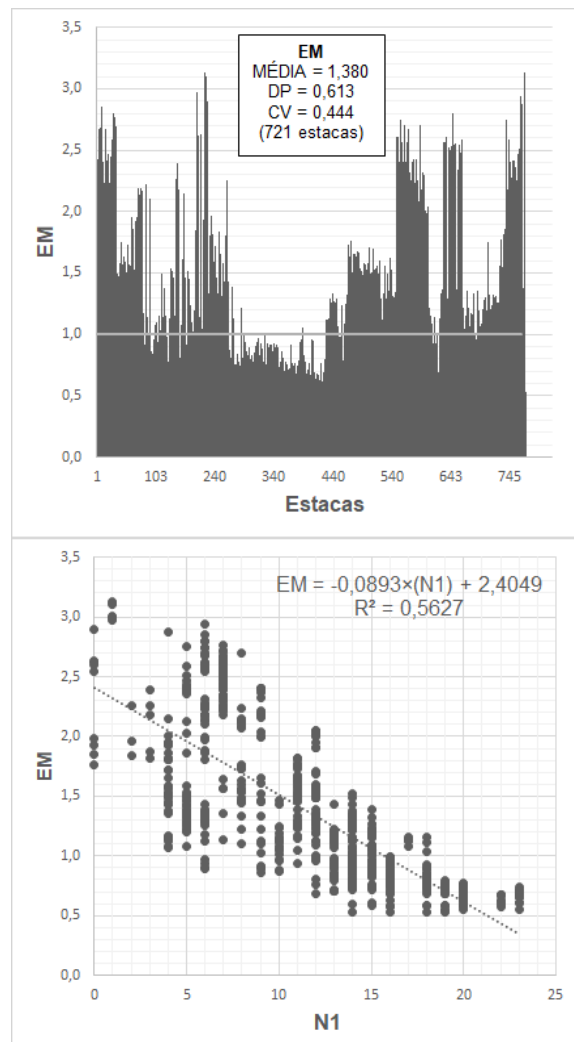

Fonte: do autor.
Figura 30 - Erro de modelo $X_{s 3,2}$ e $\delta_{r}=20^{\circ}$
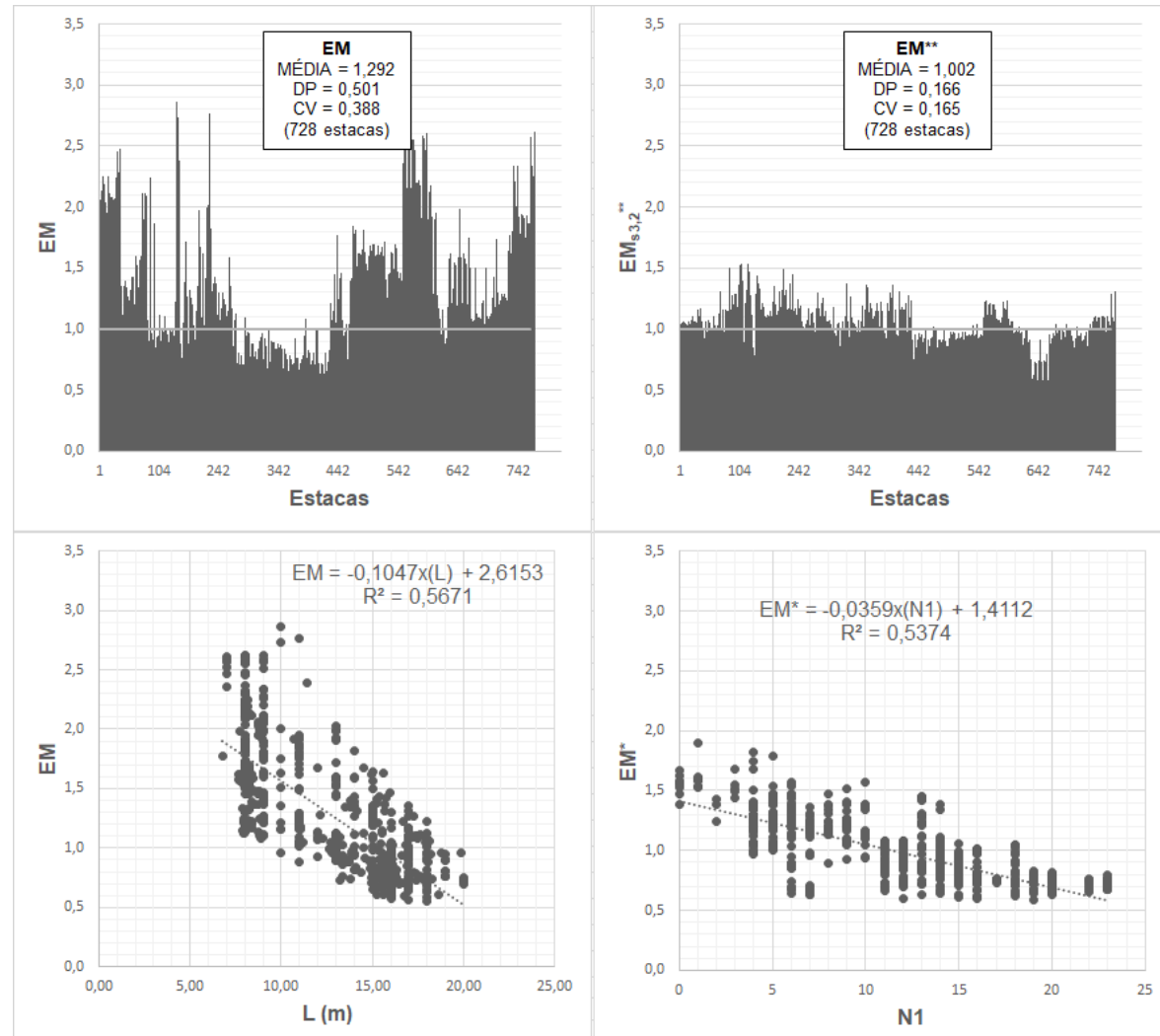

Fonte: do autor.

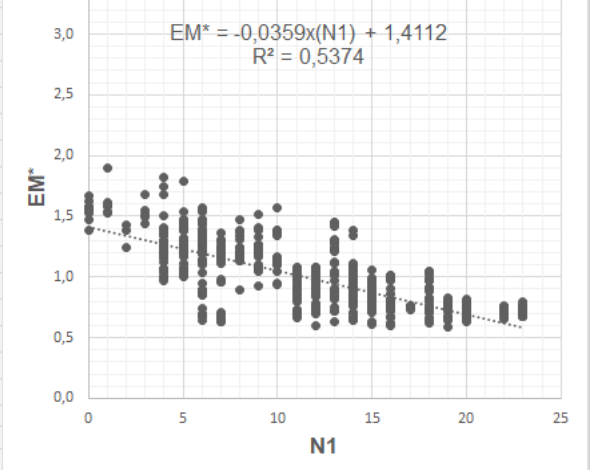


Figura 31 - Erro de modelo $X_{s 3,3}$ e $\delta_{r}=20^{\circ}$
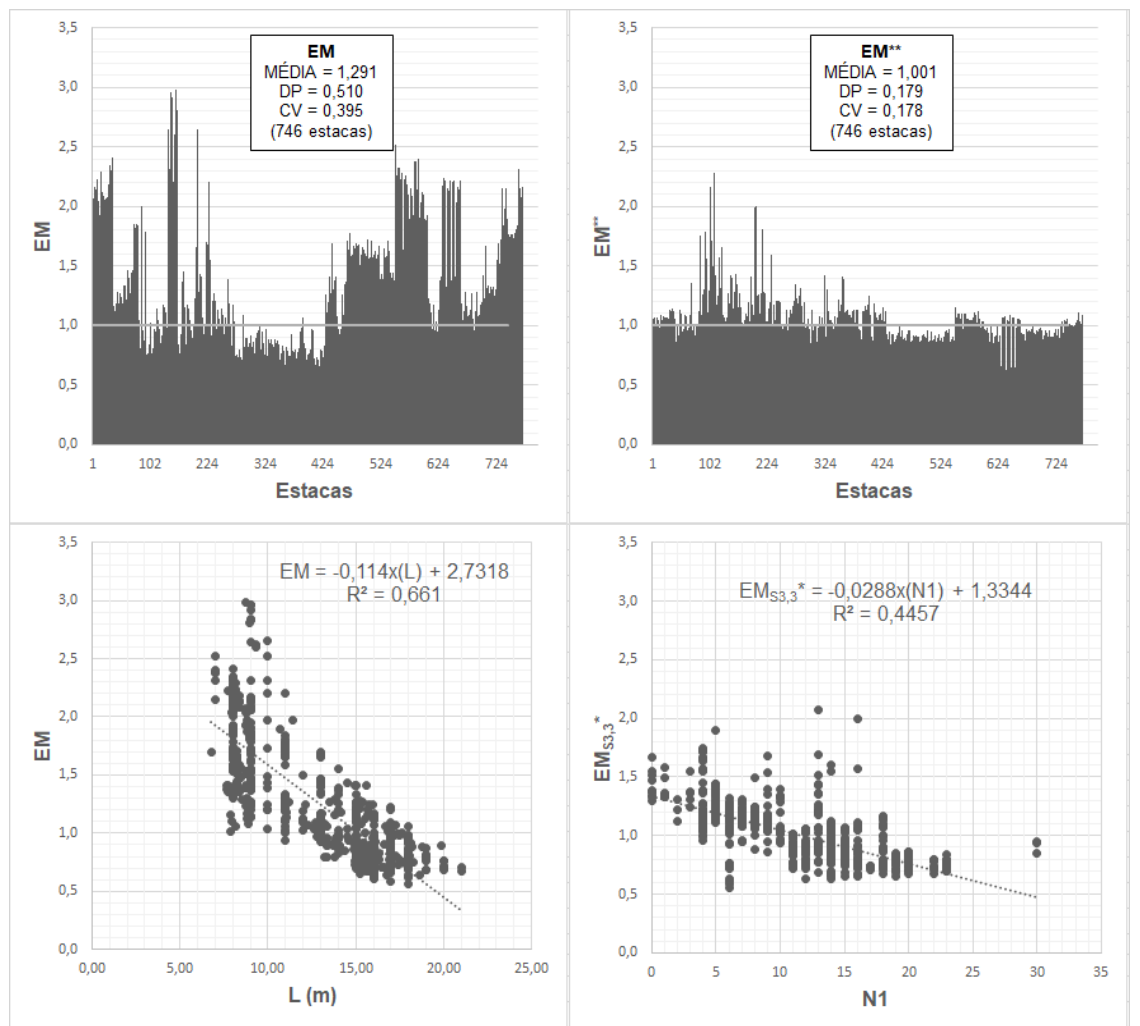

Fonte: do autor
Figura 32 - Erro de modelo $X_{s 4}$ e $\delta_{r}=20^{\circ}$

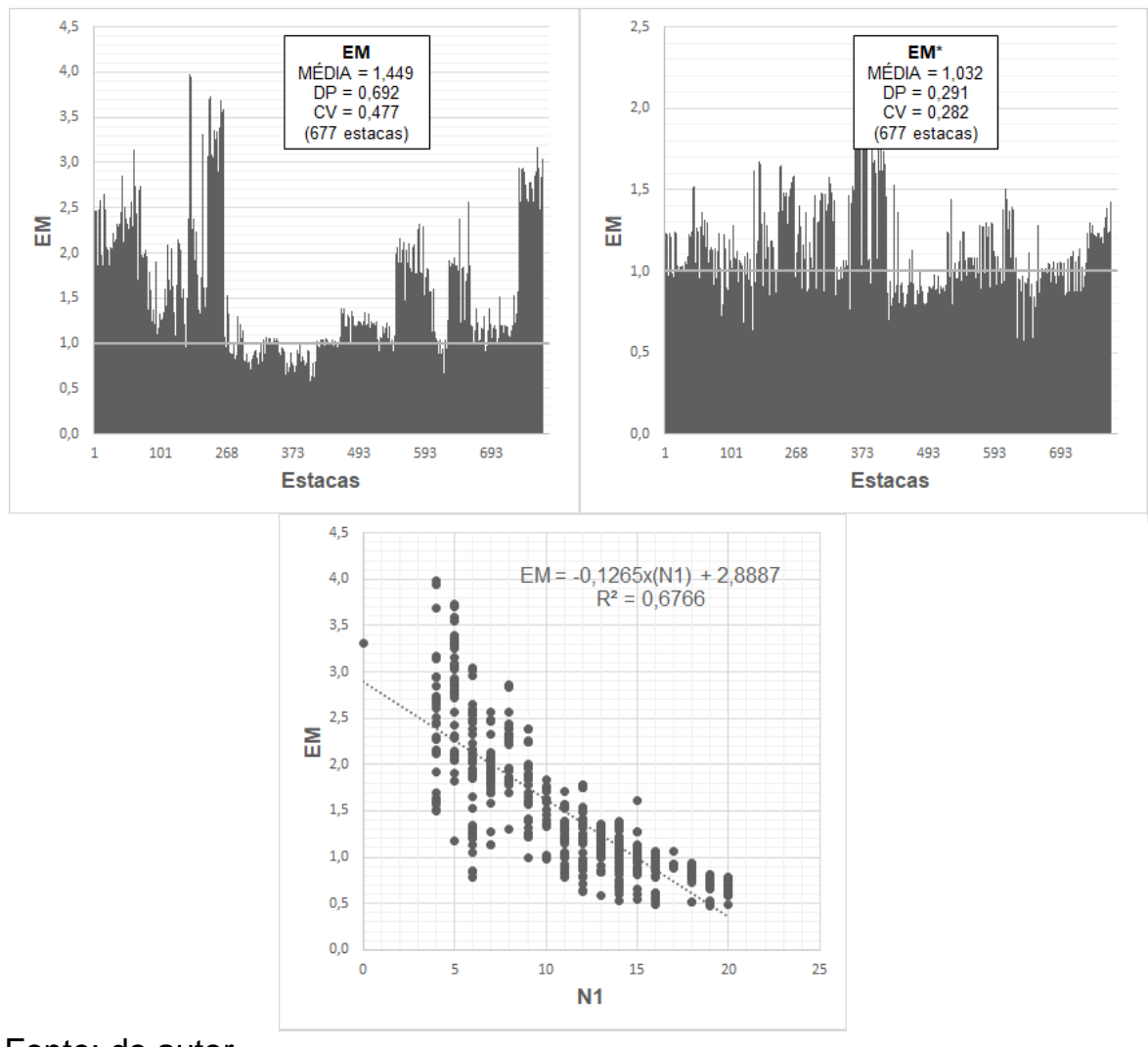

Fonte: do autor. 
Figura 33 - Erro de modelo $X_{s 1}$ e $\delta_{r}=29^{\circ}$
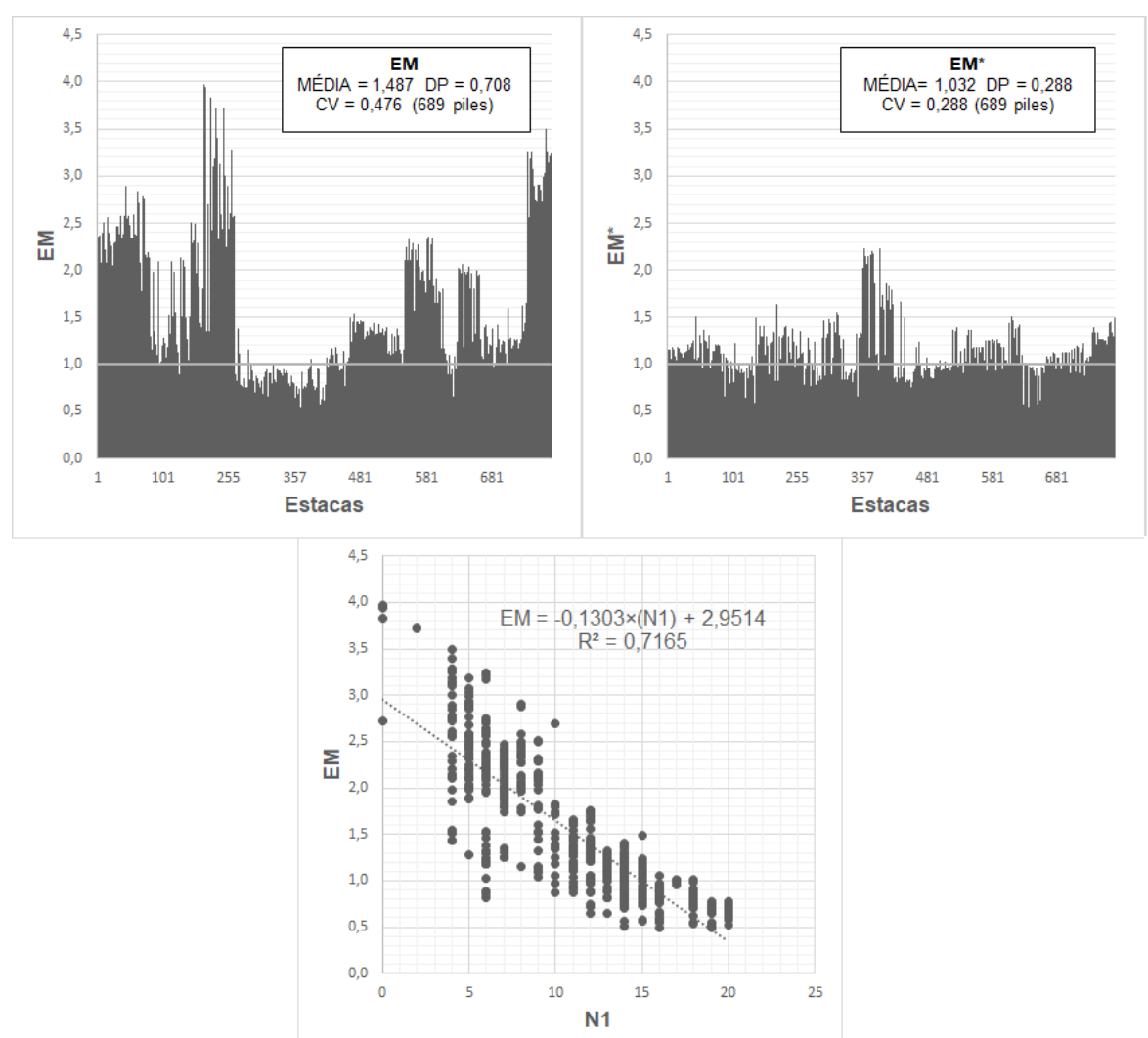

Fonte: do autor.
Figura 34 - Erro de modelo $X_{S 2}$ e $\delta_{r}=29^{\circ}$
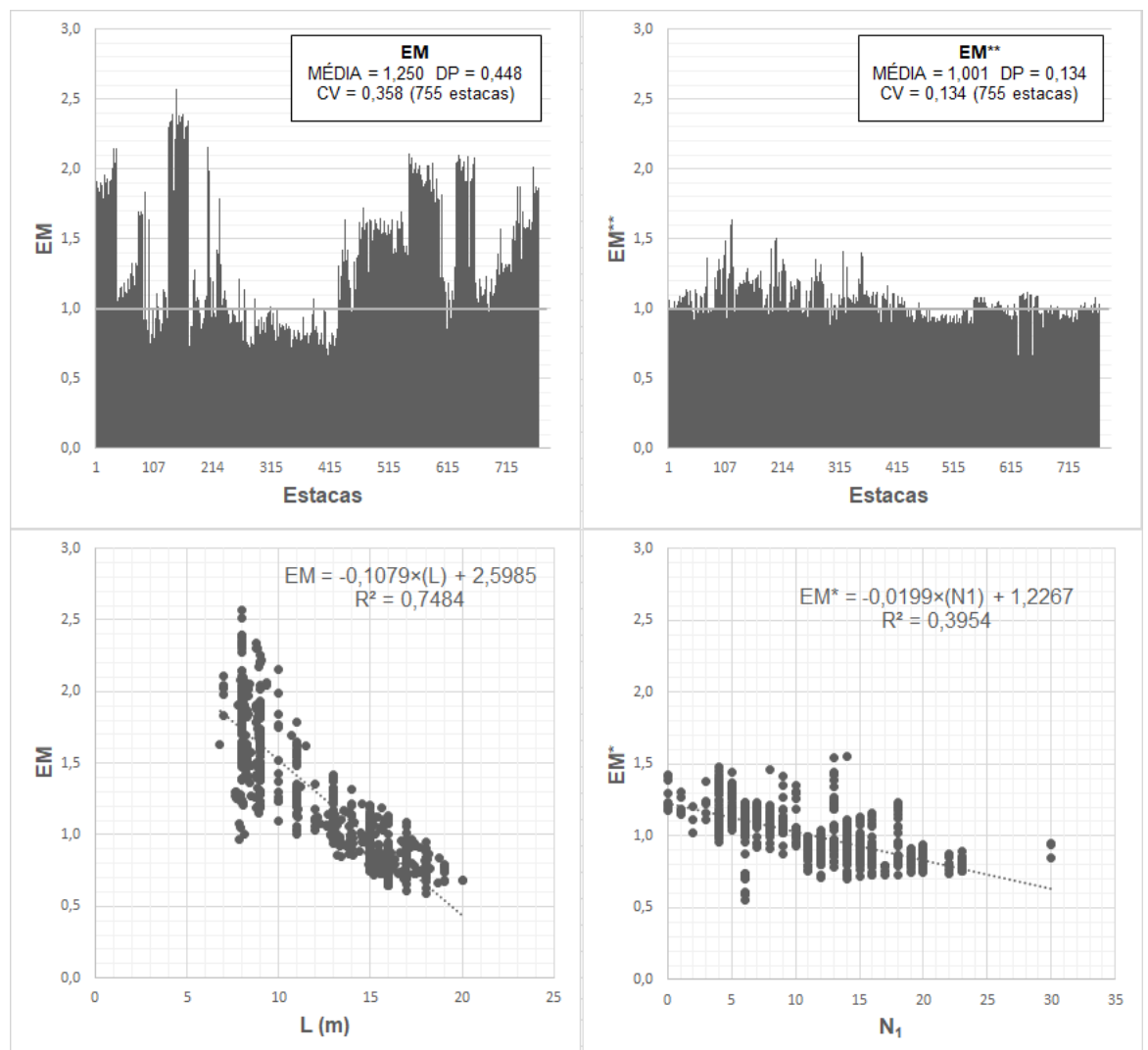

Fonte: do autor 
Figura 35 - Erro de modelo $X_{s 3}$ e $\delta_{r}=29^{\circ}$
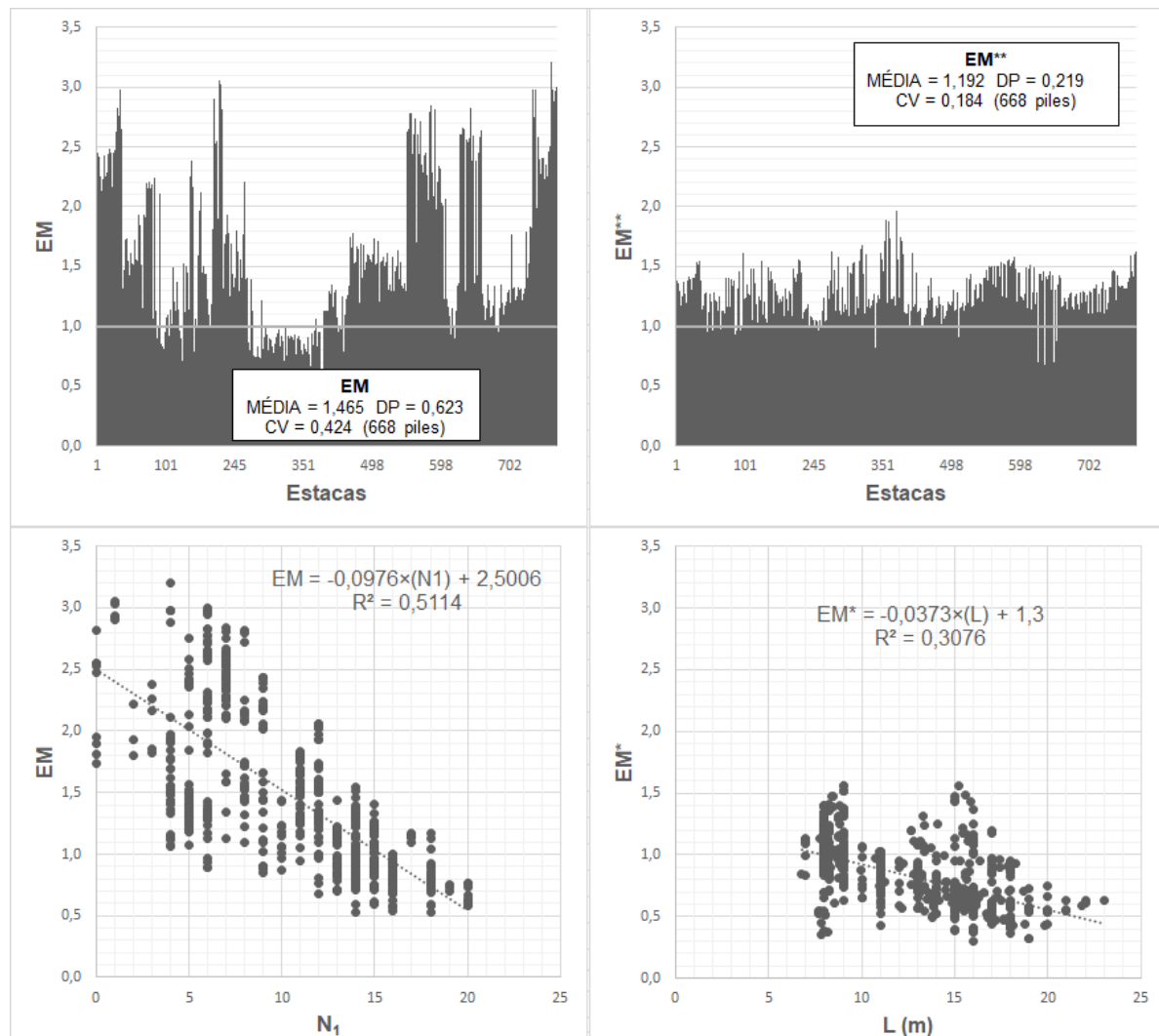

Fonte: do autor.
Figura 36 - Erro de modelo $X_{s 3,2}$ e $\delta_{r}=29^{\circ}$
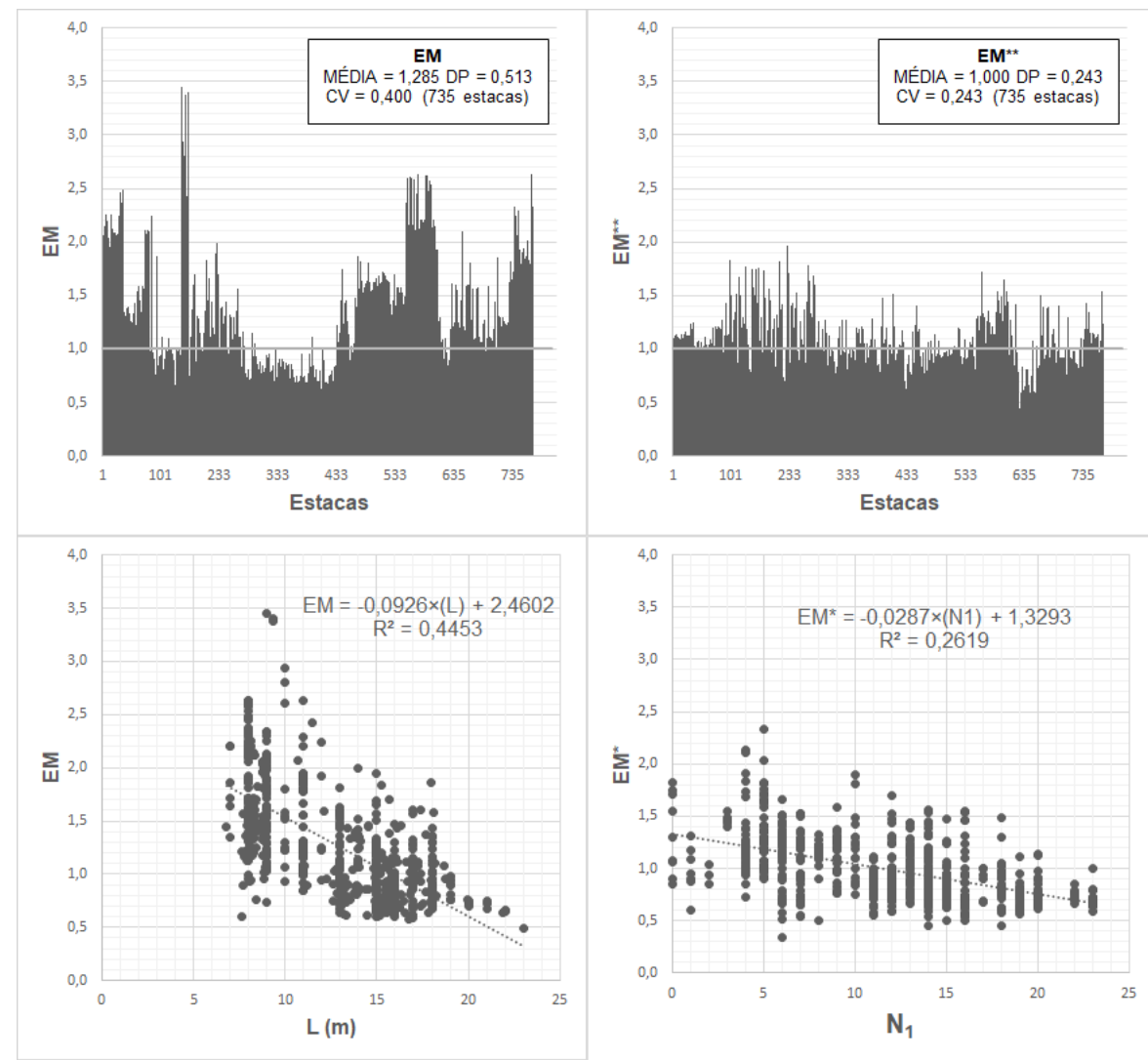

Fonte: do autor. 
Figura 37 - Erro de modelo $X_{s 33}$ e $\delta_{r}=29^{\circ}$
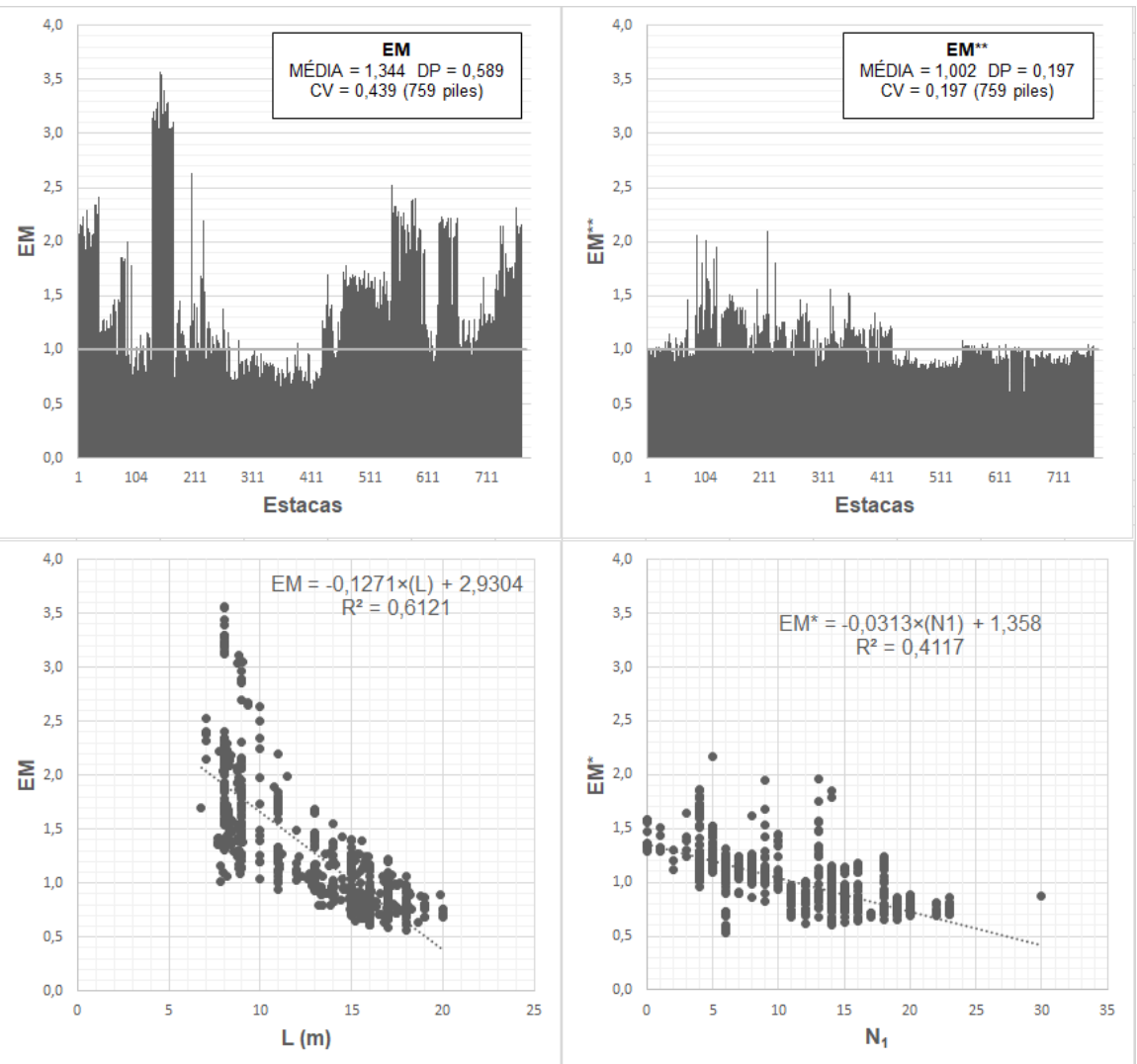

Fonte: do autor.
Figura 38 - Erro de modelo $X_{s 4}$ e $\delta_{r}=29^{\circ}$
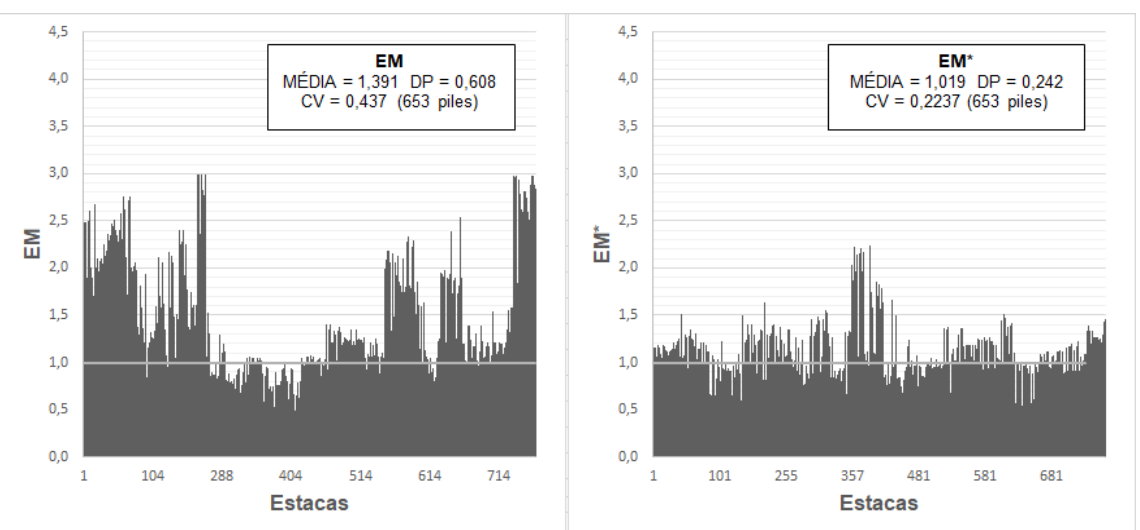

$E M=-0,1152 \times(\mathrm{N} 1)+2,7251$

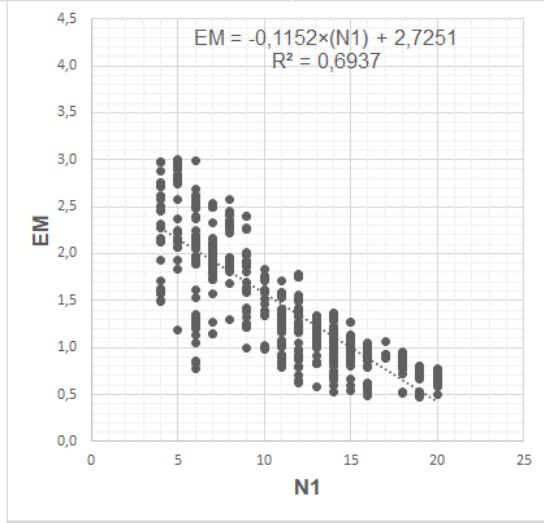

Fonte: do autor. 